\author{
UNIVERSIDADE DE SÃO PAULO \\ ESCOLA DE ENGENHARIA DE SÃO CARLOS \\ DEPARTAMENTO DE ENGENHARIA ELÉTRICA E DE \\ COMPUTAÇÃO
}

DANIEL DA COSTA PICCHI

\title{
AVALIAÇÃO DA TÉCNICA DE DECOMPOSIÇÃO POR COMPONENTES ORTOGONAIS PARA IDENTIFICAÇÃO DE FALTAS DE ALTA IMPEDÂNCIA
}

\author{
SÃO CARLOS \\ 2018
}





\author{
UNIVERSIDADE DE SÃO PAULO \\ ESCOLA DE ENGENHARIA DE SÃO CARLOS \\ DEPARTAMENTO DE ENGENHARIA ELÉTRICA E DE \\ COMPUTAÇÃO
}

DANIEL DA COSTA PICCHI

\title{
AVALIAÇÃO DA TÉCNICA DE DECOMPOSIÇÃO POR COMPONENTES ORTOGONAIS PARA IDENTIFICAÇÃO DE FALTAS DE ALTA IMPEDÂNCIA
}

Dissertação apresentada à Escola de Engenharia de São Carlos da Universidade de São Paulo, como parte dos requisitos para obtenção do título de Mestre em Ciências, Programa de Engenharia Elétrica

Área de Concentração: Sistemas Dinâmicos

Orientador: Prof. Dr. Rogério Andrade

Flauzino

SÃO CARLOS

2018

Trata-se da versão corrigida da dissertação. A versão original se encontra disponível na EESC/USP, que aloja o Programa de Pós-Graduação de Engenharia Elétrica. 
AUTORIZO A REPRODUÇÃO TOTAL OU PARCIAL DESTE TRABALHO, POR QUALQUER MEIO CONVENCIONAL OU ELETRÔNICO, PARA FINS DE ESTUDO E PESQUISA, DESDE QUE CITADA A FONTE.

Ficha catalográfica elaborada pela Biblioteca Prof. Dr. Sérgio Rodrigues Fontes da EESC/USP com os dados inseridos pelo(a) autor(a).

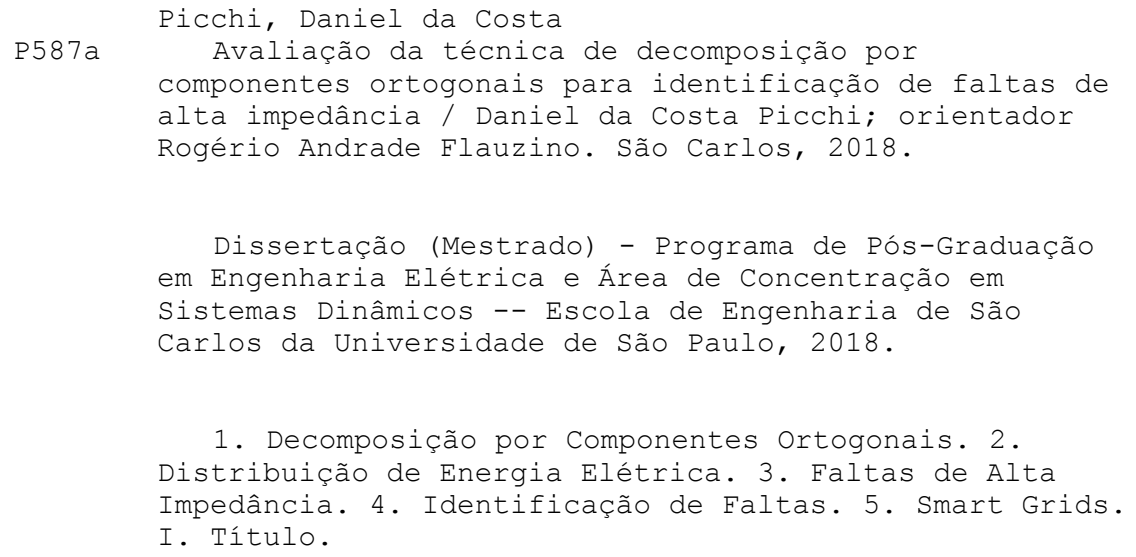

Eduardo Graziosi Silva - CRB - 8/8907 


\section{FOLHA DE JULGAMENTO}

Candidato: Engenheiro DANIEL DA COSTA PICCHI.

Título da dissertação: "Avaliação da técnica de decomposição por componentes ortogonais para identificação de faltas de alta impedância".

Data da defesa: 18/05/2018.

Comissão Julgadora:

Prof. Associado Rogério Andrade Flauzino (Orientador)

(Escola de Engenharia de São Carlos/EESC)

Prof. Dr. Danilo Hernane Spatti (Instituto de Ciências Matemáticas e de Computação/ICMC-USP)

Prof. Dr. Hélder de Paula

(Universidade Federal de Uberlândia/UFU)
Resultado:

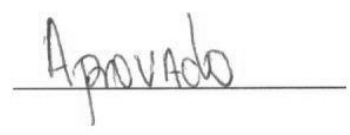

APROVADO

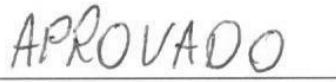

Coordenador do Programa de Pós-Graduação em Engenharia Elétrica: Prof. Associado Luís Fernando Cósta Alberto

Presidente da Comissão de Pós-Graduação:

Prof. Associado Luís Fernando Costa Alberto 



\section{AGRADECIMENTOS}

Agradeço, primeiramente, ao meu orientador Prof. Dr. Rogério Andrade Flauzino, cuja pesquisa representa os alicerces deste trabalho e que me guiou os passos para chegar ao presente resultado.

Ao Prof. Dr. Ivan Nunes da Silva, que me trouxe o conhecimento a respeito do extenso universo dos sistemas inteligentes, sem o qual não conseguiria ter desempenhado esta pesquisa.

A todos os grandes professores da Faculdade de Engenharia Elétrica e de Computação da Universidade Estadual de Campinas (UNICAMP) e meus colegas de turma, por terem contribuído com a minha formação e atual profissão de engenheiro. Em especial, agradeço ao Prof. Dr. José Pissolato Filho, que sempre me incentivou a explorar novos horizontes e contribuiu com minha dupla graduação com a Télécom Paristech.

Aos colegas de trabalho Eric Saldanha, Alexandre da Silva, Mateus Lourenço, Inácio Dantas, Heron Fontana, Daniel Nascimento e José Francisco Resende, que fazem parte da minha descoberta e atual exploração das Smart Grids.

À minha amada esposa Renata, companheira de todas as horas, que soube me apoiar e aceitar pacientemente as horas de dedicação a este trabalho.

Aos meus pais Zilma e Flávio, que me educaram e sempre me mostraram que, por meio do conhecimento, nos tornamos pessoas mais iluminadas. 


\section{RESUMO}

PICCHI, D. C. (2018). Avaliação da técnica de decomposição por componentes ortogonais para identificação de faltas de alta impedância. Mestrado - Escola de Engenharia de São Carlos, Universidade de São Paulo, São Carlos, 2018.

Este trabalho apresenta o estado da arte das técnicas mais aplicadas para localização de faltas e modelagem de faltas de alta impedância e propõe a utilização de uma recente técnica baseada na decomposição dos sinais em componentes ortogonais. Este estudo avalia a aplicabilidade da técnica proposta utilizando dados reais de um sistema de distribuição de energia brasileiro, além de apresentar os conceitos teóricos sobre a decomposição em componentes ortogonais.

Palavras-chave: Decomposição por Componentes Ortogonais, Distribuição de Energia Elétrica, Faltas de Alta Impedância, Identificação de Faltas, Smart Grids. 


\section{ABSTRACT}

PICCHI, D. C. (2018). Evaluation of the orthogonal decomposition technique for high impedance fault detection. Mestrado - Escola de Engenharia de São Carlos, Universidade de São Paulo, São Carlos, 2018.

This work presents the state of the art of the most used techniques for locating and modelling high impedance faults and proposes the use of a recent technique based on the decomposition of the signals in orthogonal components. The objective of this study is to evaluate the application of the proposed technique using real data from a Brazilian distribution network, and presents the theory on orthogonal decomposition.

Keywords: Orthogonal Decomposition, Energy Distribution, High Impedance Fault, Fault Detection, Smart Grids. 


\section{Lista de Figuras}

1.1 Evolução dos indicadores de continuidade das empresas de distribuição de energia brasileiras. Fonte: ANEEL. . . . . . . . . . . . . . 5

1.2 Modelo elétrico para uma falta de alta impedância fase-terra. Fonte: (BRETAS et al., 2006). . . . . . . . . . . . . . . . . . 7

2.1 Fluxo de potência em uma rede radial de distribuição. Fonte: (BATISTA, 2016). 12

2.2 Oscilografias de tensões e correntes de falta obtidas na subestação. . . . . . . 15

2.3 Modelo simplificado de um alimentador sob falta. Fonte: (BATISTA, 2016) . 15

2.4 Circuito equivalente para a ocorrência de falta. Fonte: (BATISTA, 2016) . . 21

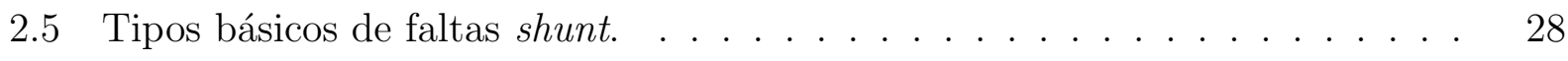

2.6 Tipos básicos de falta série. . . . . . . . . . . . . . . . . . . . . . . . 29

2.7 Forma de onda característica da corrente em uma FAI . . . . . . . . . . . 31

2.8 Relação entre tensão e corrente em uma FAI. . . . . . . . . . . . . . . . . . 34

2.9 Solução numérica da equação diferencial da condutância do arco elétrico. . 36

2.10 Modelo proposto em Emanuel e Cyganski (1990). . . . . . . . . . . . . . . 38

2.11 Modelo proposto em Nam et al. (2001). . . . . . . . . . . . . . . . 38 
3.1 Representação gráfica da decomposição de $f(t)$ em duas componentes ortogonais baseadas em $g(t) . \ldots \ldots \ldots \ldots$

3.2 Formação de base ortogonal coplanar a $v_{1}(t), v_{2}(t)$ e $v_{3}(t) . \ldots$. . . . . . . 46

3.3 Formação de base ortogonal com base em $f(t) \ldots . . . . . .48$

3.4 Representação gráfica das tensões de fase e suas projeções sobre o plano formado pelas tensões de linha. Fonte: (FLAUZINO, 2007) . . . . . . . . . . 52

3.5 Diagrama esquemático do processo de decomposição por componentes ortogonais. Fonte: $($ FLAUZINO, 2007). . . . . . . . . . . .

3.6 Oscilografia das tensões e correntes durante janela de tempo de ocorrência da falta de alta impedância. Fonte: (BATISTA, 2016). . . . . . . . . . . . 56

3.7 Decomposição em segundo nível das componentes coplanares às tensões de linha para as tensões $v_{x}(t)$ e $i_{x}(t)[x \in(a, b, c, d)]$. Fonte: (BATISTA, 2016) .

3.8 Decomposição em segundo nível das componentes ortogonais ao plano das tensões de linha para as tensões $v_{x}(t)$ e $i_{x}(t)[x \in \bar{a}, \bar{b}, \bar{c}, h]$. Fonte: (BATISTA,

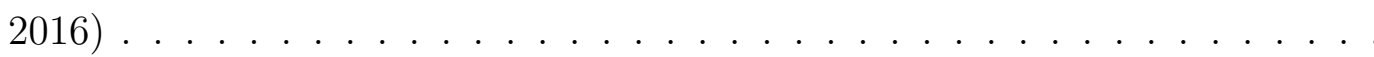

4.1 Relé modelo SEL-451 utilizado para coleta das oscilografias. . . . . . . . . . 60

4.2 Oscilografia das tensões e correntes de um alimentador sem falta. . . . . . . 60

4.3 Oscilografia das tensões e correntes de alimentadores durante janela de ocorrência de falta de alta impedância. . . . . . . . . . . . . . . . . 61

4.4 Componentes ortogonais de uma condição normal de operação. . . . . . . . . 62

4.5 Componentes ortogonais de uma condição real de falta de alta impedância. . 


\section{Lista de Tabelas}

2.1 Fator de correção de corrente de linha para faltas à terra $\ldots$. . . . . . . . . 19

2.2 Níveis de corrente típicos para FAI, em função da superfície . . . . . . . . . 33

2.3 Parâmetros do modelo baseado no princípio do equilíbrio térmico. . . . . . . 35

4.1 Valores RMS dos sinais de tensão e corrente e das componentes ortogonais de corrente das oscilografias mapeadas do Alimentador A . . . . . . . . . . . 64

4.2 Valores RMS dos sinais de tensão e corrente e das componentes ortogonais de tensão das oscilografias mapeadas do Alimentador A . . . . . . . . . . . .

4.3 Valores RMS dos sinais de tensão e corrente e das componentes ortogonais de corrente das oscilografias mapeadas do Alimentador B . . . . . . . . . . . . . 66

4.4 Valores RMS dos sinais de tensão e corrente e das componentes ortogonais de tensão das oscilografias mapeadas do Alimentador B . . . . . . . . . . . . 67

4.5 Componentes de maior correlação com $I_{n}$ para o Alimentador A. . . . . . . . 68

4.6 Componentes de maior correlação com $I_{n}$ para o Alimentador B. . . . . . . . 69 


\section{Sumário}

1 INTRODUÇÃO 1

1.1 Introdução ao Tema . . . . . . . . . . . . . . . . . . . . 1

1.2 Justificativa e Motivação do Tema . . . . . . . . . . . . . . . . . . 3

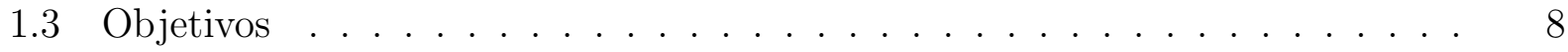

1.4 Organização da Dissertação . . . . . . . . . . . . . . . . . . . . 9

2 LOCALIZAÇÃO DE FALTAS EM SISTEMAS DE DISTRIBUIÇÃO 11

2.1 Introdução . . . . . . . . . . . . . . . . . . . . . 11

2.2 Localização de Faltas em Redes Radiais . . . . . . . . . . . . . . . . . . . . 12

2.2.1 Conceitos e Equacionamento Geral . . . . . . . . . . . . . 13

2.2.2 Principais Métodos Baseados em Impedância . . . . . . . . . . . . . . 20

2.3 Falta de Alta Impedância . . . . . . . . . . . . . . . . . 26

2.3.1 Conceitos e Características . . . . . . . . . . . . . . 30

2.3.2 Comportamento Elétrico e Modelagem . . . . . . . . . . . . 33

2.3.3 Influência na Localização de Faltas . . . . . . . . . . . . . . . . . . . 39 
3.1 Introdução . . . . . . . . . . . . . . . . . . . . 43

3.2 Espaços Vetoriais e suas Propriedades . . . . . . . . . . . . . . . . . . . . . 44

3.2.1 Componentes Ortogonais com Base em Funções Coplanares . . . . . . 45

3.2.2 Componentes Ortogonais com Base em Funções Derivadas e Integrais 47

3.3 Decomposição de Tensões e Correntes em Componentes Ortogonais . . . . . 49

$3.3 .1 \quad$ Primeiro Estágio $\ldots \ldots \ldots \ldots$

$3.3 .2 \quad$ Segundo Estágio . . . . . . . . . . . . . . . . . . . . . . . 52

3.3.3 Comportamento das Componentes Ortogonais em Faltas Fase-terra . $\quad 55$

4 RESULTADOS $\quad 59$

4.1 Oscilografias Levantadas . . . . . . . . . . . . . . . . . . 59

4.2 Decomposição das Oscilografias em Componentes Ortogonais . . . . . . . . . 61

4.3 Análise de Sensibilidade das Componentes Ortogonais . . . . . . . . . . . . 67

5 CONCLUSÃO $\quad 71$

$\begin{array}{lr}\text { BIBLIOGRAFIA } & 72\end{array}$ 


\section{Capítulo 1}

\section{INTRODUÇÃO}

\subsection{Introdução ao Tema}

Os Sistemas Elétricos de Potência (SEP) são a infraestrutura responsável pela geração, transmissão e distribuição de energia em uma região. São ativos de extrema criticidade e valor estratégico, demandando uma operação segura e eficiente, motivo pelo qual são um importante objeto de pesquisa acadêmica. Os sistemas de distribuição estão no final da cadeia de fornecimento de energia, sendo a última milha e a interface com os consumidores finais.

Entre as diversas atividades necessárias para se manter o sistema de distribuição em operação está a identificação e localização de faltas. A ocorrência de uma falta pode acarretar riscos de segurança, danos a ativos e causar a descontinuidade no fornecimento de energia. A rápida e correta localização de faltas é uma necessidade fundamental para o negócio de distribuição de energia elétrica, que é um dos serviços primordiais de utilidade pública e um dos principais vetores para o desenvolvimento econômico e social de uma área de concessão. Como consequência, a continuidade do serviço é de extrema importância e a sua interrupção é altamente danosa à sociedade em termos financeiros e de segurança, além de impactar as distribuidoras nos aspectos de integridade do sistema elétrico, regulatório e de imagem. 
Regulamentadas pela Agência Nacional de Energia Elétrica (ANEEL), no Brasil, e pelos demais órgãos reguladores no restante dos países, as concessionárias de distribuição de energia possuem metas anuais de continuidade do serviço que devem ser cumpridas. Em caso de não cumprimento, as empresas são penalizadas por meio de multas e menor repasse de recursos em suas tarifas.

Com o recente crescimento na utilização de tecnologias de automação de subestações e de redes, amplos avanços têm sido notados na eficiência das empresas com relação a seus indicadores de continuidade. A utilização de religadores é capaz de reduzir a frequência com que as interrupções ocorrem em uma determinada região do sistema elétrico e, caso a interrupção ocorra, juntamente com informações lidas remotamente de sensores de falta, é possível limitar a região onde deve se encontrar a falha. Com o advento das Smart Grids, informações coletadas de diversos dispositivos podem ser concentradas em sistemas SCADA (Supervisory Control and Data Acquisition), DMS (Distribution Management System) e OMS (Outage Management System), alimentando algoritmos que conseguem estimar o possível elemento de falha com boa efetividade e, em alguns casos, até mesmo despachar manobras remotas a chaves automatizadas, reestabelecendo o serviço ao maior número possível de clientes de forma extremamente rápida (SILVA et al., 2018). Porém, a implantação das Smart Grids depende de investimentos em equipamentos, infraestrutura de telecomunicação e tecnologia da informação, obras de redes para ampliar opções de manobras, implantação e integração de sistemas, resultando na necessidade de altos dispêndios de capital. Dessa forma, a penetração de tais tecnologias ainda é incipiente e até o momento prevalece a problemática da localização de falta em regiões extensas do sistema elétrico. Enquanto um plano nacional de implantação ainda está em discussão (KAGAN et al., 2013), as empresas brasileiras têm optado por realizar os primeiros investimentos dessas tecnologias por meio de projetos piloto (PICCHI et al., 2016), enquanto o cenário econômico ainda não é favorável para uma implantação massiva. Alterações recentes na regulação, porém, começam a estimular a viabilidade da instalação em maior escala de medidores inteligentes (FERREIRA et al., 2017).

Com a veiculação cada vez maior nas mídias de eventos de falta de energia de grande abrangência (apagões) e uma maior intolerância dos consumidores, a cobrança às conces- 
sionárias é cada vez maior para que evoluam seus indicadores de continuidade do serviço. A ANEEL vem pressionando cada vez mais as metas das distribuidoras de energia, reforçando a localização de falta como um dos desafios prioritários no âmbito técnico das atividades dessas empresas.

A identificação de faltas, realizada por relés de proteção e utilizando métodos convencionais, se baseia principalmente no monitoramento da amplitude da corrente de falta. Porém, em faltas de alta impedância, a corrente de falta atinge valores muitas vezes incapazes de sensibilizar os relés. Tal problema é enfrentado no desenvolvimento das mais recentes técnicas, como apresentado em Nunes e Bretas (2011), no qual o valor de $10 \Omega$ para a resistência de falta já é capaz de inviabilizar a aplicação da técnica proposta, limitando-a a situações com baixos valores de resistência de falta. As principais causas de faltas de alta impedância nos circuitos aéreos de distribuição são consequência de galhos de árvores ou objetos tocando as fases, isoladores com o isolamento comprometido e condutores partidos tocando em superfícies de alta resistividade, com contato direto ou indireto das fases para a terra.

\subsection{Justificativa e Motivação do Tema}

A qualidade do serviço de distribuição de energia é medida principalmente por seus indicadores de continuidade, sendo eles definidos conforme abaixo:

- DEC: Duração Equivalente de Interrupção por Unidade Consumidora. Indica o número de horas em média que um consumidor fica sem energia elétrica durante um período.

- FEC: Frequência Equivalente de Interrupção por Unidade Consumidora. Indica quantas vezes, em média, houve interrupção na unidade consumidora.

- DIC: Duração de Interrupção por Unidade Consumidora. Indica por quanto tempo uma unidade consumidora ficou sem energia elétrica durante um período considerado.

- FIC: Frequência de Interrupção por Unidade Consumidora. Indica o número de vezes (frequência) que uma unidade consumidora ficou sem energia elétrica durante um 
período considerado.

- DMIC: Duração Máxima de Interrupção por Unidade Consumidora. Indica a duração da maior interrupção que ocorreu em uma unidade consumidora durante um período considerado.

- DICRI: Duração de Interrupção por Unidade Consumidora em Dia Crítico. Indica por quanto tempo uma unidade consumidora ficou sem energia elétrica durante um período considerado, apurado somente em dias críticos. ${ }^{1}$

A localização de falta impacta diretamente os indicadores de duração das interrupções (DEC, DIC, DMIC e DICRI), sendo um dos principais aspectos a serem trabalhados pelas distribuidoras para obter melhorias nesses índices. Observando-se o histórico dos indicadores de continuidade apresentado na figura (1.1), podemos ver a importância de localizar a falta com velocidade e assertividade.

As metas de DEC vêm sendo diminuídas anualmente, porém os valores apurados pelo conjunto de todas as distribuidoras não têm sofrido grandes avanços, estando fora da meta definida pelo regulador desde 2009. Já o FEC apresenta uma meta decrescente ano a ano e as empresas têm conseguido atender estas metas e apresentar uma tendência de melhora deste indicador. Se a razão entre o DEC e FEC for avaliada anualmente, que representa a duração média de cada interrupção, nota-se que tanto os valores definidos pela ANEEL quanto aqueles apurados pela empresas têm trajetória crescente. Dessa análise pode-se concluir que os recentes investimentos em automação e recondutoramento de alimentadores com condutores isolados têm tido resultado na redução da frequência com que ocorrem as faltas de energia, tendo evitado em maior quantidade as ocorrências que resultariam em interrupções de menor duração. O conjunto de interrupções que continua ocorrendo são de maior complexidade

\footnotetext{
${ }^{1}$ A ANEEL define um dia como sendo crítico quando a quantidade de ocorrências emergenciais supera a média em 3 desvios padrões. Apura-se a média e o desvio padrão com os dados dos últimos 24 meses. As interrupções ocorridas nesse dia não são contabilizadas nos indicadores DEC, FEC, DIC, FIC e DMIC.
} 

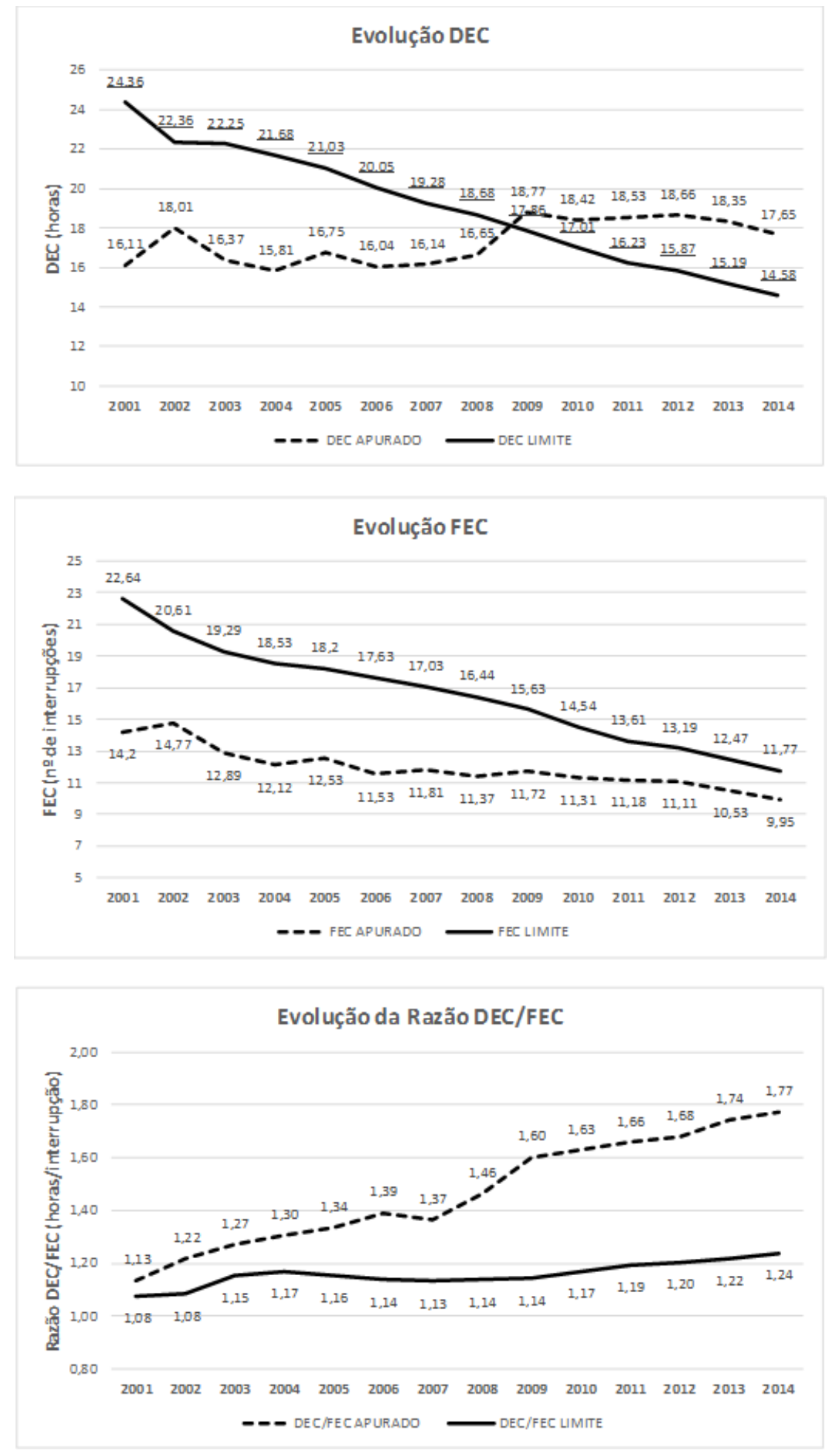

Figura 1.1: Evolução dos indicadores de continuidade das empresas de distribuição de energia brasileiras. Fonte: ANEEL. 
e, por consequência, maior duração. Dessa maneira, o estudo de técnicas cada vez mais aprimoradas para uma boa detecção e localização de falta contribui diretamente para a melhoria da qualidade do serviço de distribuição de energia e é um caminho eficiente para que as empresas voltem a cumprir suas metas de DEC. O atual descumprimento dessas metas acarreta multas que são pagas em forma de compensações pelas distribuidoras na conta de energia de seus clientes, tendo totalizado o valor de $\mathrm{R} \$ 346$ milhões no ano de 2013 (ANEEL, 2016).

Entre os diversos tipos possíveis de falta, as de alta impedância apresentam um desafio adicional, já que suas correntes de falta são de menor magnitude e muitas vezes insuficientes para sensibilizar os relés de proteção. Como consequência da não atuação dos relés, o sistema elétrico pode estar sendo operado em condição de falta, o que pode ocasionar a geração de arcos elétricos ou a presença de um condutor energizado ao solo, condições que apresentam graves riscos de segurança à população e podem causar danos aos ativos de distribuição de energia.

Além das dificuldades intrínsecas à localização de faltas de alta impedância, a disseminação de cargas sensíveis e não lineares, a regulação incisiva sobre qualidade de energia e, principalmente, a penetração de geração distribuída nos sistemas de distribuição apresentam impactos que demandam amplos e detalhados estudos para a readequação dos sistemas de controle, comunicação e proteção, a fim de realinhar a operação aos novos cenários. Esses fatos têm colaborado para o recente surgimento de novos conceitos de operação, como as amplamente discutidas Smart Grids e microgrids, que remetem a um maior investimento em infraestrutura de suporte, principalmente na parte de telecomunicações.

Em uma abordagem numérica, Jamali e Talavat (2010) considera o comportamento dinâmico do sistema de distribuição, utilizando uma análise no domínio do tempo na qual os dados da rede são atualizados a cada tempo de execução, uma vez que o comportamento dinâmico dos geradores síncronos distribuídos comprometem a aplicação dos métodos usuais baseados nas soluções em regime permanente. Com o objetivo de localização da falta, o algoritmo apresenta erros reduzidos para faltas francas, desenvolvendo, no entanto, um erro 
crescente com o aumento da resistência de falta.

Nessa mesma linha, em Faig et al. (2010), é feita uma análise por meio da qual constata-se a influência de parâmetros como o porte da geração distribuída, a impedância de falta e a posição relativa da falta na estimação do local desta. A principal observação é a redução da reatância aparente, vista pela subestação, causada pela presença de geração distribuída, aumentando o erro de localização com o aumento da potência gerada a jusante da falta.

Os trabalhos mais atuais baseados em soluções numéricas apresentam restrições de aplicação, principalmente em situações de faltas com alta impedância, assumindo, ainda, que esta deve ser puramente resistiva. De acordo com Emanuel e Cyganski (1990), mesmo a simplificação do comportamento de uma falta de alta impedância conduz a um modelo como na figura (1.2). As correntes de faltas de alta impedância possuem comportamento intermitente dado que, em muitos casos, essa corrente se faz circular por meio de arcos elétricos que apresentam variação temporal de impedância, conferindo severa não linearidade ao problema e consequente perda na exatidão dos métodos de localização de faltas baseados na relação entre tensões e correntes no sistema.

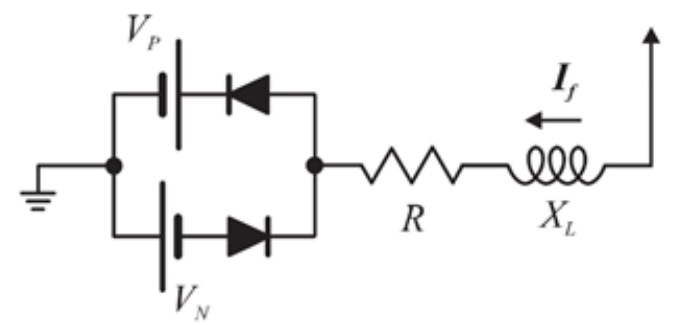

Figura 1.2: Modelo elétrico para uma falta de alta impedância fase-terra. Fonte: (BRETAS et al., 2006).

A dificuldade de um tratamento analítico e numérico tem impulsionado a aplicação de sistemas computacionais inteligentes. Uma técnica baseada em uma rede neural artificial, na arquitetura Perceptron Multicamadas, é apresentada em Javadian e Massaeli (2011) com o objetivo de classificar e localizar faltas em sistemas de distribuição com geração distribuída 
a partir das correntes de falta em cada ramal. Para reduzir o impacto da impedância de falta, as entradas da rede neural correspondem a uma razão entre a corrente de falta injetada pelos geradores distribuídos e pelo alimentador da subestação em cada ramal. Os testes foram realizados em um sistema de distribuição em tensão nominal de $20 \mathrm{kV}$ com vinte e dois ramais e dois geradores síncronos de, respectivamente, 3, $5 M V A$ e 4, $5 M V A$. Como proposto, a rede obteve expressiva exatidão mesmo para valores de $100 \Omega$ e $150 \Omega$ de impedância de falta.

Outra técnica baseada em sistemas inteligentes para a localização de falta é baseada na utilização de um estimador fuzzy e um método de pré-processamento dos sinais de tensão e corrente baseado em componentes ortogonais. A técnica foi proposta em Flauzino (2007), tendo sido realizadas simulações de faltas em um modelo de rede de distribuição e demonstrado o potencial da técnica. Em Batista (2016), o modelamento da falta de alta impedância e o método de seleção das variáveis que compõem o sistema inteligente foram aprimorados e obtiveram estimativas do local da falta com erros relativos abaixo de 10\%, porém ainda com a utilização de dados de simulação. Essa técnica tem se mostrado uma frente promissora para as pesquisas em localização de faltas de alta impedância, porém não há, até o momento, trabalhos realizados com dados de campo, coletados durante ocorrências de faltas reais, sendo necessária a comprovação prática do potencial dessa metodologia.

\subsection{Objetivos}

O objetivo deste trabalho é realizar uma avaliação prática da utilização da técnica de decomposição em componentes ortogonais para identificação de faltas de alta impedância, como proposto em Flauzino (2007), com o uso de dados reais de faltas de alta impedância obtidos de uma distribuidora de energia elétrica brasileira.

Espera-se, com esses resultados, poder confirmar a real aplicação da metodologia e identificar oportunidades de aprimoramento da técnica, contribuindo para a consolidação e evolução das pesquisas em identificação e localização de faltas de alta impedância. 


\subsection{Organização da Dissertação}

Esta dissertação está estruturada em cinco capítulos de maneira a apresentar o problema da localização de falta, as teorias que suportam a técnica utilizada e os resultados obtidos nesta pesquisa. Assim, após este primeiro capítulo introdutório, tem-se o Capítulo 2, no qual apresenta-se o problema de localização de faltas, iniciando pelos conceitos básicos e equacionamentos gerais, passando por uma revisão cronológica dos principais métodos baseados em impedância até chegar, então, ao estudo dos comportamentos das faltas de alta impedância.

No Capítulo 3, são apresentados os fundamentos da técnica de Decomposição por Componentes Ortogonais, desde suas bases matemáticas até a aplicação no estudo de faltas faseterra. No Capítulo 4, são apresentados os resultados obtidos por meio do estudo da aplicação da técnica em oscilografias reais e, por fim, as conclusões do trabalho são apresentadas no Capítulo 5. 


\section{Capítulo 2}

\section{LOCALIZAÇÃO DE FALTAS EM SISTEMAS DE DISTRIBUIÇÃO}

\subsection{Introdução}

A localização de faltas é uma tarefa que está diretamente relacionada à qualidade do serviço prestado pelas concessionárias de distribuição de energia elétrica, principalmente em relação ao indicador de duração de interrupções (DEC). O direcionamento eficiente das equipes de manutenção garante não só a continuidade do fornecimento, mas também a segurança da rede em perímetros de circulação humana, além de uma operação econômica do sistema. A eficiência está associada à velocidade e exatidão na estimação do ponto de falta. Os métodos tradicionais para localização de faltas são comumente agrupados em duas categorias, os baseados em impedância e os baseados em ondas viajantes. O primeiro utiliza medições de tensões e correntes de falta em cálculos de circuitos elétricos, enquanto o segundo se vale do intervalo de tempo entre uma onda inicial e suas reflexões no ponto de falta. Os dois possuem suas limitações, sendo o grande problema desses métodos o compromisso entre robustez e exatidão (XINZHOU et al., 2002).

Essas peculiaridades confirmam a importância da localização de faltas e têm motivado os 
esforços de inúmeros pesquisadores ao longo do tempo. Justifica, ainda, o desenvolvimento deste trabalho face às mudanças que vêm ocorrendo nos sistemas de distribuição, como a penetração de Geração Distribuída, a integração de veículos elétricos à rede, o aumento da sensibilidade dos equipamentos conectados ao sistema e a utilização de infraestrutura avançada de comunicação, culminando na evolução das redes de energia elétrica no que se tem denominado por Smart Grids. Em um futuro próximo, as técnicas convencionais estarão limitadas a condições simples de operação e sujeitas a variações tais que não será viável sua manutenção. Qualquer evolução tecnológica no setor elétrico prima por modicidade tarifária, entretanto soluções robustas serão cada vez mais necessárias e o compromisso com a qualidade do fornecimento exigirá mais investimento em equipamentos modernos como Transformadores de Corrente (TCs) e Transformadores de Potencial (TPs) Ópticos (eliminando problemas de saturação e transitórios), medidores digitais micro processados, infraestrutura de telecomunicação e centrais de processamento do grande volume de dados. Nesse cenário, cabe à pesquisa, nas áreas de detecção e localização de faltas, fornecer algoritmos avançados compatíveis com o novo poder de inferência sobre o sistema.

\subsection{Localização de Faltas em Redes Radiais}

Uma característica que difere o processo de localização de faltas entre sistemas de transmissão e distribuição é a radialidade. O fluxo de potência, em condições normais, tem origem na subestação de distribuição e se direciona para os consumidores, distribuindo-se ao longo do alimentador de forma unidirecional. A figura (2.1) exemplifica o fluxo de potência descrito.

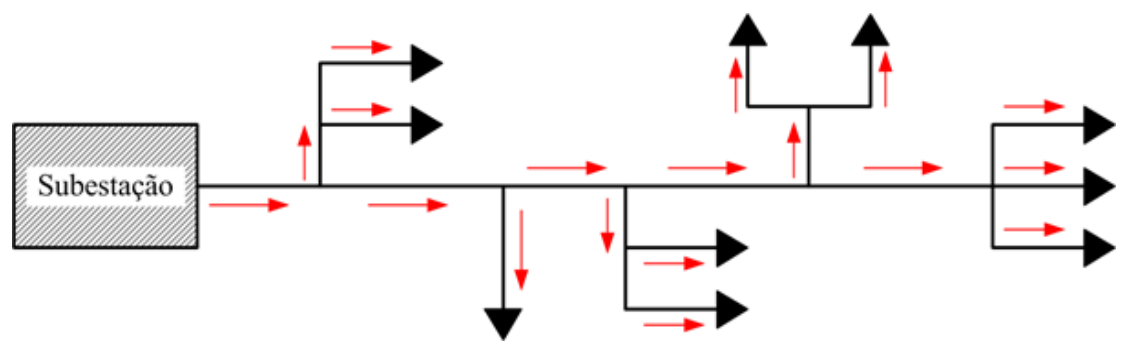

Figura 2.1: Fluxo de potência em uma rede radial de distribuição. Fonte: (BATISTA, 2016). 
Além da radialidade, outras características dos sistemas de distribuição fazem os métodos para localização de faltas nestes diferir sensivelmente dos empregados em sistemas de transmissão (SAHA; IZYKOWSKI; ROSOLOWSKI, 2010):

- Em função dos tipos de consumidores e finalidade da rede, alimentadores de uma mesma subestação podem diferir nas características dos seus condutores;

- A rede pode ser a combinação de trechos monofásicos (zonas rurais, geralmente) e trifásicos;

- As cargas podem ser alimentadas em Média Tensão (MT) ou Baixa Tensão (BT), dois tipos de sistemas com características diferentes;

- As distâncias abrangidas pelos alimentadores vão de centenas de metros a dezenas de quilômetros;

- Os esquemas de reconfiguração de rede tornam a topologia da rede variável;

- Sistema não homogêneo e desbalanceado, com grande ramificação e dinâmica aleatória das cargas;

- Variedade de tipos de condutores e equipamentos.

\subsubsection{Conceitos e Equacionamento Geral}

A localização de faltas em sistemas de distribuição de energia elétrica compreende os procedimentos posteriores à detecção e identificação de uma condição faltosa, nos quais a concessionária tem o objetivo de determinar o ponto exato de ocorrência da falta, em relação à subestação de distribuição. A medição das grandezas elétricas são realizadas na subestação por meio de relés de proteção e sistemas supervisórios (SCADA), as informações são enviadas ao Centro de Operações de Distribuição (COD) e este aciona a unidade de manutenção mais 
próxima. Quando a informação sobre a falta envolve apenas sua ocorrência, recorre-se à forma primordial de localização da falta: a inspeção visual em conjunto com as informações de consumidores. Nesta, as equipes percorrem o alimentador em busca do problema e, como em todo processo de busca, o tempo de localização pode ser elevado. A necessidade de otimizar essa tarefa nas concessionárias motivou a pesquisa e o desenvolvimento de técnicas para a localização automática de faltas, dando às equipes de manutenção uma estimação da região ou ponto de falta.

A localização automática de faltas em Sistemas Elétricos de Potência (SEP) é considerada como uma função complementar aos sistemas de proteção e pode ser realizada das seguintes formas (SAHA; IZYKOWSKI; ROSOLOWSKI, 2010):

- Relés de proteção microprocessados;

- Registradores Digitais de Perturbações (RDPs);

- Equipamentos dedicados;

- Indicadores de falta;

- Softwares de análise pós-falta.

Estas são, muitas vezes, empregadas de forma combinada, sendo o último item o núcleo do sistema de localização e a fonte dos maiores desafios de desenvolvimento. Esses softwares ou algoritmos são agrupados em duas grandes vertentes, com relação ao procedimento aplicado:

- Baseados em ondas viajantes: os transitórios provocados pelas faltas viajam pela rede como ondas. Esses sinais são monitorados e a posição da falta se dá pelo tempo entre a viagem da onda e seu retorno, após refletir na falta, em relação à velocidade de propagação. Em sistemas de distribuição, a relação entre as capacitâncias e indutâncias dos cabos e as curtas distâncias entre pontos de reflexão tornam elevado o custo desse método, dadas as altíssimas frequências de aquisição necessárias e a necessidade de medidores com grande precisão para captar a diferença de tempo (LIN et al., 2012); 
- Baseados em impedância: as medidas de tensão e corrente na subestação são utilizadas para determinar o ponto de falta (figura 2.2). Os valores pré e pós-falta são, usualmente, empregados em algoritmos derivados da análise do circuito elétrico equivalente do sistema. Muitas propostas vislumbram, ainda, a utilização de sistemas de inteligência artificial para inferir sobre essas medidas e conferir robustez ao método. Essa vertente é, portanto, amplamente utilizada em sistemas de distribuição e foi a abordagem escolhida para o desenvolvimento da proposta desta dissertação.
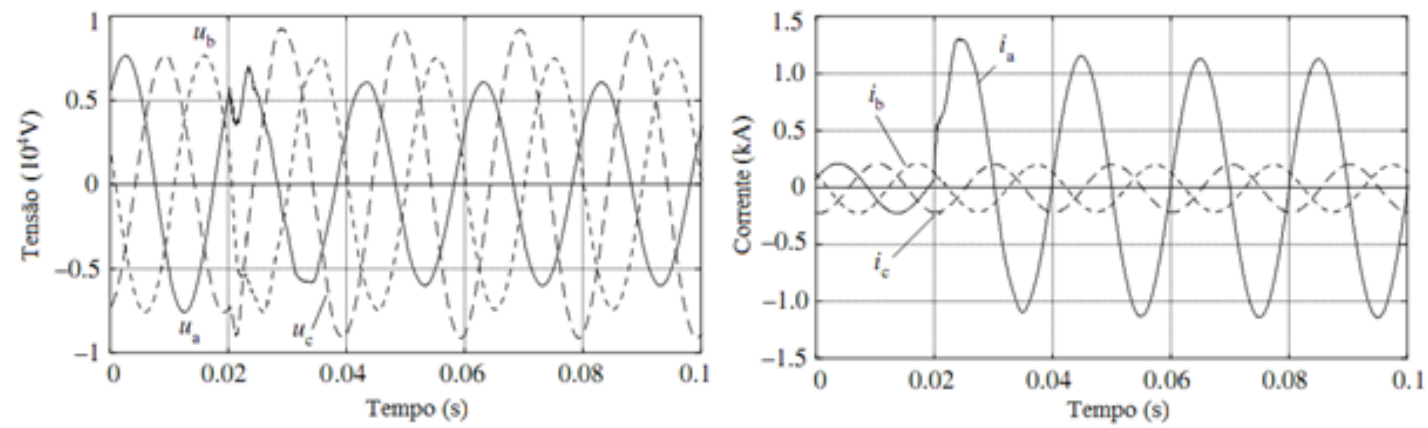

Figura 2.2: Oscilografias de tensões e correntes de falta obtidas na subestação.

Partindo da representação simplificada do modelo equivalente de um alimentador, como indicado na figura (2.3), e admitindo um comportamento linear para uma falta fase-terra a uma distância $x$ da subestação, obtém-se o equacionamento geral para o processo de localização de falta baseado em impedância.

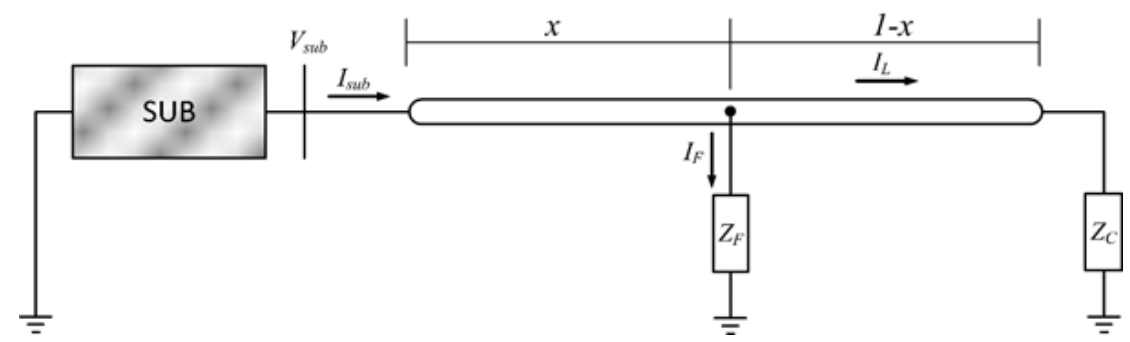

Figura 2.3: Modelo simplificado de um alimentador sob falta. Fonte: (BATISTA, 2016) 
Na figura (2.3), ao aplicar-se a Lei das Tensões de Kirchhoff à malha de falta (fault loop) e sendo $Z_{L}$ a impedância do cabo por unidade de distância, $Z_{F}$ a impedância de falta e $Z_{C}$ a impedância da carga, tem-se a relação apresentada em (2.1).

$$
V_{\text {sub }}=x\left(Z_{L} I_{\text {sub }}\right)+Z_{F} I_{F}
$$

A corrente de falta $I_{F}$ é expressa pela lei das correntes de Kirchhoff no ponto de falta, como em (2.2).

$$
I_{F}=I_{s u b}-I_{L}
$$

A equação (2.1) representa a tensão pós-falta na subestação, para a fase faltosa, em função da distância de falta x. Embora o equacionamento seja trivial, salienta-se que foi necessário assumir um modelo linear, magneticamente desacoplado e simplificado da rede, e ainda as grandezas $Z_{F}$ e $I_{L}$ são incógnitas, visto que a concessionária monitora apenas as tensões e correntes na subestação. Outra forma de visualização da equação (2.1) pode ser obtida dividindo ambos os lados pela corrente na subestação $\left(I_{s u b}\right)$, chegando ao desenvolvimento em (2.3).

$$
\frac{V_{\text {sub }}}{I_{\text {sub }}}=x \frac{Z_{L} I_{\text {sub }}}{I_{\text {sub }}}+Z_{F} \frac{I_{F}}{I_{\text {sub }}}
$$

A relação entre tensão e corrente medidas na subestação denomina-se por impedância aparente $\left(Z_{k}\right)$, que representa a impedância vista a partir da subestação. Para a fase faltosa, essa grandeza assume a forma descrita em (2.4).

$$
Z_{k}=x Z_{L}+\alpha Z_{F}
$$

O coeficiente $\alpha$ é a razão entre a corrente de falta e a corrente na subestação, como em 


$$
\alpha=\frac{I_{F}}{I_{\text {sub }}}
$$

Nessa relação, se a impedância de falta é nula (falta sólida ou franca), a impedância aparente guarda a informação direta da localização da falta, dada por $x=Z_{k} / Z_{L}$. Entretanto, se $Z_{F}$ é diferente de zero, à medida que seu valor aumenta, a impedância aparente pode assumir os mais variados valores, dificultando sua supervisão.

Visto que a impedância de falta restringe a avaliação de sua localização por meio do equacionamento geral, outra simplificação pode conduzir a uma solução estimada para faltas não francas. Assumindo nula a parte imaginária de $Z_{F}$, a equação (2.1) é reescrita em (2.6).

$$
V_{s u b}=x\left(Z_{L} I_{s u b}\right)+R_{F} I_{F}
$$

Agora, a resistência de falta $\left(R_{F}\right)$ pode ser isolada, como feito em (2.7).

$$
R_{F} I_{F}=V_{\text {sub }}-x\left(Z_{L} I_{\text {sub }}\right)
$$

Multiplicando-se ambos os lados pelo conjugado de $I_{F}$, tem-se (2.8).

$$
R_{F}\left(I_{F}^{*} I_{F}\right)=I_{F}^{*}\left(V_{s u b}-x Z_{L} I_{s u b}\right)
$$

Dado que o produto de um número complexo pelo seu conjugado resulta em um número real, o produto $R_{F}\left(I_{F}^{*} I_{F}\right)$ será real e pode-se tomar a relação em (2.9), na qual a parte imaginária do segundo membro da equação (2.8) é igual a zero.

$$
\operatorname{Im}\left(I_{F}^{*} V_{\text {sub }}-x Z_{L} I_{F}^{*} I_{\text {sub }}\right)=0
$$


Logo, o valor da distância $x$ pode ser encontrado em (2.10).

$$
x=\frac{\operatorname{Im}\left(I_{F}^{*} V_{\text {sub }}\right)}{\operatorname{Im}\left(Z_{L} I_{F}^{*} I_{\text {sub }}\right)}
$$

Na equação (2.10), a determinação de $x$ independe da impedância de falta, desde que ela seja resistiva, e apenas $I_{F}$ é desconhecida. Essa grandeza pode ser estimada a partir da equação $(2.2)$, pois, assumindo que os valores pré-falta e pós-falta da corrente de carga $\left(I_{L}\right)$ sejam iguais, como em (2.11), a corrente de falta pode ser estimada como a diferença entre as correntes pós-falta e pré-falta na subestação $\left(I_{s u b}\right)$ em (2.12).

$$
\begin{gathered}
I_{L}=I_{L}^{p r e ́}=I_{s u b}^{p r e ́} \\
I_{F}=I_{s u b}-I_{s u b}^{p r e ́}
\end{gathered}
$$

Portanto, obtém-se a estimativa da distância da falta, descrita em (2.13), utilizando apenas os dados de tensão e corrente na subestação, bem como a impedância da linha de distribuição $\left(Z_{L}\right)$. Esse resultado é similar ao encontrado em Takagi et al. (1982), no qual é proposto um método para localização de faltas em linhas curtas de transmissão (até $100 \mathrm{~km}$ de extensão).

$$
x=\frac{\operatorname{Im}\left[\left(I_{\text {sub }}-I_{\text {sub }}^{\text {pré }}\right)^{*} V_{\text {sub }}\right]}{\operatorname{Im}\left[Z_{L}\left(I_{\text {sub }}-I_{\text {sub }}^{\text {pré }}\right)^{*} I_{\text {sub }}\right]}
$$

Se a modelagem do alimentador for conduzida para uma representação um pouco mais fiel à realidade, admitindo as ramificações e a queda de tensão ao longo do alimentador, como ilustrado na figura (2.3), a consideração em (2.11) não será mais admissível.

De forma geral, o processo de localização de falta pode ser afetado por alguns fatores, 
como (IEEE, 2005):

- Compensação imprecisa para o efeito da reatância da falta;

- Identificação imprecisa do tipo de falta e fases envolvidas;

- Incertezas sobre os parâmetros da linha de distribuição;

- Compensação imprecisa para os efeitos mútuos, principalmente sobre as componentes de sequência-zero;

- Modelagem pouco representativa do alimentador;

- Presença de banco de capacitores no sistema;

- Fluxo de carga desequilibrado;

- Erros em transformadores de medição.

À medida que se deseja minimizar tais efeitos, a complexidade de desenvolvimento do método de localização de falta aumenta. Se, por exemplo, o sistema de proteção da subestação utiliza a impedância aparente, para detectar e localizar uma falta corretamente, será preciso fazer uma correção nos valores de corrente conforme a tabela (2.1).

Tabela 2.1: Fator de correção de corrente de linha para faltas à terra

\begin{tabular}{|c|c|}
\hline Tipo de Falta & Correção \\
\hline Fase a-terra & $I=I_{a}+k I_{r}$ \\
Fase b-terra & $I=I_{b}+k I_{r}$ \\
Fase c-terra & $I=I_{c}+k I_{r}$ \\
Fases a-b ou a-b-terra & $I=I_{a}-I_{b}$ \\
Fases b-c ou b-c-terra & $I=I_{b}-I_{c}$ \\
Fases c-a ou c-a-terra & $I=I_{c}-I_{a}$ \\
Trifásica a-b-c & $I=I_{a b}$ ou $I=I_{b c}$ ou $I=I_{c a}$ \\
\hline
\end{tabular}

Na tabela (2.1), $k$ é dado por $\frac{Z_{L}^{0}-Z_{L}^{1}}{3 Z_{L}^{1}}, I_{x}$ é a corrente de linha na fase $x, Z_{L}^{0}$ é a impedância de sequência zero da linha, $Z_{L}^{1}$ é a impedância de sequência positiva da linha e $I_{r}$ é a corrente 
residual, de neutro ou $3 I_{0}$. Nota-se que, nesse caso, o conhecimento sobre os parâmetros da rede influencia diretamente a utilização das medidas de corrente.

Historicamente, com os critérios apresentados nesta seção, as pesquisas mais expressivas nesse campo envolveram a estimação das correntes no ponto de falta por processos iterativos de atualização da equação (2.2) e formulações com extensão para o cálculo trifásico. Com origem em uma extensiva pesquisa em localização de faltas para linha de transmissão, os primeiros métodos aplicáveis a sistemas de distribuição são baseados na aproximação destes às linhas curtas de transmissão, como na figura (2.3), nos quais toda a carga do alimentador é concentrada no terminal remoto.

Na evolução da pesquisa, os métodos passaram a considerar as ramificações, ganhando em fidelidade e, proporcionalmente, em complexidade. Nos últimos anos, os avanços computacionais tornaram factível a simulação de SEPs com grande nível de detalhamento, permitindo o desenvolvimento de métodos que lidam, por exemplo, com a presença de geração distribuída, faltas de alta impedância, cargas dinâmicas e a existência de infraestrutura Smart Grid.

\subsubsection{Principais Métodos Baseados em Impedância}

Como visto na seção anterior, em (2.4), a análise das medidas de tensão e corrente e a formulação por circuitos elétricos equivalem a analisar a impedância da rede a partir da subestação, a qual se denomina impedância aparente, ou seja, uma impedância que contém informações sobre os efeitos da falta. Essa interpretação deu origem à denominação dos métodos que nesta se fundamentam em "Baseados em Impedância".

A formulação geral apresentada tem origem no método desenvolvido em Takagi et al. (1981) para linhas de transmissão, que fora, ainda, particularizado para linhas de curta extensão em Takagi et al. (1982). Como visto na Seção 2.2.1, esse método se vale de duas principais hipóteses:

1. A impedância de falta é puramente resistiva; 
2. Não há ramais em derivação entre a subestação e a carga.

Embora a primeira consideração seja aceitável, em prol da factibilidade da solução, a segunda não é aplicável em alimentadores de distribuição e o método perde em exatidão, pois cada ramificação drena uma parcela da corrente da subestação.

Partindo-se de um modelo simplificado, agrupando-se os ramais a jusante e a montante da falta, o alimentador pode ser representado como na figura (2.4). O ramal equivalente $\left(Z_{R}\right)$ está a uma distância y da subestação.

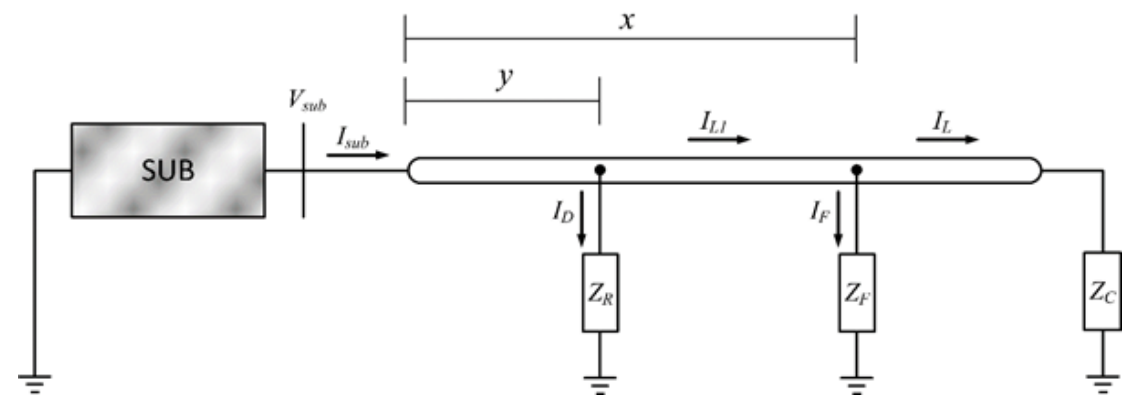

Figura 2.4: Circuito equivalente para a ocorrência de falta. Fonte: (BATISTA, 2016)

Para o cálculo da malha de falta, tem-se a equação (2.1) corrigida em (2.14).

$$
V_{\text {sub }}=y Z_{L} I_{\text {sub }}+(x-y) Z_{L} I_{L 1}+R_{F} I_{F}
$$

Reordenando e fatorando os termos em y, tem-se (2.15).

$$
V_{\text {sub }}=y Z_{L}\left(I_{\text {sub }}-I_{L 1}\right)+x Z_{L} I_{L 1}+R_{F} I_{F}
$$

Verificando as correntes nos nós de falta e do ramal a montante, tem-se $(2.16),(2.17)$ e a equação (2.15) reescrita em termos da corrente de derivação no ramal $\left(I_{D}\right)$. 


$$
\begin{gathered}
I_{L 1}=I_{\text {sub }}-I_{D} \\
I_{L 1}=I_{L}+I_{F} \\
V_{\text {sub }}=y Z_{L} I_{D}+x Z_{L} I_{L 1}+R_{F} I_{F}
\end{gathered}
$$

Analogamente ao desenvolvimento para obter a solução (2.10), a nova solução é expressa em (2.19).

$$
x=\frac{\operatorname{Im}\left[I_{F}^{*} V_{\text {sub }}-y\left(Z_{L} I_{F}^{*} I_{D}\right)\right]}{\operatorname{Im}\left[Z_{L} I_{F}^{*}\left(I_{\text {sub }}-I_{D}\right)\right]}
$$

Agrupando as equações (2.16) e (2.17), obtém-se a relação corrigida entre a corrente de falta $\left(I_{F}\right)$ e a corrente a jusante desta $\left(I_{L}\right)$ em função da corrente na subestação $\left(I_{\text {sub }}\right)$ em $(2.20)$.

$$
I_{F}=I_{s u b}-\left(I_{L}+I_{D}\right)
$$

A corrente de derivação no ramal a montante da falta $\left(I_{D}\right)$ é uma nova incógnita e, se for assumido que o valor pré-falta de $I_{L}$ se preserva durante a falta, obtém-se (2.21) e a equação (2.19) toma a forma apresentada em (2.22).

$$
I_{F}=I_{s u b}-I_{s u b}^{p r e ́}+I_{D}
$$




$$
x=\frac{\operatorname{Im}\left[\left(I_{\text {sub }}-I_{\text {sub }}^{\text {pré }}+I_{D}\right)^{*} V_{\text {sub }}-y\left(Z_{L}\left(I_{\text {sub }}-I_{\text {sub }}^{\text {pré }}+I_{D}\right)^{*} I_{D}\right)\right]}{\operatorname{Im}\left[Z_{L}\left(I_{\text {sub }}-I_{\text {sub }}^{p r e ́}+I_{D}\right)^{*}\left(I_{\text {sub }}-I_{D}\right)\right]}
$$

A equação (2.22) mostra que a presença de ramais impõe uma dificuldade extra, uma vez que não há acesso à medida da corrente que flui por estes, tanto a jusante quanto a montante da falta, e seus valores mudam para cada ponto em que a falta ocorre. Em função desse problema, diversas pesquisas foram desenvolvidas assumindo essas novas variáveis como parte do conjunto de incógnitas do algoritmo.

O início da década de 1980 marcou a pesquisa no campo da localização de faltas em sistemas de distribuição. Alguns métodos começaram a ser propostos já na década de 1950, como apresentado em Report (1955) e Stringfield, Marihart e Stevens (1957), mas só com os resultados de Takagi et al. (1982) houve um amplo crescimento. De fato, Takagi et al. (1982) motivou a exploração de métodos baseados em impedância, pois pouco se havia desenvolvido na análise de circuitos elétricos para o problema em questão (SALIM et al., 2009).

O método de Takagi (TAKAGI et al., 1982) aplica-se a linhas curtas de transmissão com geometria assimétrica, o que acabou conduzindo pesquisas posteriores aos sistemas de distribuição, uma vez que os métodos para tais sistemas apresentam grande semelhança com o de Takagi (TAKAGI et al., 1982). Esse método é fundamentado no princípio da superposição dos circuitos pré-falta e puramente faltoso para compor a situação de falta. O equacionamento foi desenvolvido para faltas fase-terra, mas também é demonstrada sua generalização para outros tipos de faltas. O método apresenta grande exatidão para faltas francas, mas o aumento da resistência de falta eleva o erro consideravelmente. Tal fator é crítico até mesmo em propostas recentes, como será discutido mais adiante.

Em Srinivasan e St-Jacques (2009), a proposta utiliza a análise de componentes simétricas para avaliar sistemas de distribuição e subtransmissão com ramais em derivação. O sistema estudado foi similar ao da figura (2.3) e, diferentemente do que foi desenvolvido em Takagi et al. (1982), não se assume que a corrente de falta está em fase com a corrente na subestação. Para tratar a influência das ramificações, o método gera um conjunto de soluções do local de 
falta para diversos casos de conexão de cargas, sendo as cargas a jusante da falta agrupadas em um equivalente. Por fim, executa-se uma lógica de seleção da melhor estimativa. Esse método constituiu um grande avanço na área por introduzir o tratamento dos ramais e possui um desempenho equiparável a métodos mais recentes (MORA-FLOREZ; MELENDEZ; CARRILLO-CAICEDOC, 2008).

Além de considerar as ramificações e utilizar do princípio da superposição entre o circuito pré-falta e puramente faltoso, como no método anterior, Novosel et al. (1998) é fundamentado no cálculo das impedâncias da fonte e da carga e agrupa todos os ramais intermediários (a montante e jusante da falta) em um único equivalente passivo no terminal remoto. Neste trabalho, são propostos dois cálculos do local da falta. Em um deles, a solução é analítica (relação quadrática), enquanto o outro depende de um processo iterativo linear. O método é primordialmente para linhas curtas de transmissão, embora o terminal remoto seja assumido como uma carga passiva. Os autores apresentam, ainda, uma forma de estendê-lo para um sistema trifásico, visto que todo desenvolvimento é monofásico, como na maioria dos métodos. O desempenho dessa proposta é significativamente afetado pela simplificação dos ramais no terminal remoto, além de acarretar erro em linhas assimétricas ao utilizar componentes simétricas para a extensão trifásica do equacionamento.

O método proposto em Das, Sachdev e Sidhu (2000) é um aprimoramento dos dois anteriores e também aplica-se a linhas curtas, transpostas e isentas do efeito capacitivo. A linha de transmissão é modelada com o terminal remoto passivo, aproximando-a ao que ocorre em sistemas de distribuição radiais. A solução é processada por um algoritmo iterativo que compara a impedância aparente durante a falta com a impedância entre a subestação e cada ramal, até que se obtenha um valor positivo da diferença entre a primeira e a segunda. Com a estimativa da região faltosa, o algoritmo simplifica o circuito agrupando os ramais a montante da falta em um equivalente e os a jusante em outro. Por fim, o circuito equivalente é tratado por meio das equações de linhas curtas para estimar os estados de tensão e corrente no ponto de falta e no terminal remoto. O ponto de falta é obtido considerando a impedância de falta puramente resistiva, como em Takagi et al. (1982), e relacionando os valores estimados de tensão e corrente. Embora esse método apresente grande eficiência, a solução pode conduzir 
a múltiplos locais de falta. Segundo os autores, esse problema pode ser contornado pela utilização de indicadores de falta na rede, o que acarretaria considerável aumento no custo de implantação dessa proposta.

Diferentemente da maioria dos trabalhos da época, Zhu, Lubkeman e Girgis (1997) apresentam um método baseado em componentes de fase. Como os sistemas de distribuição possuem grande assimetria, o tratamento a partir de componentes de fase é mais representativo que componentes simétricas. As ramificações são consideradas individualmente e os estados de tensão e corrente são estimados a cada iteração. Um processo de busca é feito a partir da subestação por meio de um novo equacionamento que compara a impedância estimada no ponto da falta com a impedância equivalente da carga no alimentador. Assumindo as cargas dos ramais conhecidas, as iterações são iniciadas com a estimação da corrente de falta e então procede-se analogamente ao método de Takagi (TAKAGI et al., 1982). Um advento importante desse trabalho é o estudo probabilístico do problema após o processo iterativo. Como o método prevê a existência de múltiplas soluções, foi proposta a busca por uma região de possíveis locais de falta, obtida pela relação entre as soluções e incertezas nas medições e dados da rede. A região encontrada torna-se foco de extensivas simulações da rede, com o máximo de fidelidade, para determinar o local exato da falta. A aplicação restringe-se, ainda, a redes com baixo efeito capacitivo e faltas fase-terra. Entretanto, esse método obteve grande repercussão na área de pesquisa.

Na mesma linha do método anterior, e também assumindo destaque, Lee et al. (2004) apresenta uma formulação menos extensa e não faz uso de cálculos de fluxo de potência para atualizar a corrente de falta. O método é desenvolvido a partir do equacionamento trifásico da relação entre tensão e corrente no alimentador, resultando em matrizes de impedância e admitância. A carga a jusante da falta é agrupada em um equivalente oriundo da associação das impedâncias dos trechos de linha e das cargas, assumindo conhecidas as características das cargas. A estimativa da corrente ao longo do alimentador é feita assumindo que as tensões nas cargas são conhecidas, o que é um limitante nesse método. O trabalho propõe uma metodologia eficiente para identificar o ramal de ocorrência da falta, em vista da multiplicidade de soluções. Simulações extensivas não são necessárias, pois é feita uma avaliação da forma 
de onda da corrente na subestação, juntamente com a quantidade de carga interrompida, dada pela diferença entre a carga total e a carga a montante da falta.

As inovações na formulação concisa da proposta em Lee et al. (2004) representam um marco na área e diversos métodos surgiram como extensão de seus resultados. Em Salim et al. (2009), são propostos três aprimoramentos: o primeiro é a extensão do método para todos os tipos de falta, o que já era praticado em soluções que utilizam componentes simétricas; o segundo é a execução de um cálculo de fluxo de potência pré-falta para obter as informações necessárias à atualização da corrente de falta e tratativa dos ramais, dando mais aplicabilidade a sistemas com muitas ramificações; o terceiro, e principal, é referente à variação da carga, calculando a variação relativa entre a carga nominal e a carga a poucos ciclos antes da falta. Os resultados apresentam significativa melhoria, o que deu grande visibilidade à proposta, mesmo sendo ela uma extensão de outra.

Com o objetivo de isentar-se dos erros advindos dos métodos iterativos, Choi et al. (2004) retorna ao equacionamento analítico em componentes de fase. As considerações sobre o sistema são as mesmas do método de Lee et al. (2004), porém o local da falta é obtido diretamente por uma equação quadrática dependente dos parâmetros das linhas, medições na subestação e características das cargas. O método pode fornecer dupla solução e destaca que a solução correta deverá estar entre 0 e 1, mas não há descrição do procedimento para o caso em que as duas estejam nesse intervalo.

\subsection{Falta de Alta Impedância}

As falhas mais comuns em sistemas de distribuição são a ocorrência de curto-circuito na média e baixa tensão, a queima de transformadores e o afrouxamento de conexões entre condutores e demais componentes da rede. Essas falhas são normalmente ocasionadas por: rompimento de cabos aéreos, quebra de isoladores, deterioração dos transformadores de distribuição e seus componentes, acúmulo de sujeira sobre os isoladores, atos de vandalismo, fenômenos da natureza (como raios, ventos e queda de árvores ou galhos) e acidentes com animais. Tipi- 
camente, entre $80 \%$ e $90 \%$ das faltas ocorrem em ramais de distribuição aéreos e o restante, em subestações e barramentos (TLEIS, 2007). As faltas em sistemas elétricos de potência (SEP) podem, então, ser classificadas quanto à sua causa: mecânica (golpes de máquinas, galhos de árvore, animais), elétrica (degradação do isolante, sobretensões) e humana (erro de operação), e podem se manifestar em duas formas básicas (SAHA; IZYKOWSKI; ROSOLOWSKI, 2010):

- Faltas shunt: curto-circuito que produz fluxo de corrente entre fases e/ou terra. As correntes de falta podem conter componentes de frequências diferentes da fundamental, principalmente as altas frequências. A magnitude destas depende da impedância aparente até o ponto de falta, do tipo de aterramento do sistema, da impedância da própria falta e do tipo de falta, como apresentado na figura (2.5), variando de condições severas em faltas trifásicas sólidas à terra até poucos ampères em faltas de alta impedância;

- Faltas série: situação na qual a impedância das fases é alterada, modificando o fluxo normal de corrente, em geral causada pela interrupção de uma ou mais fases. A falta série pode ser interpretada eletricamente como o surgimento de uma impedância série de valor elevado que reduz drasticamente o fluxo de potência. As formas pelas quais esse tipo de falta podem se estabelecer são apresentadas por meio da figura (2.6).

Da figura (2.5) pode-se verificar a existência dos seguintes tipos de falta shunt:
a) Fase-terra;
b) Fase-fase;
c) Fase-fase-terra;
d) Trifásica;
e) Trifásica-terra. 

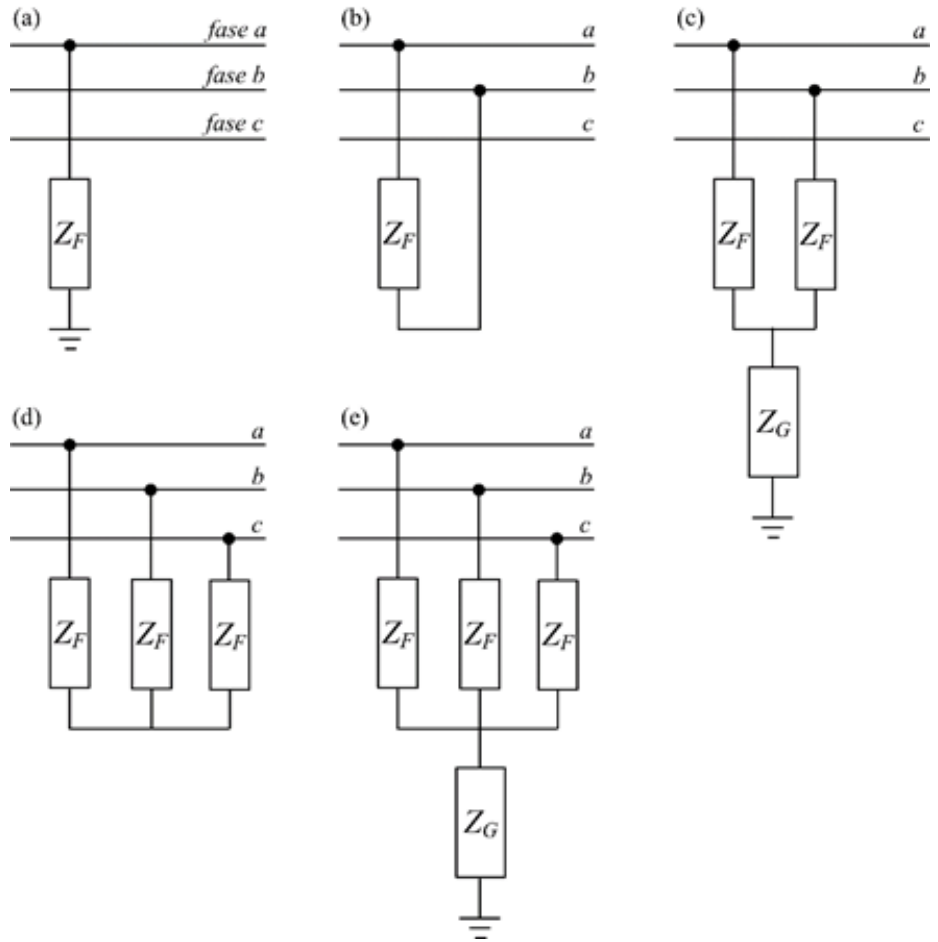

Figura 2.5: Tipos básicos de faltas shunt.

A ocorrência desses tipos de falta depende das características topológicas do sistema elétrico. Em sistemas de distribuição com linhas aéreas, caso mais comum no Brasil, há grande influência de eventos climáticos, como as chuvas, e as faltas shunt fase-terra são as mais frequentes (KELLER; KROPOSKI, 2010). As faltas shunt podem ter comportamento intermitente, no qual, havendo a operação de um equipamento de proteção, a causa do defeito é isolada e o sistema retorna a operar normalmente depois de religado ou, se forem permanentes, exigem intervenção humana.

Da figura (2.6) pode-se verificar a existência dos seguintes tipos de falta série:

a) Fase rompida;

b) Fase rompida-terra pelo lado da subestação;

c) Fase rompida-terra pelo lado da carga. 


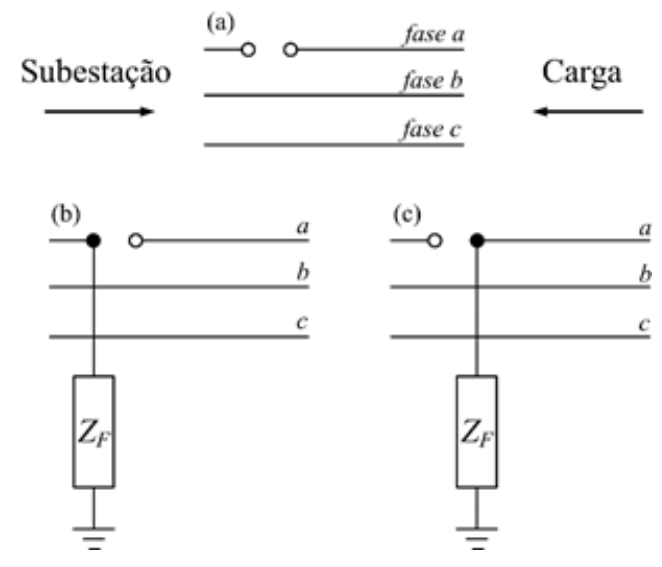

Figura 2.6: Tipos básicos de falta série.

Faltas série promovem a interrupção imediata e permanente do fornecimento de energia aos consumidores e exigem, inevitavelmente, o deslocamento da equipe de manutenção ao local. A corrente de falta apenas existirá no caso em que o condutor rompido vai à terra no lado da subestação, comportando se como uma uma falta shunt. Entretanto, seu valor é, em geral, da ordem da corrente de carga. As causas mais comuns são o rompimento de condutor, operação de elo fusível e mal funcionamento de disjuntores.

As consequências das elevadas correntes de falta são geralmente graves e podem causar danos permanentes à rede. Uma falta introduz perturbações à rede nas proximidades do ponto de ocorrência, ocasionando afundamentos de tensão ou desconexão, pelos dispositivos de proteção, de uma parte da rede. Os equipamentos e conexões (cabos, linhas, barras e isoladores) sujeitos a um curto-circuito são submetidos a um forte esforço mecânico (forças eletrodinâmicas) que pode causar rupturas e a um esforço térmico que pode provocar a queima dos condutores e a destruição dos isolantes, no ponto da falha, onde frequentemente ocorre arco elétrico com grande potência. Embora as faltas de alta impedância provoquem correntes de magnitude reduzida, suas consequências podem ser igualmente severas, pois a não sensibilização da proteção impede o reconhecimento do defeito e expõe a região próxima à sua ocorrência à formação de arcos elétricos, chamas e tensões (IEEE, 2007). 


\subsubsection{Conceitos e Características}

As faltas de alta impedância (FAI) são faltas assimétricas, em geral entre fase e terra, que possuem uma corrente com amplitude incapaz de ser detectada por técnicas convencionais e, por consequência, promover a atuação de relés e fusíveis (XU; CHOW, 2006). Valores estatísticos relatados na literatura técnica exprimem que cerca de 90\% das faltas em um sistema de distribuição são faltas de alta impedância, sendo as causas mais comuns o rompimento de condutores ou o contato destes com objetos mal aterrados, como veículos, árvores, cruzetas, postes e cercas de madeira ((BRETAS et al., 2006);(ELMORE, 2004)).

Em situações de falta de alta impedância, além dos transitórios eletromagnéticos, tem-se que sua característica de assimetria compromete o balanço das tensões de fase, degradando ainda mais a qualidade do fornecimento de energia aos consumidores (BI; ZHAO; ZHANG, 2004). Em adição, as faltas de alta impedância fase-terra, mesmo quando caracterizadas por pequenas correntes em magnitude, criam na região de sua ocorrência tensões de passo e de contato que colocam em risco a segurança de pessoas, animais e instalações (TENGDIN et al., 1996).

Das causas mais frequentes para as faltas de alta impedância permanentes, podem-se citar: o rompimento e queda ao solo de cabos-fase, o abalroamento de postes, o contato acidental permanente e, com destaque, danos permanentes em isoladores, danos na isolação de equipamentos e a deterioração de para-raios. Por outro lado, as causas mais comuns para o desencadeamento de faltas de alta impedância temporárias são o arco elétrico em isoladores, a contaminação de isoladores por poeira e poluição, as correntes subsequentes em para-raios, a umidade, a salinidade e as condições atmosféricas. Observando as causas mais comuns associadas às faltas de alta impedância, constata-se a dificuldade em determinar o local de sua ocorrência pela simples inspeção visual da rede de distribuição de energia elétrica que, como anteriormente comentado, constitui a prática mais comum quando da ocorrência desse tipo de falta.

Conforme sua causa, as faltas de alta impedância podem se apresentar como faltas série, 
quando do rompimento de cabos que vão à terra, ou shunt, se há problemas na isolação de elementos com estruturas de suporte, como cadeia de isoladores e para-raios. Entretanto, seu comportamento não é linear, muito menos resistivo. De acordo com Nam et al. (2001), a assinatura da forma de sua corrente possui quatro características peculiares, que podem ser observadas na figura (2.7) e são listadas a seguir. Essas características podem ser compreendidas como componentes lineares do comportamento da corrente de falta.

1. Build-up: A corrente de falta cresce até seu valor máximo após algumas dezenas de ciclos;

2. Shoulder: O processo de crescimento do valor da corrente (build-up) é interrompido ou atenuado por alguns ciclos;

3. Não-Linearidade: A relação tensão-corrente na falta não é linear;

4. Assimetria: A corrente de falta possui formas de onda diferentes para os semiciclos positivo e negativo.

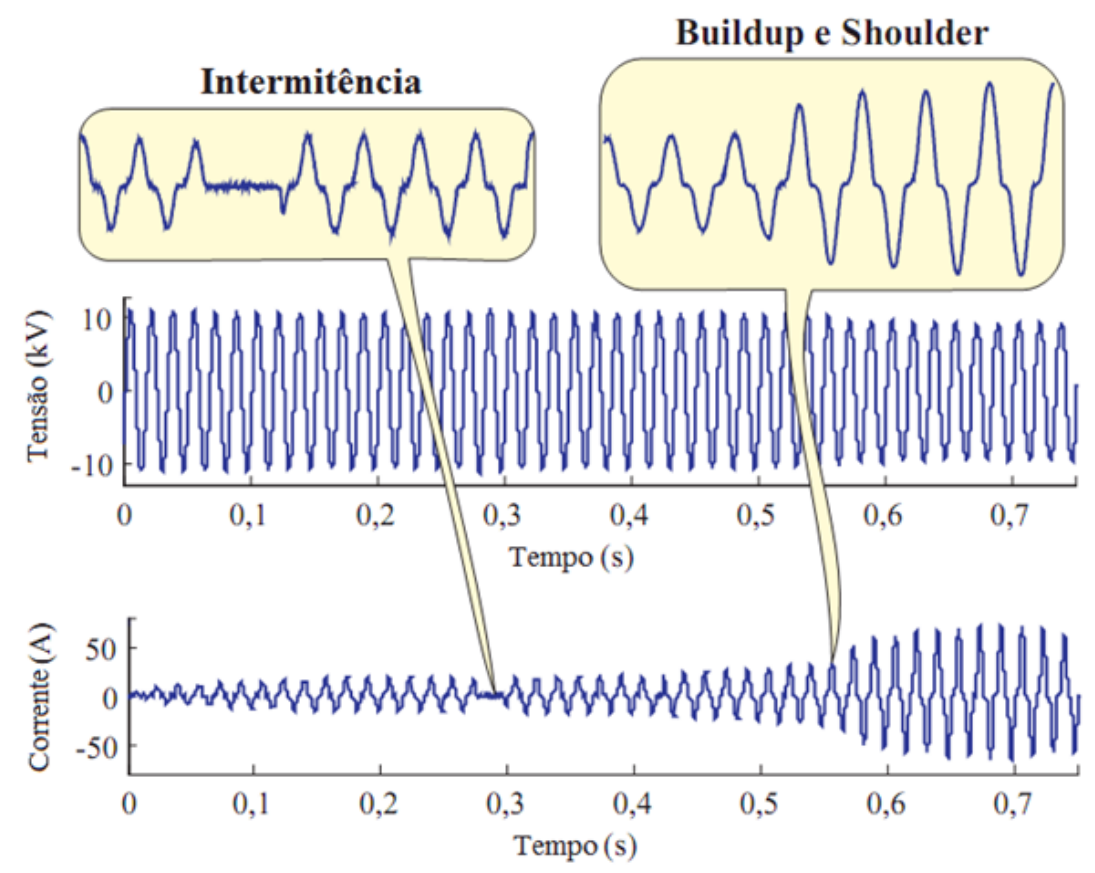

Figura 2.7: Forma de onda característica da corrente em uma FAI. 
Na figura (2.7), mostra-se a oscilografia de tensão e corrente de uma falta de alta impedância aferida em campo. A assimetria e não linearidades permeiam a forma de onda em todos os ciclos. Um evento de intermitência (shoulder) ocorre pouco antes de 0, 3s e, detalhando-se a imagem em torno de $0,55 \mathrm{~s}$, observa-se outro processo de intermitência, agora atenuando o build-up, que se verifica desde os primeiros ciclos. Tais características da falta promovem a geração de transitórios eletromagnéticos na faixa de $2 \mathrm{kHz}$ a $10 \mathrm{kHz}$ (SEDIGHI et al., 2005).

O aspecto intermitente característico das correntes de faltas de alta impedância é fruto da formação de arcos elétricos, que possuem variação temporal de sua impedância. Dessa forma, mesmo que a corrente de falta seja capaz de sensibilizar a proteção do sistema, dada sua magnitude, ocorre que sua extinção natural pode se dar antes da atuação da proteção temporizada. No entanto, a extinção natural da falta não é sinônimo de que o sistema esteja íntegro e isso se observa pela contínua repetição da falta, ou seja, tem-se sua evolução de falta intermitente para uma falta permanente. A ocorrência de períodos de intermitência pode mascarar a presença da falta e fazer, por exemplo, com que o trecho seja religado com o defeito ainda existente.

Outro aspecto importante é a influência do tipo de superfície de contato na magnitude da corrente de falta. A tabela (2.2) apresenta os valores para as superfícies mais comuns de ocorrência de queda de condutores, com base nas medições relatadas em Lazkano et al. (2000).

Em Jeerings e Linders (1989), a análise do contato do condutor no solo constatou o aparecimento de componentes harmônicos na corrente de falta advindos do comportamento não linear. Destaca-se que esse tipo de falta em sistemas de distribuição apresenta uma corrente inicial menor que 100A e o arco elétrico possui cerca de $5 \mathrm{~cm}$. Nessas condições, não há vaporização completa das partes metálicas do condutor, impossibilitando a formação de íons para uma melhor condução elétrica e consequente baixa impedância. A vaporização de elementos não metálicos nas proximidades do arco, como vegetação, agrava o desenvolvimento caótico da corrente. Esse fenômeno é um dos principais motivos do comportamento altamente 
Tabela 2.2: Níveis de corrente típicos para FAI, em função da superfície

\begin{tabular}{|c|cc|}
\hline Superfície & Condição & Corrente \\
\hline Areia & Úmido & $25,6 \mathrm{4A}$ \\
& Seco & $8,91 \mathrm{~A}$ \\
\hline Asfalto & Úmido & $36,63 \mathrm{~mA}$ \\
& Seco & $95,94 \mathrm{~mA}$ \\
\hline Gramado & Úmido & $57,18 \mathrm{~A}$ \\
\hline Cascalho Fino & Seco & $28,89 \mathrm{~A}$ \\
\hline Cascalho Grosso & Úmido & $31,24 \mathrm{~A}$ \\
& Seco & $114,5 \mathrm{~mA}$ \\
\hline Concreto & Úmido & $62,92 \mathrm{~A}$ \\
& Seco & $32,08 \mathrm{~A}$ \\
\hline Terra & Úmido & $46,73 \mathrm{~A}$ \\
& Seco & $10,52 \mathrm{~A}$ \\
\hline Árvore (Conífera) & Úmido & $4,89 \mathrm{~A}$ \\
& Seco & $22,56 \mathrm{~A}$ \\
\hline
\end{tabular}

não linear da corrente em uma falta de alta impedância.

\subsubsection{Comportamento Elétrico e Modelagem}

As faltas de alta impedância possuem duas características primordiais: as baixas correntes de falta e a formação de arcos elétricos. A primeira é decorrente da alta impedância formada entre o condutor e a superfície de contato ou entre a isolação do condutor e um objeto, produzindo pouca ou nenhuma corrente. A segunda característica é o fenômeno de formação de arco elétrico pois, dada a alta impedância de contato, a diferença de potencial cria caminhos preferenciais pelos gaps de ar, nos quais tem-se elevado potencial a uma curta distância, favorecendo a ruptura do dielétrico. Entretanto, dado o nível de tensão dos sistemas de distribuição, a energia do arco não é suficiente para manter a corrente sustentada, tornando-a intermitente. Parte disto se deve às condições em constante mudança da superfície de contato. Portanto, o comportamento elétrico dinâmico não linear (caótico) é um traço marcante das faltas de alta impedância (NARASIMHARAO, 2012). Devido à formação do arco elétrico, a tarefa de desenvolver um modelo fiel à falta de alta impedância tem sido um enorme desafio. 
O comportamento do arco diferencia-se consideravelmente entre um semiciclo e outro, como pode ser visto na figura (2.8), e essa assimetria compromete a obtenção de equações diretas para a tensão em função da corrente (ELKALASHY et al., 2007).

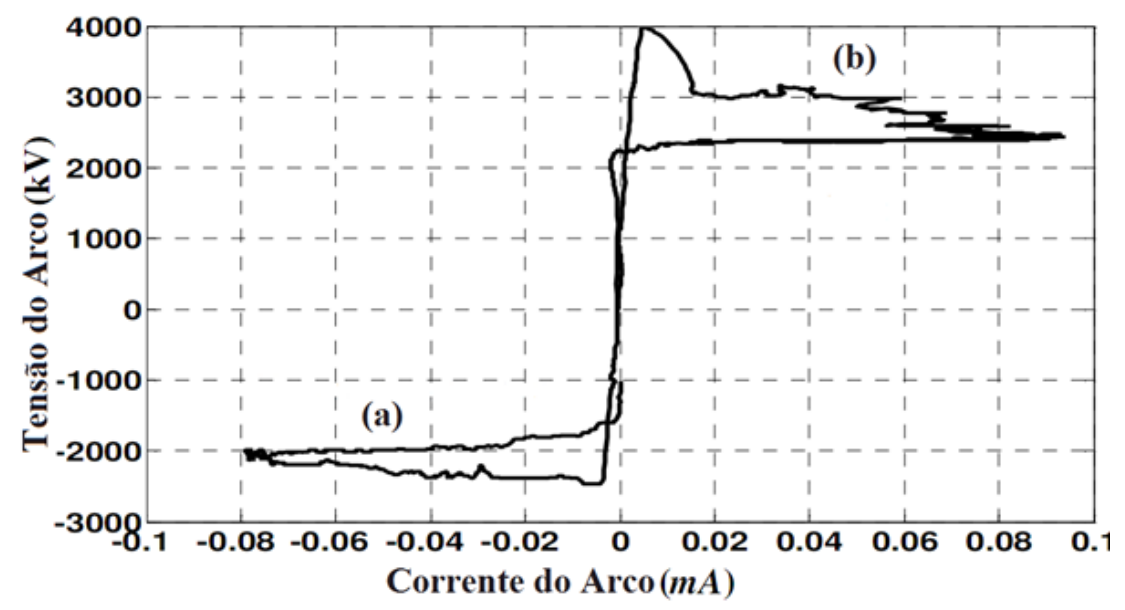

(a) Semiciclo Negativo

(b) Semiciclo Positivo

Figura 2.8: Relação entre tensão e corrente em uma FAI.

A origem das diversas pesquisas em busca de um modelo para faltas com arco elétrico está no princípio do equilíbrio térmico, com a introdução das primeiras descrições da condutividade do arco elétrico, na forma de uma equação diferencial de primeira ordem, em Cassie (1939) e Mayr (1943):

$$
\begin{gathered}
\frac{\partial g(t)}{\partial t}=\frac{G(t)-g(t)}{\tau} \\
G(t)=\frac{|i(t)|}{V_{a r c}} \\
\tau=A e^{B g(t)}
\end{gathered}
$$


Na equação (2.23), $g(t)$ é a condutância do arco, que varia com o tempo; $G(t)$ é a condutância estacionária do arco, dada por (2.24), e $\tau$ é a "constante"de tempo do arco, dada por (2.25). Em (2.24), $|i|$ é o valor absoluto da corrente do arco e $V_{\text {arc }}$ é a constante de tensão do arco. Em (2.25), $A$ e $B$ são os parâmetros constantes que representam o comportamento da forma de onda em cada semiciclo.

Para determinar os parâmetros constantes, são utilizados dados experimentais em Elkalashy et al. (2007) para interpolar as curvas de tensão e corrente da falta. Em função da assimetria, foi realizada uma interpolação para cada semiciclo, resultando em dois valores para cada parâmetro, como apresentado na tabela (2.3).

Tabela 2.3: Parâmetros do modelo baseado no princípio do equilíbrio térmico.

\begin{tabular}{|c|c|c|}
\hline Parâmetro & Semiciclo Positivo & Semiciclo Negativo \\
\hline$V_{\text {arc }}$ & $2520 \mathrm{~V}$ & $2100 \mathrm{~V}$ \\
$A$ & $6,6 \cdot 10^{-5} \mathrm{~s}$ & $2,0 \cdot 10^{-5} \mathrm{~s}$ \\
$B$ & $41977 \Omega$ & $85970 \Omega$ \\
\hline
\end{tabular}

O equacionamento baseado nos fundamentos do equilíbrio térmico pode ser utilizado para construir um modelo computacional, como proposto em Darwish e Elkalashy (2005), discretizando a equação (2.23) na forma de (2.26). O algoritmo de resolução dessa equação diferencial deve envolver um processo iterativo e está representado na forma de fluxograma na figura (2.9).

$$
\frac{g(k+1)-g(k)}{\Delta t}=\frac{1}{A e^{B g(k)}}\left[\frac{|i(k)|}{V_{\text {arc }}}-g(k)\right]
$$

O fato de necessitar de dados experimentais e interpolação das curvas de tensão e corrente motivou pesquisadores a partir da abordagem térmica para a obtenção de modelos elétricos. Nesse sentido, norteou-se a busca pelas características da falta de alta impedância em relação aos fenômenos de faltas em sistemas elétricos de potência. Uma análise comparativa em Jeerings e Linders (1990) apresentou um conjunto de características únicas baseadas no conteúdo harmônico das faltas em relação a diversas outras fontes harmônicas: 


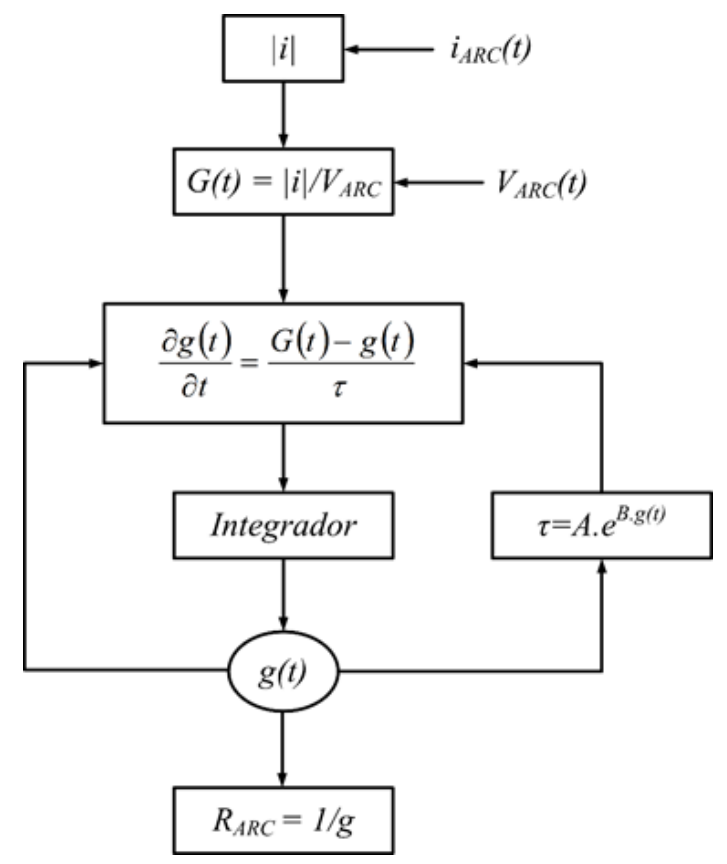

Figura 2.9: Solução numérica da equação diferencial da condutância do arco elétrico.

- Faltas de Alta Impedância são monofásicas (fase-terra). Quando mais de uma fase está envolvida, ou é uma falta convencional de corrente elevada ou pode ser tratada como duas faltas de alta impedância separadas. A interação normal entre fases durante uma falta fase-fase-terra convencional não ocorre de forma significativa;

- As componentes harmônicas são geradas em um único local. A complexidade do modelo total de harmônicos de dezenas de fontes, cada uma com um fator de distribuição diferente, não ocorre;

- As correntes de falta estão, substancialmente, em fase com a tensão do sistema, resultando no sincronismo do valor de pico entre as correntes harmônicas e a componente fundamental;

- As harmônicas são funções da tensão no ponto de falta. Já alguns dos harmônicos do ambiente são funções das correntes de carga no sistema.

A partir dos trabalhos de Emanuel e Cyganski (1990) e Nam et al. (2001), surgiram dois 
grandes grupos de modelos de faltas de alta impedância. O primeiro deu origem aos modelos ativos (presença de fontes), que conseguem simular as características de não linearidade e assimetria. O segundo propõe um modelo passivo utilizando resistências não lineares, conseguindo simular também os efeitos de build-up e o shoulder.

O trabalho desenvolvido em Emanuel e Cyganski (1990) é uma grande referência na área devido a seus ensaios em campo. Faltas foram aplicadas ao final de um alimentador real e os dados foram submetidos a uma detalhada análise harmônica, comparando com os dados de operação normal. Os resultados evidenciaram que os valores da $3^{\text {a }}$ harmônica da corrente de linha e $2^{\text {a }}$ harmônica da corrente de neutro são diferenciais das faltas de alta impedância. De fato, Jeerings e Linders (1990) também constataram que a magnitude da $3^{\text {a }}$ harmônica e a diferença de fase entre esta e a componente fundamental da tensão são indicadores da ocorrência de tal falta. Com base no estudo harmônico, propõe-se em Emanuel e Cyganski (1990) um modelo composto por uma impedância resistiva e indutiva em série com a associação antiparalela de diodos em série com fontes de tensão em corrente contínua, conforme a figura (2.10). As características de condução dos diodos permitem representar a assimetria pois, no ciclo positivo, a corrente de falta flui pela fonte $V_{P}$ e, no ciclo negativo, pela fonte $V_{N}$. Com os testes de validação do modelo apresentados, concluiu-se que a $2^{\mathrm{a}}$ harmônica está estreitamente relacionada à assimetria dada por $\Delta V=V_{N}-V_{P}$ e que a $3^{\text {a }}$ harmônica depende fortemente da relação $X_{L} / R$.

O modelo proposto em Nam et al. (2001) é baseado na associação série de dois resistores não lineares, ou seja, $R_{f}(t)=R_{1}(t)+R_{2}(t)$. O resistor $R_{1}$ é responsável pelas características de assimetria e não linearidade nos regimes permanente e transitório, e tem característica periódica. Já $R_{2}$ atua em regime transitório, com um valor elevado no começo e decrescendo monotonicamente até zero, agregando os efeitos de build-up e shoulder, como apresentado na figura (2.11).

Como indicado na figura (2.11), a implementação do modelo foi conduzida em EMTP ${ }^{1}$

\footnotetext{
${ }^{1}$ Eletromagnetics Transient Program (EMTP), software dedicado à simulação de transitórios eletromagnéticos em sistemas elétricos de potência.
} 
e, por meio do módulo TACS ${ }^{2}$, foi criada a rotina de controle dos resistores. Medidas experimentais nos regimes permanente e transitório formaram a base de dados utilizada pelo controle TACS para simular a curva real de tensão por corrente.

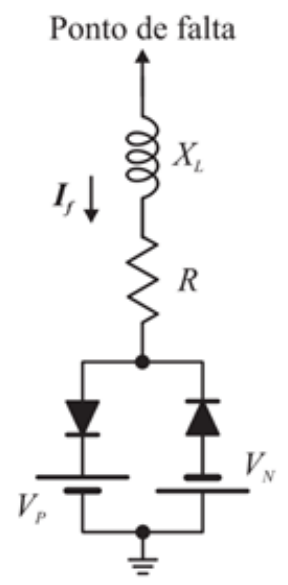

Figura 2.10: Modelo proposto em Emanuel e Cyganski (1990).

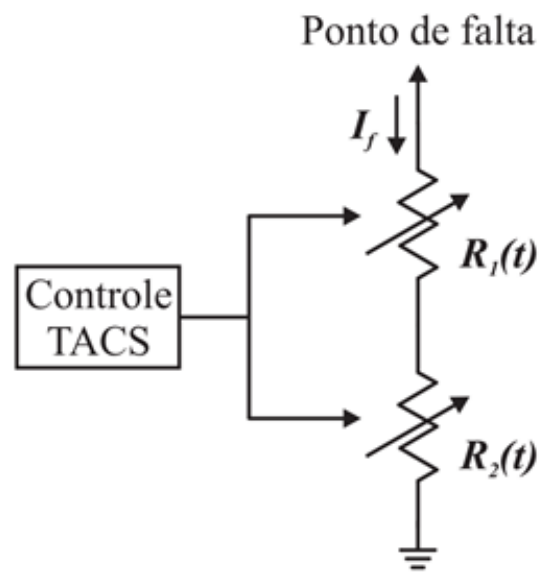

Figura 2.11: Modelo proposto em Nam et al. (2001).

Desde a publicação desses dois modelos, houve modesto avanço no sentido de novas abordagens, e percebe-se que mesmo as proposições mais modernas são variações ou combinações

\footnotetext{
${ }^{2}$ Transient Analysis of Control Systems (TACS), módulo do EMTP responsável pelo uso de componentes controlados por variáveis de outros pontos do sistema.
} 
dos modelos anteriores ((ELKALASHY et al., 2007), (GAUTAM; BRAHMA, 2013), (TERZIJA et al., 2007) e (WU et al., 2005)), assim como diversas proposições para detecção e localização de faltas de alta impedância têm feito ((ELKALASHY et al., 2008), (ETEMADI; SANAYE-PASAND, 2008) e (AKOREDE; KATENDE, 2010)).

Em função de sua simplicidade e praticidade de implementação, destaca-se o modelo apresentado em Sharaf (2003), que se vale da associação série de um resistor linear com um resistor que é função não linear da corrente de falta, como em (2.27).

$$
R_{f}=R_{f_{0}}\left[1+\alpha\left(\frac{i_{f}}{i_{f_{0}}}\right)^{\beta}\right]
$$

A única variável desse modelo é a corrente de falta $i_{f}$. As demais grandezas são constantes: resistência de falta inicial $R_{f_{0}}=20 \Omega$, ganho $\alpha=0,6$, expoente $\beta=2$ e corrente de falta inicial $i_{f_{0}}=70 \mathrm{~A}$, podendo-se, ainda, associar uma indutância de falta $L_{f}=3 \mathrm{mH}$ em série. $\mathrm{O}$ modelo consegue simular razoavelmente o efeito de não linearidade e em sua implementação podem, facilmente, ser adicionados os efeitos de assimetria, build-up e shoulder, combinando com outras funções temporais.

\subsubsection{Influência na Localização de Faltas}

Os métodos convencionais fazem a consideração de que a impedância de falta é puramente resistiva, o que os torna indiferentes às não linearidades. Dadas as demais considerações e as dificuldades inerentes ao problema de localização de faltas, as duas maiores fontes de erro e desafios a serem enfrentadas são: o efeito da impedância de falta, quando do aumento de sua magnitude, e o efeito da distância desta, pois, quanto mais distante, menores são as informações contidas nas medições na subestação (MORA-FLOREZ; MELENDEZ; CARRILLO-CAICEDOC, 2008).

O efeito da impedância de falta dificulta muito a consolidação de um único modelo eficiente tanto para baixas quanto para altas impedâncias de falta. Dessa forma, as pesquisas têm 
conduzido, cada vez mais, a métodos específicos para compor módulos de um sistema maior. Embora o início das discussões sobre faltas com formação de arcos elétricos em sistemas de média e baixa tensão date da década de 1940 ((IEEE, 1941), (WAGNER; FOUNTAIN, 1948)) e que Shields (1967) tenha consolidado amplo estudo sobre os efeitos destas, os desenvolvimentos para a área de localização de faltas de alta impedância em sistemas de distribuição são recentes e foram impulsionados pelos resultados apresentados em Emanuel e Cyganski (1990). Em 2001, Funabashi et al. (2001) estudaram a influência das características do arco elétrico na exatidão de localizadores digitais de falta. Nesse trabalho, concluiu-se que diversos parâmetros, como tamanho, tensão e constante de tempo do arco, são diretamente proporcionais ao erro máximo de estimação.

O uso da Transformada Wavelet ${ }^{3}$ é muito recorrente nos métodos para detecção de faltas de alta impedância e, em Elkalashy et al. (2008), utiliza-se a Transformada Discreta Wavelet (TDW) para analisar os transitórios iniciais dos arcos, dado que as ignições apresentam traços comportamentais (ELKALASHY et al., 2007). Foi utilizado um sistema de distribuição em $20 \mathrm{kV}$ não aterrado e com medição sem fio em múltiplos nós. O local da falta é determinado por meio das polaridades na faixa da banda de potência entre $6,25 \mathrm{kHz}$ a $12,5 \mathrm{kHz}$, obtidas multiplicando os coeficientes wavelet (apenas o detalhe d3) da tensão e corrente de neutro, em cada nó. Apenas para um nó faltoso a polaridade será positiva e o ramal de falta é identificado.

Os métodos baseados em impedância na frequência fundamental são aplicáveis a faltas permanentes e, por isso, em Alamuti et al. (2012), tem-se uma formulação no domínio do tempo que considera a curta duração de faltas, como as que produzem arco, para a localização sob efeito de intermitência. Um aspecto marcante do método é a utilização de poucos dados amostrais (apenas um ponto de medição) e o conhecimento das impedâncias dos cabos (próprias e mútuas), conferindo-lhe elevado custo-benefício de implementação, em vista dos bons resultados obtidos. O conhecimento sobre a carga não é necessário, visto que esta varia ao longo do dia, garantindo robustez. No entanto, considera-se o alimentador isento

\footnotetext{
${ }^{3}$ Wavelet é uma função capaz de representar outra função, originalmente no domínio do tempo, em diferentes escalas de frequência e de tempo. A decomposição de uma função com o uso de wavelets é conhecida como Transformada Wavelet e é uma ferramenta poderosa de processamento de sinais.
} 
de ramais e sem realocação de cargas entre fases, o que limita a aplicação do método, mas não perdendo o mérito, dada sua originalidade. O equacionamento dessa proposta é similar ao encontrado nos métodos tradicionais baseados em impedância, porém trabalhado no domínio do tempo para melhor interpretar os transitórios. Em seus resultados, é destacada a influência dos seguintes fatores:

- Impedância e distância da falta: o aumento de ambos acarreta aumento proporcional do erro;

- Ângulo de falta ${ }^{4}$ : uma falta intermitente é geralmente extinta após a passagem da tensão por zero. Assim, o ângulo de falta determina sua duração e, quanto menor for esse tempo, menos dados serão disponíveis e maior será o erro;

- Capacitância do cabo: em sistemas de distribuição, o efeito capacitivo na localização de faltas pode ser desprezado, pois a corrente de fuga é muito menor que as correntes de falta no fim do alimentador.

Em consonância com a tendência da área rumo às Smart Grids, Milioudis, Andreou e Labridis (2012) contemplam o aporte de dispositivos e infraestrutura de uma rede moderna, denotada por "Power Line Comunication (PLC)", para executar uma generalização do teste de reflectometria. Cada dispositivo injeta um sinal (impulso) na rede e, analisando as múltiplas propagações (respostas ao impulso), o local de falta pode ser determinado. A validação é conduzida pela aplicação em um sistema de distribuição rural com grande ramificação e conclui-se que o método consegue determinar a posição de falta com grande exatidão, sendo, porém, afetado pelo tipo de falta e pela impedância desta.

A alocação de medidores digitais, dependendo da extensão da rede, representa alto custo e mesmo a utilização da infraestrutura de comunicação Smart Grid exige o tratamento de um volume de dados que inviabiliza o armazenamento dos dados provenientes de todos os pontos de medição (YIN et al., 2013). Em vista da otimização de recursos, em Zhou et al. (2012) propõe-se um método rápido (processamento inferior a $50 \mathrm{~ms}$ ), de baixo custo (não

\footnotetext{
${ }^{4} \mathrm{O}$ ângulo da falta é o momento do ciclo da tensão em que ocorre a falta, variando de $0^{\circ}$ a $360^{\circ}$.
} 
requer medidores de alto desempenho e utiliza medição em poucos nós) e de alta performance (robusto frente a ruídos e aplicável em caso de múltiplas faltas). Baseado em recuperação de esparsidade em medidas, o método compara os dados esparsos dos poucos nós de medição com a matriz de impedância do sistema, de forma que o resíduo resultante na solução do equacionamento matricial forneça informações sobre o estado do sistema suficientes para localizar o ponto de falta. Simulações extensivas foram realizadas para demonstrar a eficiência do algoritmo. Para um sistema com 454 nós, em apenas $20 \%$ destes foram feitas medições. A solução é apresentada de forma gráfica em matrizes de cores, com resultados significativos mesmo para um sistema de grande extensão. Não são feitas restrições quanto à modelagem do sistema, visto que seu desenvolvimento visa aplicação com medidas de campo. 


\section{Capítulo 3}

\section{DECOMPOSIÇÃO EM \\ COMPONENTES ORTOGONAIS}

\subsection{Introdução}

Neste capítulo será apresentada a base teórica e a definição da técnica de decomposição por componentes ortogonais, fortemente baseadas em conceitos de álgebra linear.

A técnica de decomposição em componentes ortogonais foi proposta em Flauzino (2007) e tem por finalidade extrair informações de tensões e correntes trifásicas no domínio do tempo, resultando na fragmentação do conteúdo em 64 componentes. A principal característica da ferramenta apresentada é a sua independência de uma base, diferente da transformada de Fourier e a transformada Wavelet, ou seja, a decomposição em componentes ortogonais não se fundamenta na projeção de funções sobre outras pré-estabelecidas. Ao contrário disso, procura-se extrair das próprias formas de onda as funções base para a decomposição, de maneira que o sistema de coordenadas esteja autocontido nas funções que serão decompostas. 


\subsection{Espaços Vetoriais e suas Propriedades}

A técnica de decomposição em componentes ortogonais está pautada nas propriedades inerentes a espaços vetoriais, em especial, o espaço vetorial das funções periódicas $f(t)$, de período $T$, denotado como $\mathfrak{F}_{T}$. Esse espaço vetorial contém todas as funções periódicas, conforme a definição de (3.1), e possui dimensão infinita, sendo uma possível base para esse espaço as infinitas funções do tipo $e^{-j 2 \pi \frac{n}{T} t}$, conforme decomposição pela transformada de Fourier.

$$
f(k T+t)=f(t), \forall k \in \mathbb{N}
$$

Sobre o espaço vetorial $\mathfrak{F}_{T}$, é definido o produto interno $<f, g>$ entre as funções $f(t)$ e $g(t)$ conforme abaixo:

$$
<f, g>=\frac{1}{T} \int_{t-T}^{t} f(\tau) g(\tau) d \tau
$$

Com base na definição de produto interno, é possível definir a projeção de uma função $f$ sobre outra função $g$, que representa qual parcela colinear a $g$ compõe a função $f$. Seja $\operatorname{proj}_{g} f(t)$ a projeção de $f$ sobre $g$, cuja definição é:

$$
\operatorname{proj}_{g} f(t)=\frac{<f, g>}{\|g\|^{2}} g(t)
$$

onde $\|g\|$ é norma de $g$, que representa a amplitude do sinal em valores RMS, definida por:

$$
\|g\|=\sqrt{<g, g>}
$$

A amplitude da função $f$ projetada na direção de $g$ é proporcional ao produto interno entre as duas funções. Caso esse produto interno seja nulo, define-se que as duas funções são ortogonais. Uma função $f$ não ortogonal a $g$ pode então ser decomposta em duas componentes, sendo a primeira uma componente colinear a $g$ e a segunda uma componente ortogonal a $g$, que é a diferença entre a função original e sua parcela colinear:

$$
f(t)=\operatorname{proj}_{g} f(t)+\operatorname{proj}_{g_{\perp}} f(t)
$$


onde

$$
\operatorname{proj}_{g_{\perp}} f(t)=f(t)-\operatorname{proj}_{g} f(t)
$$

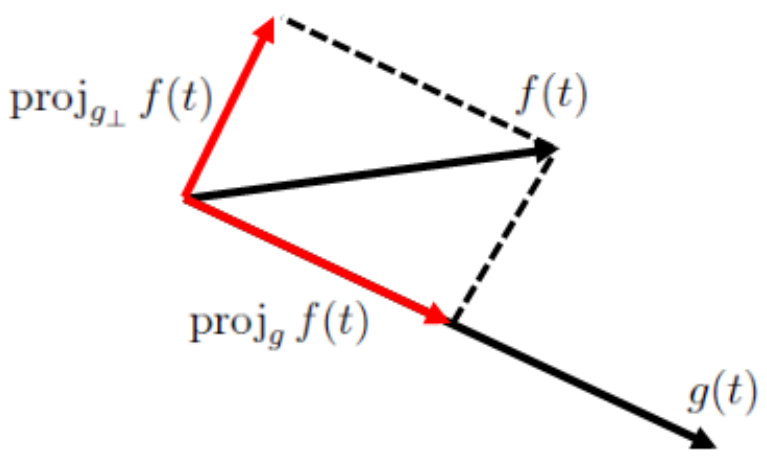

Figura 3.1: Representação gráfica da decomposição de $f(t)$ em duas componentes ortogonais baseadas em $g(t)$.

\subsubsection{Componentes Ortogonais com Base em Funções Coplanares}

Uma das abordagens para se decompor uma função em componentes ortogonais é baseada em conceitos espaciais de um espaço vetorial, sendo de grande interesse nesse desenvolvimento o conceito de funções coplanares. Como o interesse deste estudo é a aplicação dos conceitos de álgebra linear para o estudo de sistemas elétricos trifásicos, será considerada a análise de conjuntos de três funções distintas. Dado um conjunto de três funções $v_{1}(t), v_{2}(t)$ e $v_{3}(t)$, estas são coplanares se são linearmente dependentes, ou seja, se existe no mínimo um dos coeficientes $\alpha_{i}$ não nulo que satisfaça a condição (3.7). Ainda, se duas das funções $v_{i}(t)$ não forem colineares, ou seja, $v_{i}(t) \neq \alpha v_{j}(t)$, então elas geram um subespaço $\mathcal{V}$ de dimensão 2 (plano) contido no espaço $\mathfrak{F}_{T}$.

$$
\alpha_{1} v_{1}(\tau)+\alpha_{2} v_{2}(\tau)+\alpha_{3} v_{3}(\tau)=0, t-T \leq \tau \leq t
$$

Ao se obter um conjunto de funções coplanares, é possível decompor qualquer função de $\mathfrak{F}_{T}$ em uma componente coplanar e uma componente normal (ortogonal) ao plano $\mathcal{V}$ definido por 
essas funções. Para se obter a componente coplanar, serão definidas duas bases ortogonais para o plano, e a componente coplanar será composta pela soma das projeções da função sobre cada uma dessas bases. Assim como definido em (3.6), a parcela ortogonal ao plano será obtida por meio da diferença entre a componente coplanar e a função original.

Sendo $\left[v_{1}(t), v_{2}(t), v_{3}(t)\right]$ três funções coplanares, define-se $v_{\|}(t)=v_{1}(t)$ como sendo uma das funções base para a decomposição. A partir de uma das outras duas funções coplanares, pode-se definir uma componente coplanar a essas funções e ortogonal a $v_{\|}(t)$. Para tanto, projeta-se $v_{2}(t)$ sobre $v_{\|}(t)$, sendo essa projeção pertencente ao plano $\mathcal{V}$. A partir da diferença de $v_{2}(t)$ à sua projeção na direção de $v_{\|}(t)$, obtém-se a base $v_{\perp}(t)$ :

$$
\left\{\begin{array}{l}
v_{\|}(t)=v_{1}(t) \\
v_{\perp}(t)=v_{2}(t)-\operatorname{proj}_{v_{\|}} v_{2}(t)
\end{array}\right.
$$

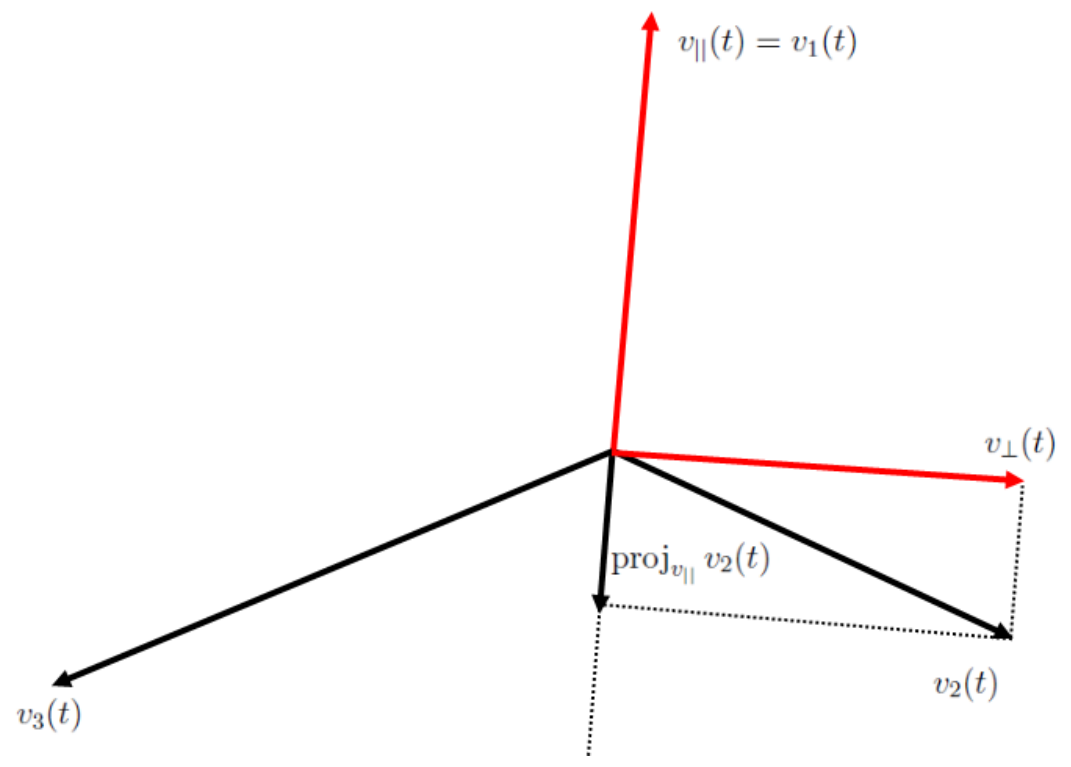

Figura 3.2: Formação de base ortogonal coplanar a $v_{1}(t), v_{2}(t)$ e $v_{3}(t)$.

Dada a base $\left[v_{\|}(t), v_{\perp}(t)\right]$ para o plano $\mathcal{V}$, é possível decompor qualquer função de $\mathfrak{F}_{T}$ conforme (3.9).

$$
f(t)=f_{\|}(t)+f_{\perp}(t)+\bar{f}(t)
$$


onde

$$
\left\{\begin{array}{l}
f_{\|}(t)=\operatorname{proj}_{v_{\|}} f(t) \\
f_{\perp}(t)=\operatorname{proj}_{v_{\perp}} f(t) \\
\bar{f}(t)=f(t)-f_{\|}(t)-f_{\perp}(t)
\end{array}\right.
$$

\subsubsection{Componentes Ortogonais com Base em Funções Derivadas e Integrais}

Uma outra abordagem para se decompor funções em componentes ortogonais é baseada nas propriedades das funções derivada e integral. Dada uma função $f(t)$, tem-se, por definição, as suas respectivas funções derivada e integral conforme (3.11).

$$
\left\{\begin{array}{l}
f^{\prime}(t)=\frac{d f(t)}{d t} \\
F(t)=\int f(t) d t
\end{array}\right.
$$

Pode-se verificar a ortogonalidade da função $f(t)$ com sua derivada $f^{\prime}(t)$ calculando o produto interno das duas funções.

$$
\begin{aligned}
& <f(t), f^{\prime}(t)>=\frac{1}{T} \int_{t-T}^{t} f(\tau) \frac{d f(\tau)}{d \tau} d \tau=\frac{1}{T} \int_{t-T}^{t} f(\tau) d f(\tau) \\
& <f(t), f^{\prime}(t)>=\frac{1}{2 T}\left(f^{2}(t)-f^{2}(t-T)\right)=\frac{1}{2 T}\left(f^{2}(t)-f^{2}(t)\right) \\
& <f(t), f^{\prime}(t)>=0
\end{aligned}
$$

Conforme demonstrado em (3.16), uma função $f(t)$ é ortogonal à sua função derivada. Da mesma maneira, conclui-se que $f(t)$ também é ortogonal à sua primitiva $F(t)$, uma vez que $F^{\prime}(t)=f(t)$. Sendo assim, uma função periódica $f(t)$ é ortogonal às suas funções derivada e integral. Em Flauzino (2007) é demonstrado que o mesmo não ocorre entre as funções 
derivada e integral, sendo elas não ortogonais e, em caso de funções puramente senoidais, elas são colineares, formando um ângulo de $180^{\circ}$ entre elas.

Para se obter uma decomposição em três componentes ortogonais, pode-se utilizar as funções $f(t)$ e $f^{\prime}(t)$ como as duas primeiras bases da decomposição. Para se obter a terceira base ortogonal, faz-se a diferença da função integral $F(t)$ à sua projeção sobre $f^{\prime}(t)$, obtendo assim três bases ortogonais para a decomposição de qualquer função de $\mathfrak{F}_{T}$, conforme (3.13).

$$
\left\{\begin{array}{l}
f_{1}(t)=f(t) \\
f_{2}(t)=f^{\prime}(t) \\
f_{3}(t)=F(t)-\operatorname{proj}_{f^{\prime}(t)} F(t)
\end{array}\right.
$$

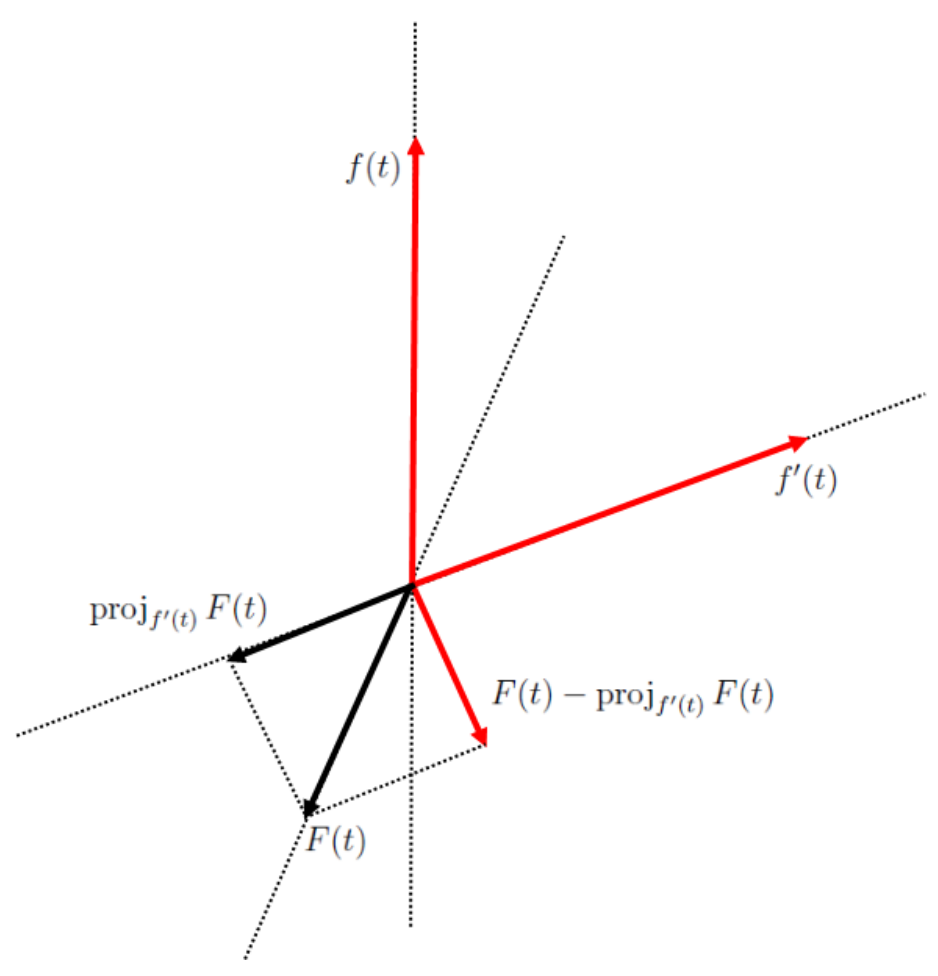

Figura 3.3: Formação de base ortogonal com base em $f(t)$. 


\subsection{Decomposição de Tensões e Correntes em Compo- nentes Ortogonais}

Seja um sistema de distribuição de energia trifásico com suas tensões de fase $v_{A}(t), v_{B}(t)$ e $v_{C}(t)$ e correntes de linha $i_{A}(t), i_{B}(t)$ e $i_{C}(t)$. Além disso, também será de interesse a análise da tensão e corrente de neutro $v_{N}(t)$ e $i_{N}(t)$. O objetivo da técnica de decomposição em componentes ortogonais será decompor cada uma dessas grandezas do sistema elétrico em oito componentes, totalizando 64 componentes ortogonais capazes de sintetizar os sinais originais.

A decomposição se dará em dois estágios, sendo que, no primeiro, serão decompostas as tensões de fase e correntes de linha em componentes ortogonais com base no plano formado pelas tensões de linha. No segundo estágio serão decompostas cada uma das componentes geradas no primeiro estágio em outras quatro componentes ortogonais com base nas funções derivada e integral da grandeza complementar, ou seja, as tensões serão decompostas no espaço das correntes, e vice-versa.

\subsubsection{Primeiro Estágio}

Dadas as tensões de fase do sistema elétrico em estudo, primeiro verifica-se se elas são coplanares. Para que as tensões de fase sejam coplanares, é preciso existir no mínimo um coeficiente $\alpha_{i}$ não nulo que satisfaça a condição (3.14).

$$
\alpha_{1} v_{A}(\tau)+\alpha_{2} v_{B}(\tau)+\alpha_{3} v_{C}(\tau)=0, t-T \leq \tau \leq t
$$

É possível identificar situações em que a condição (3.14) é satisfeita, como em sistemas em que haja uma perfeita defasagem de $120^{\circ}$ entre as tensões de fase. Porém, interessando-se na aplicação mais ampla da técnica, não é possível afirmar que essa condição seja verdadeira para qualquer situação. 
Será analisado, portanto, o comportamento geométrico das tensões de linha para qualquer sistema elétrico trifásico. Sejam as tensões de linha $v_{A B}(t), v_{B C}(t)$ e $v_{C A}(t)$ definidas conforme $(3.15)$

$$
\left\{\begin{array}{l}
v_{A B}(t)=v_{A}(t)-v_{B}(t) \\
v_{B C}(t)=v_{B}(t)-v_{C}(t) \\
v_{C A}(t)=v_{C}(t)-v_{A}(t)
\end{array}\right.
$$

Dada uma combinação linear das três tensões de linha, com coeficientes iguais para cada tensão, obtém-se:

$$
\begin{aligned}
& \alpha v_{A B}(t)+\alpha v_{B C}(t)+\alpha v_{C A}(t)=\alpha\left(v_{A}(t)-v_{B}(t)+v_{B}(t)-v_{C}(t)+v_{C}(t)-v_{A}(t)\right) \\
& \alpha v_{A B}(t)+\alpha v_{B C}(t)+\alpha v_{C A}(t)=0, t-T \leq \tau \leq t
\end{aligned}
$$

Dessa forma, pode-se afirmar que, independentemente da condição do sistema elétrico, as tensões de linha sempre serão coplanares, definindo um plano $\mathcal{V}$. Com base nessa constatação, pode-se definir um conjunto de bases ortogonais para a realização da projeção de qualquer função no plano $\mathcal{V}$, conforme definido em (3.17).

$$
\left\{\begin{array}{l}
v_{\|}(t)=v_{A B}(t) \\
v_{\perp}(t)=v_{B C}(t)-\operatorname{proj}_{v_{\|}} v_{B C}(t)
\end{array}\right.
$$

Assim, cada função descritora de tensão de fase e corrente de linha será decomposta em duas componentes, sendo uma a projeção da função no plano $\mathcal{V}$ e a outra a sua componente ortogonal ao plano.

$$
\left\{\begin{array}{l}
v_{A}(t)=v_{a}(t)+v_{\bar{a}}(t) \\
v_{B}(t)=v_{b}(t)+v_{\bar{b}}(t) \\
v_{C}(t)=v_{c}(t)+v_{\bar{c}}(t) \\
v_{N}(t)=v_{d}(t)+v_{h}(t)
\end{array}\right.
$$




$$
\left\{\begin{array}{l}
i_{A}(t)=i_{a}(t)+i_{\bar{a}}(t) \\
i_{B}(t)=i_{b}(t)+i_{\bar{b}}(t) \\
i_{C}(t)=i_{c}(t)+i_{\bar{c}}(t) \\
i_{N}(t)=i_{d}(t)+i_{h}(t)
\end{array}\right.
$$

onde

$$
\begin{gathered}
\left\{\begin{array}{l}
v_{a}(t)=v_{a_{||}}(t)+v_{a_{\perp}}(t)=\operatorname{proj}_{v_{||}} v_{A}(t)+\operatorname{proj}_{v_{\perp}} v_{A}(t) \\
v_{b}(t)=v_{b_{||}}(t)+v_{b_{\perp}}(t)=\operatorname{proj}_{v_{||}} v_{B}(t)+\operatorname{proj}_{v_{\perp}} v_{B}(t) \\
v_{c}(t)=v_{c_{||}}(t)+v_{c_{\perp}}(t)=\operatorname{proj}_{v_{||}} v_{C}(t)+\operatorname{proj}_{v_{\perp}} v_{C}(t) \\
v_{d}(t)=v_{d_{||}}(t)+v_{d_{\perp}}(t)=\operatorname{proj}_{v_{||}} v_{N}(t)+\operatorname{proj}_{v_{\perp}} v_{N}(t) \\
v_{\bar{b}}(t)=v_{B}(t)-v_{b}(t) \\
v_{\bar{c}}(t)=v_{C}(t)-v_{c}(t) \\
v_{h}(t)=v_{N}(t)-v_{d}(t) \\
v_{\bar{a}}(t)=v_{A}(t)-v_{a}(t) \\
i_{\bar{b}}(t)=i_{a_{||}}(t)+i_{a_{\perp}}(t)=\operatorname{proj}_{v_{||}} i_{A}(t)+\operatorname{proj}_{v_{\perp}} i_{A}(t) \\
i_{b}(t)=i_{b_{||}}(t)+i_{b_{\perp}}(t)=\operatorname{proj}_{v_{\| \mid}} i_{B}(t)+\operatorname{proj}_{v_{\perp}} i_{B}(t)-i_{b}(t)-i_{c}(t) \\
i_{c}(t)=i_{c_{||}}(t)+i_{c_{\perp}}(t)=\operatorname{proj}_{v_{||}} i_{C}(t)+\operatorname{proj}_{v_{\perp}} i_{C}(t)-i_{d}(t) \\
i_{d}(t)=i_{d_{||}}(t)+i_{d_{\perp}}(t)=\operatorname{proj}_{v_{||}} i_{N}(t)+\operatorname{proj}_{v_{\perp}} i_{N}(t)
\end{array}\right. \\
\left\{\begin{array}{l}
i_{\bar{a}}(t)=i_{A}(t)-i_{a}(t) \\
i_{\bar{b}}(t)
\end{array}\right.
\end{gathered}
$$

É demonstrado em Flauzino (2007) que, assim como $v_{N}(t)$ e $i_{N}(t)$ só existem quando há diferença de amplitudes e defasagem entre as tensões de fase e correntes de linha, $v_{d}(t)$ e $i_{d}(t)$ 


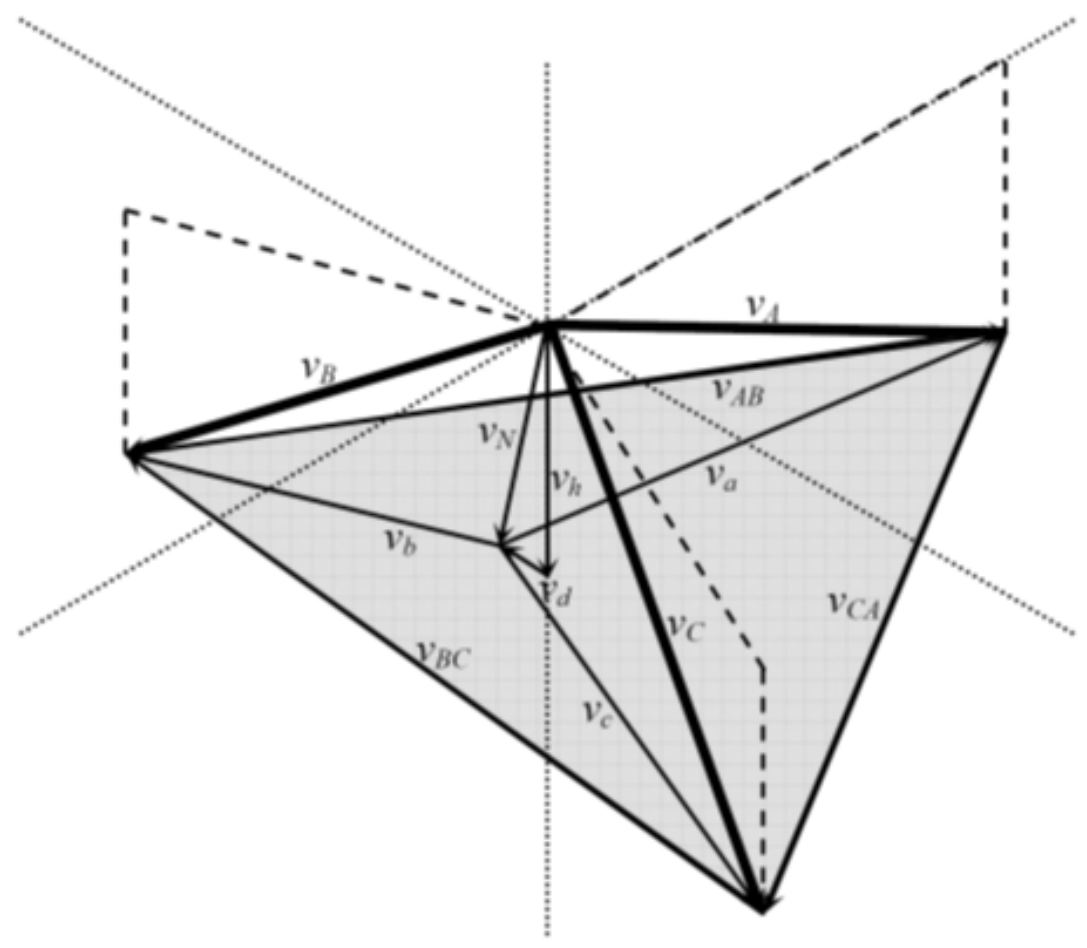

Figura 3.4: Representação gráfica das tensões de fase e suas projeções sobre o plano formado pelas tensões de linha. Fonte: (FLAUZINO, 2007)

também são não nulos somente no caso em que há desbalanço entre as projeções das tensões de fase e correntes de linha. Por essa razão, essas componentes são denotadas com o índice $d$, sendo chamadas deste ponto em diante de tensão de desbalanço e corrente de desbalanço, cuja definição também pode ser conforme (3.24).

$$
\left\{\begin{array}{l}
v_{d}(t)=v_{a}(t)+v_{b}(t)+v_{c}(t) \\
i_{d}(t)=i_{a}(t)+i_{b}(t)+i_{c}(t)
\end{array}\right.
$$

\subsubsection{Segundo Estágio}

Para o segundo estágio da decomposição em componentes ortogonais, cada componente do estágio anterior será decomposta em três outras componentes ortogonais e mais um sinal que será a projeção sobre uma grandeza de desbalanço. As novas bases utilizadas para a decomposição nas novas componentes ortogonais serão obtidas conforme o conceito apresentado na 
seção (3.2.2).

$$
\begin{aligned}
& \left\{\begin{array}{l}
v_{x}(t)=v_{x}(t) \\
v_{x}^{\|}(t)=v_{x}^{\prime}(t) \\
v_{x}^{\perp}(t)=V_{x}(t)-\operatorname{proj}_{v_{x}(t)} V_{x}(t)
\end{array} \quad, x \in[a, b, c, d, \bar{a}, \bar{b}, \bar{c}, h]\right. \\
& \left\{\begin{array}{l}
i_{x}(t)=i_{x}(t) \\
i_{x}^{\|}(t)=i_{x}^{\prime}(t) \\
i_{x}^{\perp}(t)=I_{x}(t)-\operatorname{proj}_{i_{x}(t)} I_{x}(t)
\end{array}\right.
\end{aligned}
$$

Cada tensão $v_{x}(t)$ será decomposta em quatro componentes, $v_{x}^{p}(t), v_{x}^{q^{\|}}(t), v_{x}^{q^{\perp}}(t)$ e $v_{x}^{d}(t)$. O mesmo será feito para as correntes $i_{x}(t)$, que gerarão as componentes $i_{x}^{p}(t), i_{x}^{q^{\|}}(t), i_{x}^{q^{\perp}}(t)$ e $i_{x}^{d}(t)$.

As componentes são obtidas sempre realizando a projeção de tensões de fase no espaço das correntes de linha, e vice-versa, selecionando-se sempre as grandezas da mesma fase. Dessa forma, obtêm-se as seguintes definições para as componentes resultantes da decomposição:

$$
\begin{aligned}
& \left\{\begin{array}{l}
v_{x}^{p}(t)=\operatorname{proj}_{i_{x}(t)} v_{x}(t) \\
v_{x}^{q^{\|}}(t)=\operatorname{proj}_{i_{x}(t)} v_{x}(t) \\
v_{x}^{q^{\perp}}(t)=\operatorname{proj}_{i_{x}^{\perp}(t)} v_{x}(t) \\
v_{x}^{d}(t)=\operatorname{proj}_{i_{d}(t)} v_{x}(t)
\end{array}\right. \\
& \left\{\begin{array}{l}
i_{x}^{p}(t)=\operatorname{proj}_{v_{x}(t)} i_{x}(t) \\
i_{x}^{q^{\|}}(t)=\operatorname{proj}_{v_{x}(t)} i_{x}(t) \\
i_{x}^{q^{\perp}}(t)=\operatorname{proj}_{v_{x}^{\perp}(t)} i_{x}(t) \\
i_{x}^{d}(t)=\operatorname{proj}_{v_{d}(t)} i_{x}(t)
\end{array}\right.
\end{aligned}
$$


Como resultado desse processo de decomposição, obtêm-se 64 componentes ortogonais que servirão de análise para a identificação e estimação do local da falta. Na figura (3.5), é apresentado de forma sintetizada o processo de decomposição em componentes ortogonais.

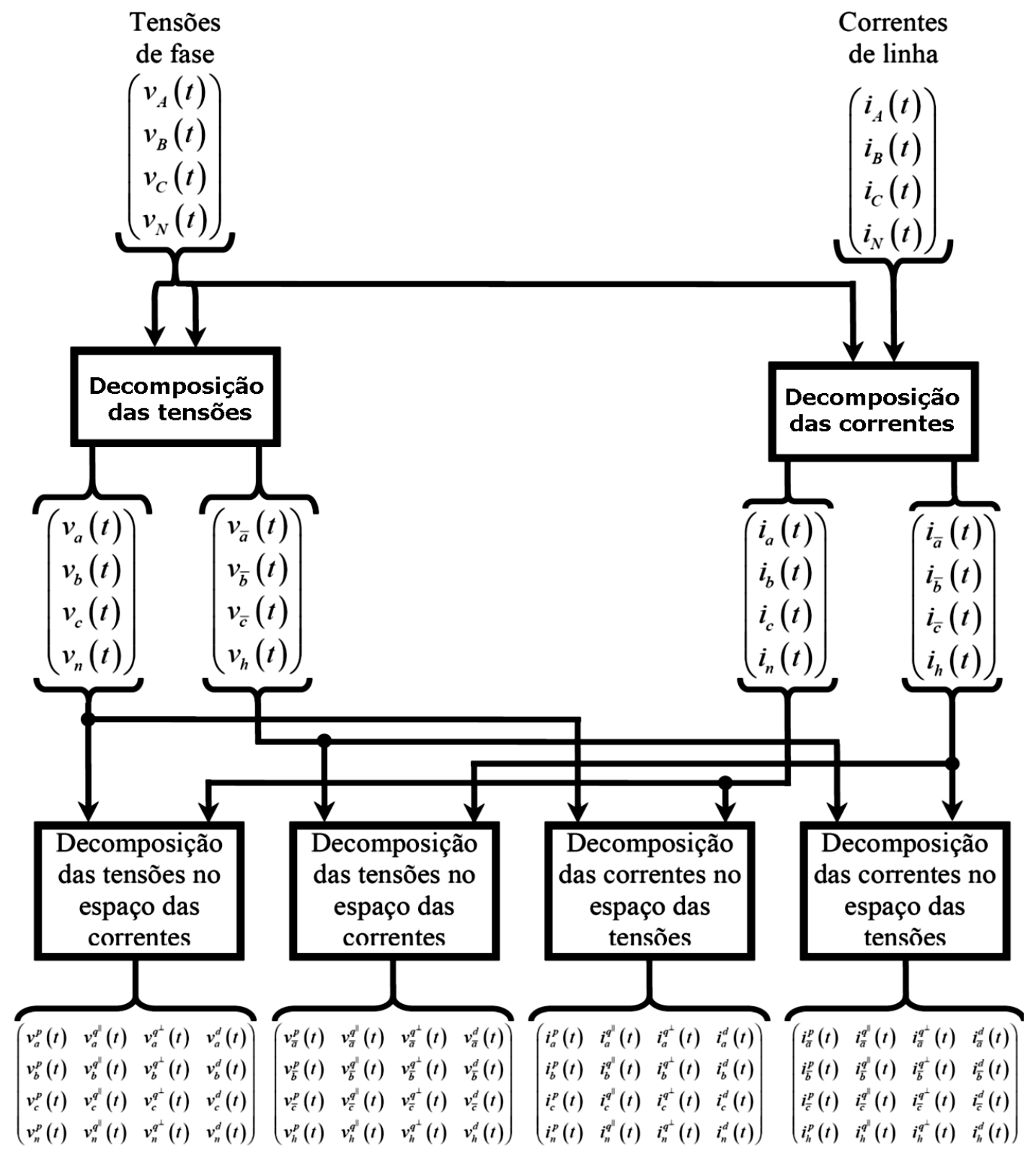

Figura 3.5: Diagrama esquemático do processo de decomposição por componentes ortogonais. Fonte: (FLAUZINO, 2007). 


\subsubsection{Comportamento das Componentes Ortogonais em Faltas Fase- terra}

Com os desenvolvimentos apresentados nas seções anteriores é possível criar rotinas para pré-processamento das oscilografias coletadas em sistemas elétricos de potência e analisar o comportamento de suas componentes ortogonais. Sendo o objeto de estudo deste trabalho a utilização da técnica para a análise de faltas de alta impedância, atém-se, no momento, à análise do comportamento das componentes obtidas na decomposição para faltas fase-terra, envolvendo somente uma das fases do sistema trifásico.

Para as análises que seguem, serão discutidos os dados resultantes da aplicação da técnica de decomposição realizado em Batista (2016), utilizando-se de resultados de experimentos realizados em Ziolkowski (2007), em que foram causadas e oscilografadas diversas ocorrências de faltas de alta impedância.

A falta avaliada teve seu início em $0,032 s$ e ocorreu na fase C. As oscilografias dos sinais de tensão e corrente obtidas na subestação são apresentadas na figura (3.6). Na figura (3.7) são apresentadas as componentes ortogonais coplanares às tensões de linha, enquanto na figura (3.8) são apresentadas as componentes ortogonais ao plano formado pelas tensões de linha.

Com relação às componentes coplanares, é possível identificar uma influência marcante da falta nas componentes provenientes da decomposição da tensão de fase $v_{C}$, sendo elas $v_{c}^{p}(t)$, $v_{c}^{q \|}(t), v_{c}^{q^{\perp}}(t)$ e $v_{c}^{d}(t)$. Além das tensões da fase faltosa, a componente de tensão $v_{n}^{q \|}$ também apresenta um padrão temporal capaz de ser relacionado à falta. Com relação às correntes de linhas, todas as componentes coplanares provenientes da decomposição de $i_{C}$ e $i_{N}$ também apresentam oscilações que caracterizam a falta.

Avaliando as componentes ortogonais ao plano das tensões de linha, nota-se que as componentes de tensão $v_{\bar{c}}^{p}(t), v_{h}^{q^{\perp}}(t)$ e $v_{h}^{p}(t)$ possuem um padrão bem pronunciado e que está ligado à ocorrência da falta. Neste ponto é interessante notar que, nas componentes ortogonais ao plano das tensões de linha, aquelas que mais apresentaram informação com relação 
à falta não estão vinculadas à fase faltosa, mas sim ao neutro. Com relação às correntes, em todas as decomposições ortogonais ao plano das correntes de linha $i_{C}$ e $i_{N}$, é possível detectar padrões que sinalizam a ocorrência da falta.

Com essa simples análise, é possível ilustrar o potencial da utilização da técnica de decomposição em componentes ortogonais como pré-processamento dos dados buscando a localização da falta, uma vez que, nessas componentes é possível identificar padrões bastante pronunciados relacionados à ocorrência da falta.

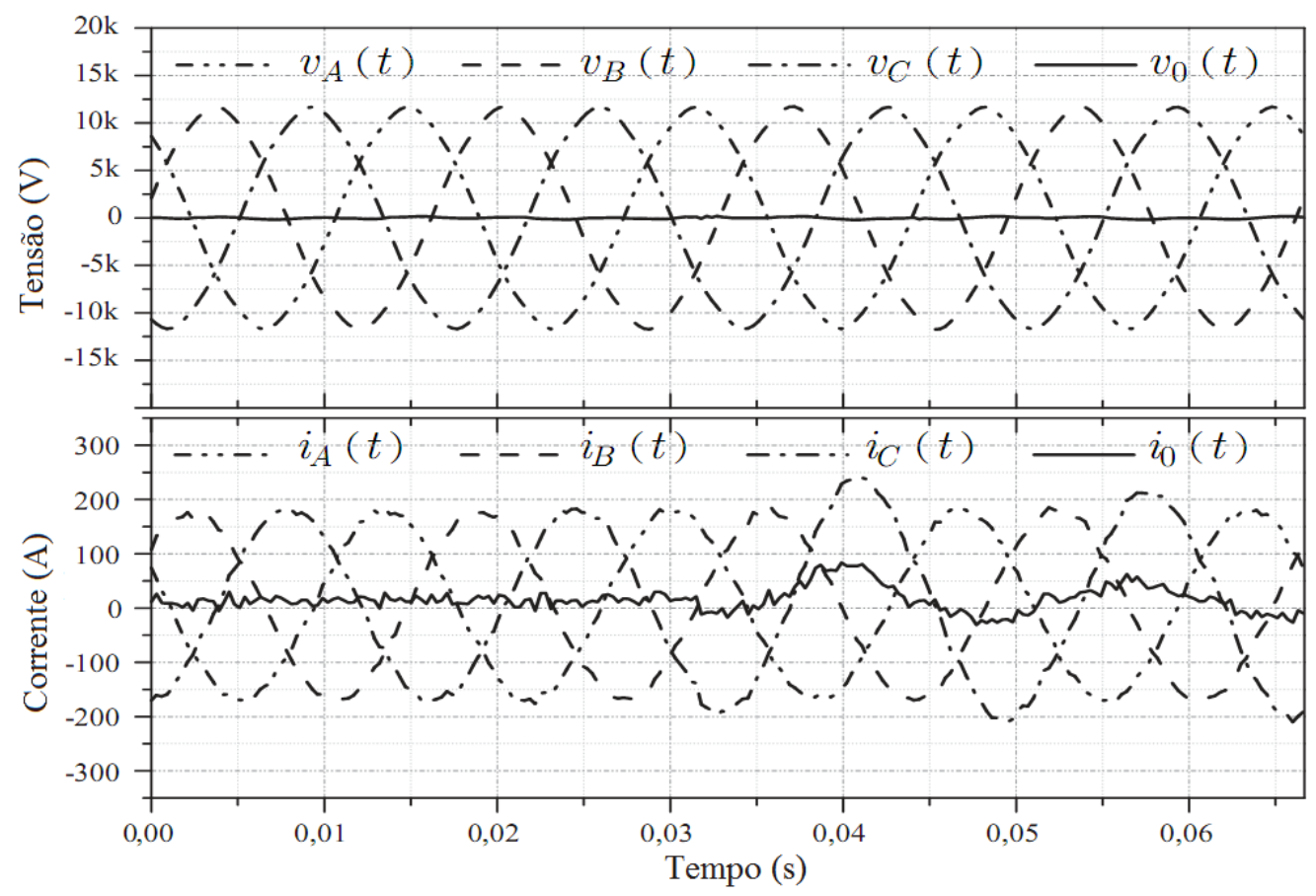

Figura 3.6: Oscilografia das tensões e correntes durante janela de tempo de ocorrência da falta de alta impedância. Fonte: (BATISTA, 2016). 

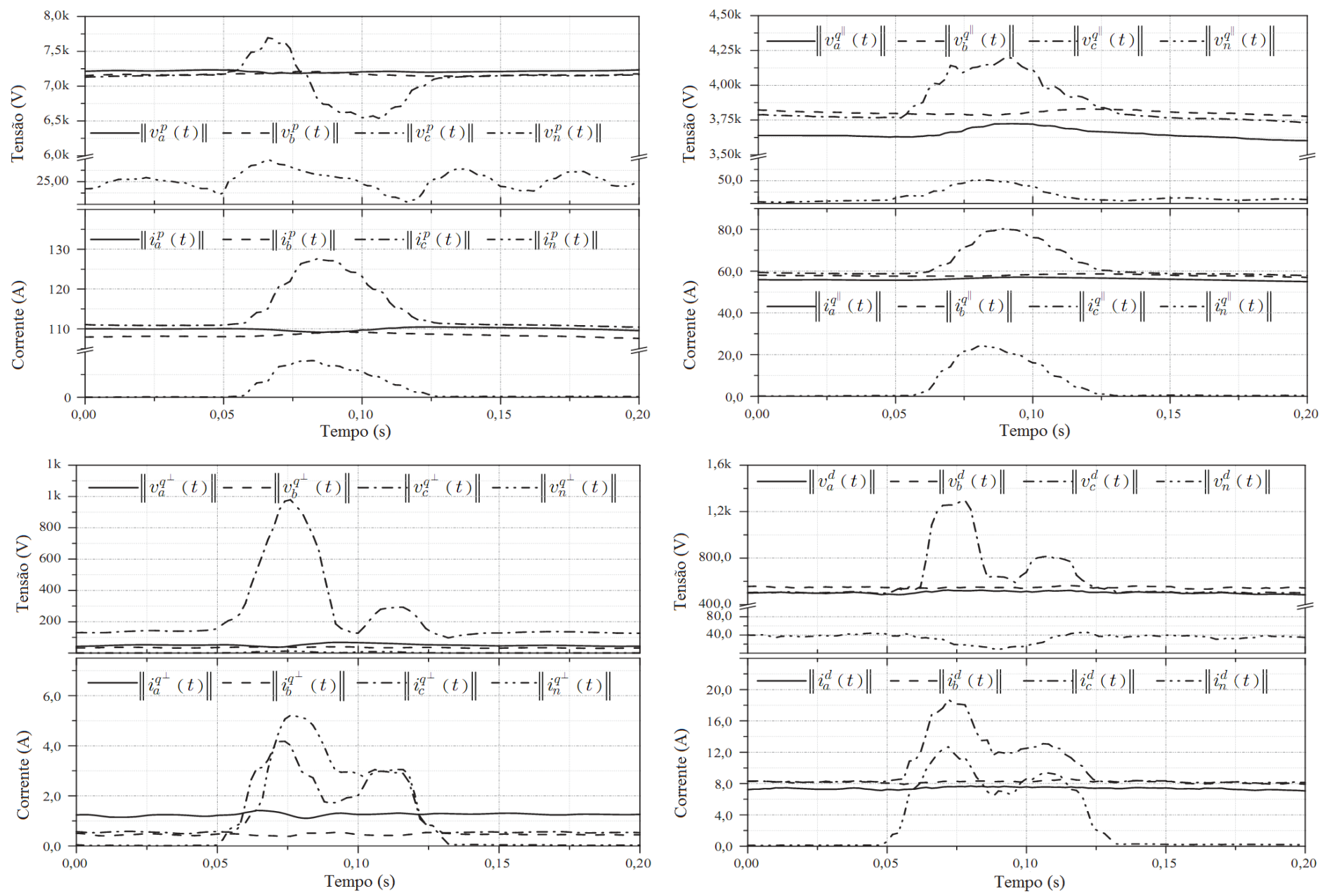

Figura 3.7: Decomposição em segundo nível das componentes coplanares às tensões de linha para as tensões $v_{x}(t)$ e $i_{x}(t)[x \in(a, b, c, d)]$. Fonte: (BATISTA, 2016) 

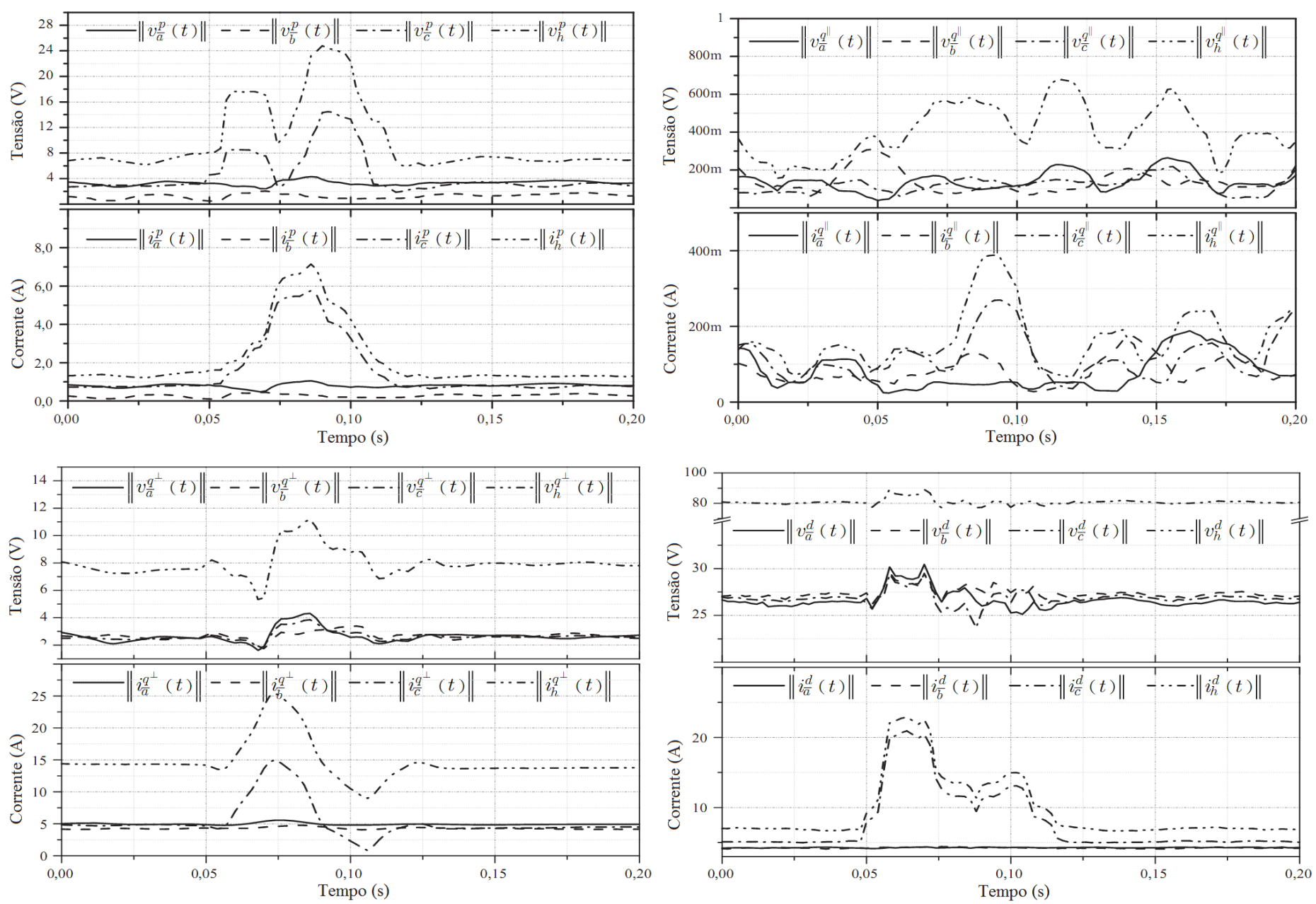

Figura 3.8: Decomposição em segundo nível das componentes ortogonais ao plano das tensões de linha para as tensões $v_{x}(t)$ e $i_{x}(t)[x \in \bar{a}, \bar{b}, \bar{c}, h]$. Fonte: (BATISTA, 2016) 


\section{Capítulo 4}

\section{RESULTADOS}

\subsection{Oscilografias Levantadas}

Para avaliar a utilização do método de decomposição em componentes ortogonais em casos reais, foram utilizadas oscilografias coletadas em relés para proteção de alimentadores do modelo SEL-451, com taxa de amostragem de $2 \mathrm{kHz}$, em formato COMTRADE. Foram selecionadas 22 oscilografias referentes a faltas de alta impedância em que houve atuação do relé por meio da função de proteção 51NS (neutro-sensível), além de situações normais de operação da rede elétrica. Essas oscilografias foram obtidas após seleção e monitoramento de dois alimentadores por um período superior a doze meses, sendo necessário esse largo período de tempo devido à baixa quantidade de atuações dos relés para esse tipo específico de falta. As faltas de alta impedância identificadas estão relacionadas a eventos de cabo ao solo, cabo rompido, vegetação em contato com a rede e falha em isolador. Foram coletadas oscilografias em dois alimentadores distintos (11 de cada), de forma a poder estudar o comportamento das componentes ortogonais em diversas amostras de uma mesma rede elétrica.

As oscilografias obtidas em formato COMTRADE foram convertidas de forma a poderem 


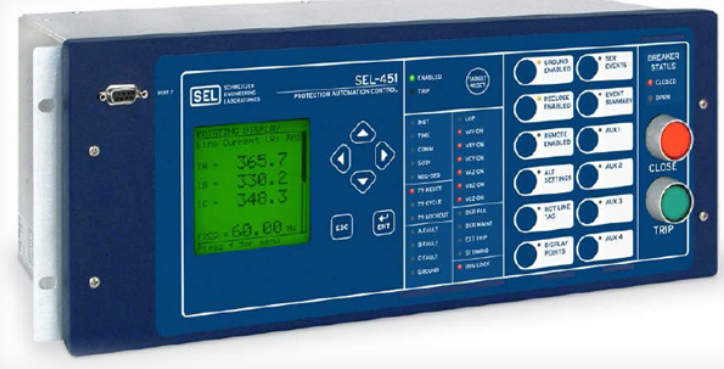

Figura 4.1: Relé modelo SEL-451 utilizado para coleta das oscilografias.

ser processadas utilizando o software Matlab. Na figura (4.2), são apresentados os sinais de tensão e corrente de um alimentador em uma condição normal de operação da rede elétrica. Na figura (4.3), são apresentadas duas oscilografias de condições de falta de alta impedância reais registradas pelo relé de proteção de dois alimentadores distintos.
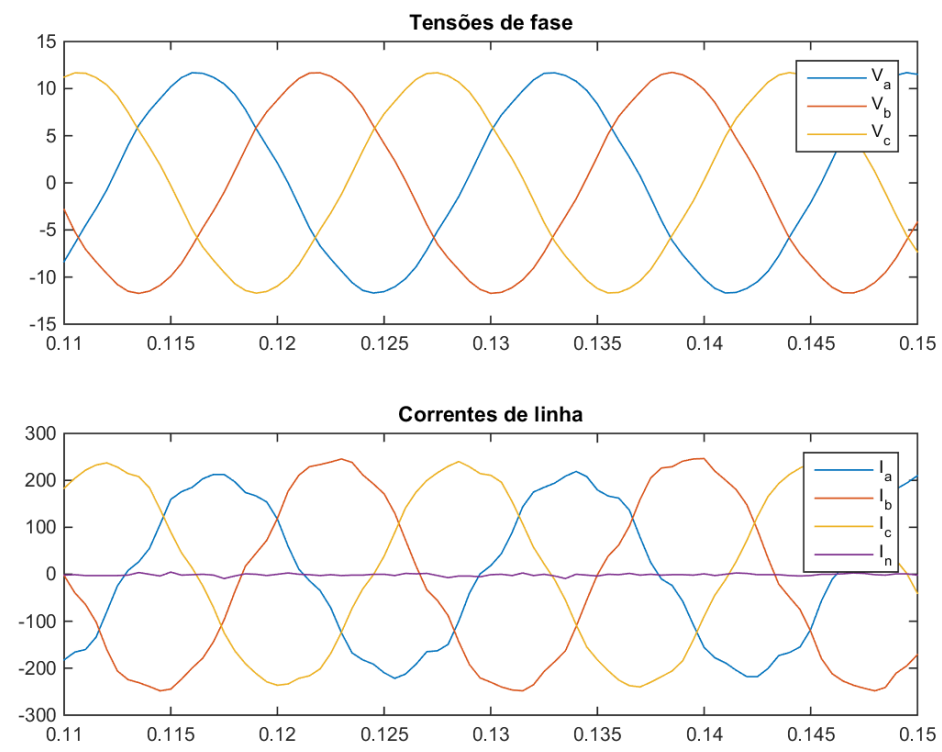

Figura 4.2: Oscilografia das tensões e correntes de um alimentador sem falta. 

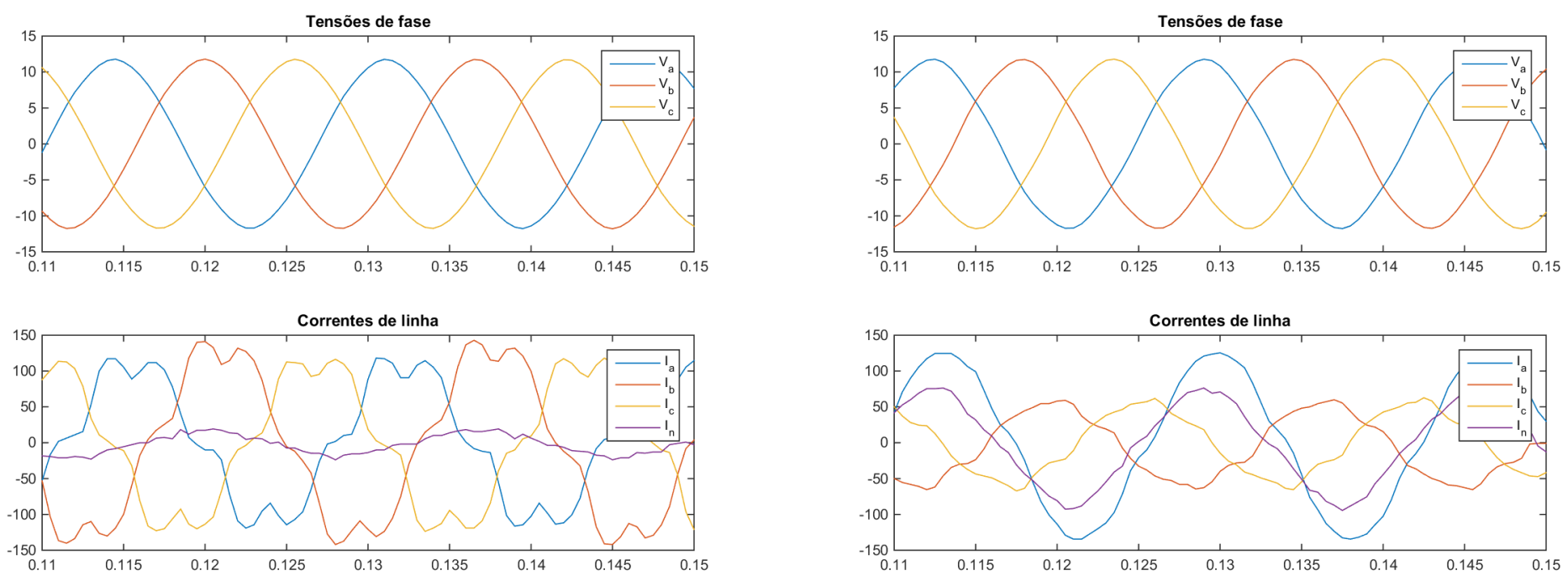

Figura 4.3: Oscilografia das tensões e correntes de alimentadores durante janela de ocorrência de falta de alta impedância.

\subsection{Decomposição das Oscilografias em Componentes Ortogonais}

Todas as oscilografias de condições de falta de alta impedância identificadas em campo foram processadas de forma a obter suas componentes ortogonais. Na figura (4.4), é possível observar todas as componentes ortogonais dos sinais obtidos em uma condição normal de operação da rede elétrica, enquanto na figura (4.5) são apresentadas as componentes para uma condição de falta de alta impedância.

Com exceção das componentes $i_{d}^{p}$ e $i_{d}^{q^{\|}}$, cujos valores são significantemente mais elevados no caso com falta, as demais componentes devem ser analisadas em termos numéricos para identificar algum padrão que possa estar diretamente relacionado à ocorrência da falta e, dessa forma, permitir que um sistema inteligente possa se utilizar dessa informação para identificar a condição faltosa de forma automática. 
Nas tabelas 4.1, 4.2, 4.3 e 4.4, são apresentados os valores RMS dos sinais de tensão, corrente e de todas as componentes ortogonais para todas as oscilografias analisadas de cada alimentador em estudo. As oscilografias HR-13074, HR-11906 e HR-11910 representam condições normais de operação das suas respectivas redes.
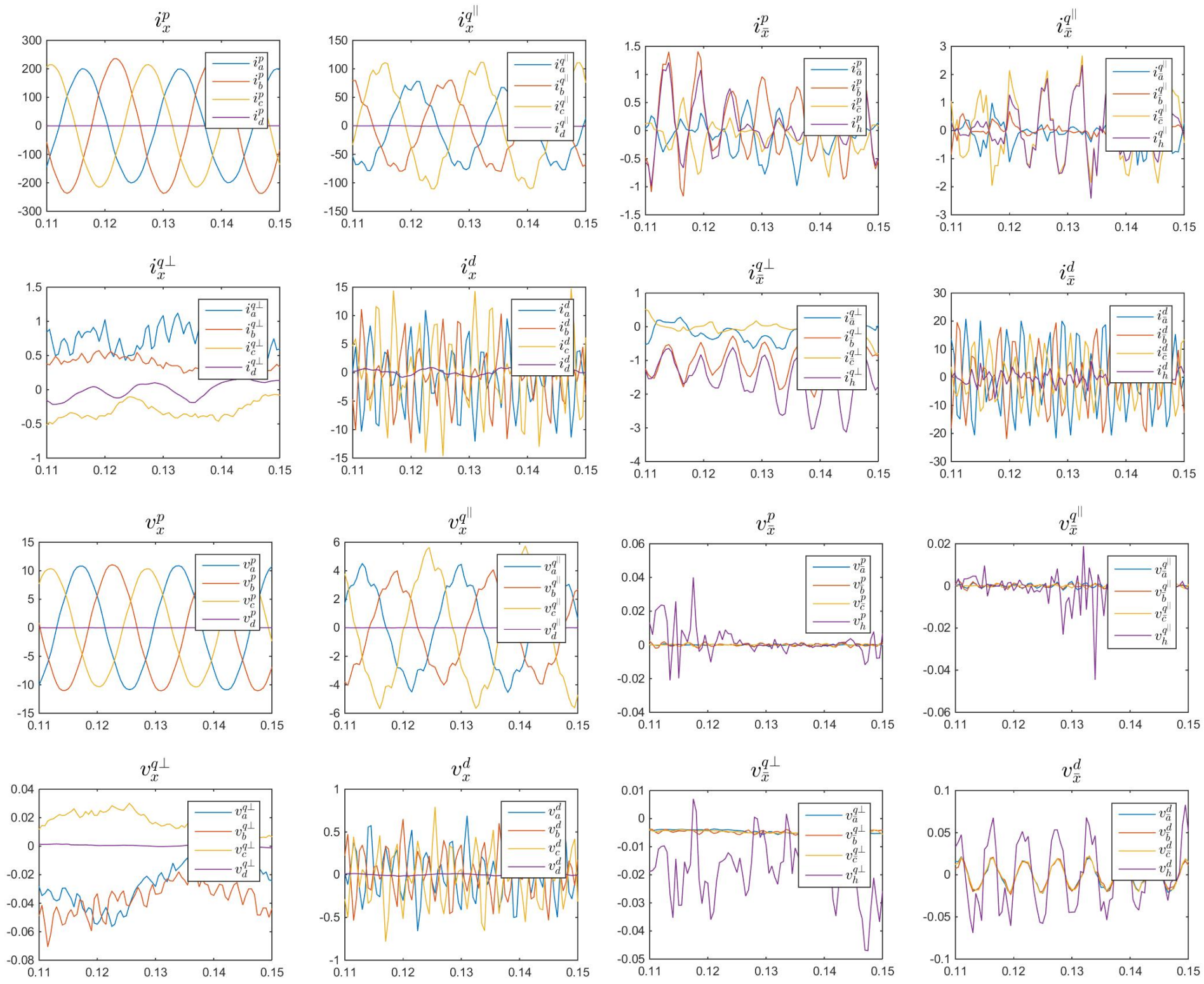

Figura 4.4: Componentes ortogonais de uma condição normal de operação. 

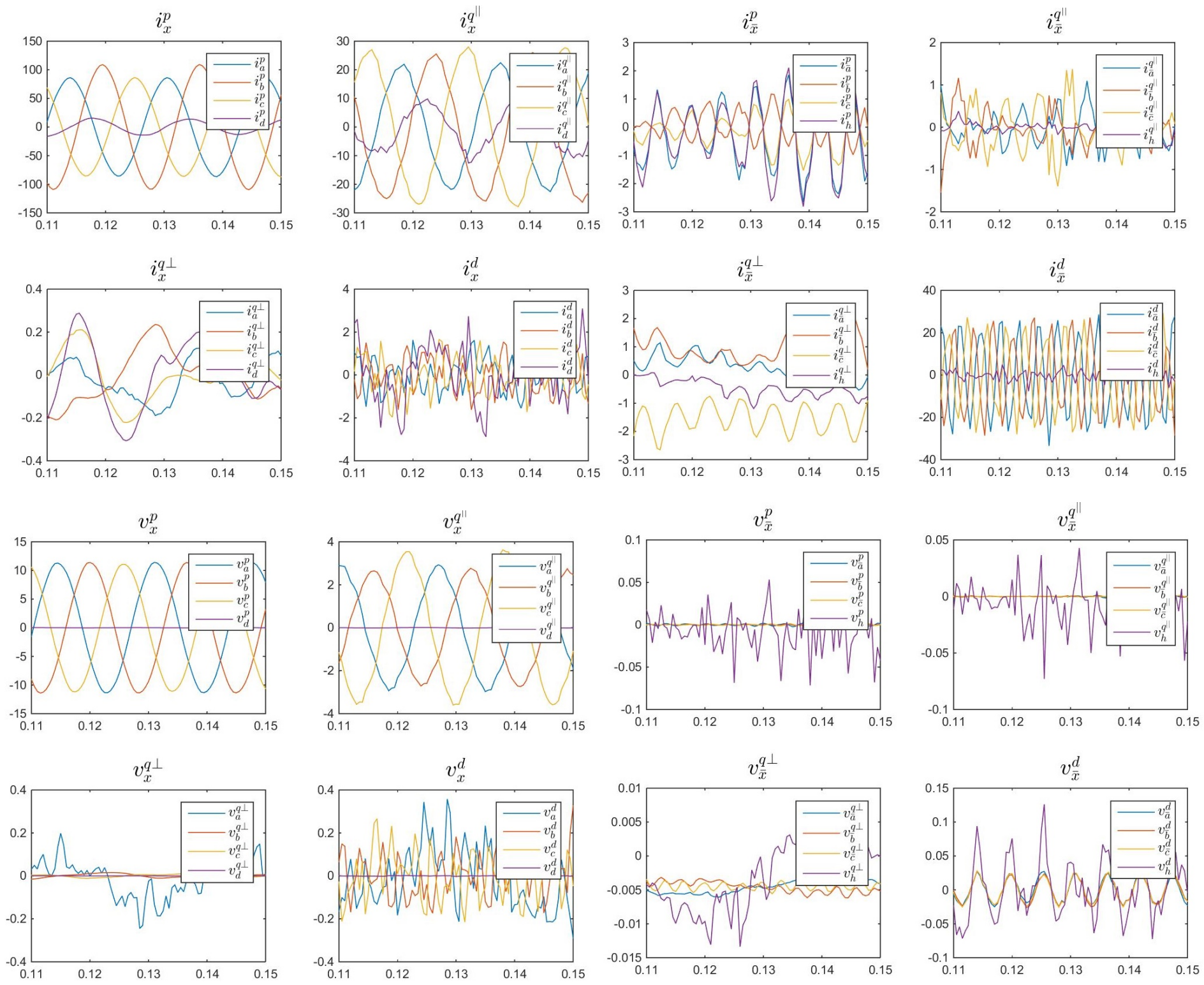

Figura 4.5: Componentes ortogonais de uma condição real de falta de alta impedância. 
Tabela 4.1: Valores RMS dos sinais de tensão e corrente e das componentes ortogonais de corrente das oscilografias mapeadas do Alimentador A

\begin{tabular}{|c|c|c|c|c|c|c|c|c|c|c|c|c|}
\hline Componente & Correlação com $I_{n}$ & HR-12915 & HR-12917 & HR-12919 & HR-12921 & HR-12925 & HR-12938 & HR-13062 & HR-13064 & HR-13066 & HR-13068 & HR-13074* \\
\hline$V_{a}$ & - & 8,2375 & 8,2352 & 8,236 & 8,2442 & 8,2144 & 8,2794 & 8,256 & 8,2403 & 8,2268 & 8,2698 & 8,2448 \\
\hline$V_{b}$ & - & 8,241 & 8,2415 & 8,2391 & 8,2464 & 8,2168 & 8,2694 & 8,2481 & 8,2294 & 8,2206 & 8,2619 & 8,2465 \\
\hline$V_{c}$ & - & 8,2333 & 8,2313 & 8,23 & 8,2373 & 8,2099 & 8,2739 & 8,229 & 8,2124 & 8,2011 & 8,243 & 8,2316 \\
\hline$I_{a}$ & - & 93,5525 & 90,0583 & 81,8114 & 65,2396 & 19,9483 & 168,0952 & 71,5276 & 73,8452 & 75,5238 & 38,1006 & 151,0446 \\
\hline$I_{b}$ & - & 107,8882 & 107,2358 & 97,6828 & 80,5039 & 27,4239 & 105,9241 & 147,4859 & 153,8158 & 154,4291 & 127,1755 & 176,3053 \\
\hline$I_{c}$ & - & 93,1574 & 93,3266 & 85,1261 & 65,9749 & 17,239 & 101,9718 & 88,058 & 94,0062 & 96,6697 & 56,0763 & 169,6436 \\
\hline$I_{n}$ & - & 12,8864 & 13,1436 & 13,0789 & 12,4226 & 13,9903 & 74,037 & 54,0471 & 61,0578 & 68,6601 & 71,7507 & 2,7462 \\
\hline$I_{a}^{p}$ & 0,0129 & 90,4048 & 83,3773 & 72,627 & 60,4762 & 8,1492 & 154,5212 & 69,4903 & 66,695 & 57,8147 & 34,911 & 141,1321 \\
\hline$I_{b}^{p}$ & 0,337 & 104,6339 & 101,3798 & 89,943 & 76,4312 & 22,9132 & 86,0229 & 146,6082 & 150,2855 & 145,5614 & 126,5014 & 166,8631 \\
\hline$I_{c}^{p}$ & 0,1682 & 89,3839 & 85,5942 & 74,6465 & 60,385 & 6,4579 & 79,4925 & 83,3856 & 78,6476 & 74,463 & 52,3842 & 151,6035 \\
\hline$I_{d}^{p}$ & 0,4868 & 9,8562 & 9,3576 & 10,2685 & 10,5135 & 9,9496 & 40,343 & 7,5736 & 7,0214 & 10,4939 & 11,2883 & 0,1367 \\
\hline$I_{a}^{q \|}$ & 0,0957 & 22,2977 & 30,5092 & 33,56 & 15,2478 & 17,5527 & 63,5455 & 7,8401 & 36,566 & 46,4374 & 1,4633 & 51,9712 \\
\hline$I_{b}^{q u}$ & 0,0916 & 25,0841 & 32,1532 & 34,2356 & 17,9057 & 13,9288 & 58,9225 & 10,7398 & 42,9567 & 47,997 & 3,0596 & 54,3612 \\
\hline$I_{c}^{q^{\|}}$ & 0,1848 & 24,7442 & 34,8699 & 36,9535 & 19,0125 & 14,9847 & 60,9866 & 26,9137 & 55,8158 & 59,7255 & 15,0603 & 75,1241 \\
\hline$I_{d}^{q \|}$ & 0,9924 & 7,3231 & 9,0452 & 8,1208 & 7,0119 & 8,3934 & 60,6998 & 52,8555 & 60,319 & 67,5567 & 70,4873 & 0,3411 \\
\hline$I_{a}^{q^{\perp}}$ & 0,2294 & 0,1355 & 0,1654 & 0,1257 & 0,0812 & 0,062 & 0,1224 & 0,0685 & 0,4886 & 0,1355 & 0,0835 & 0,8528 \\
\hline$I_{b}^{q^{\perp}}$ & 0,0414 & 0,1248 & 0,0777 & 0,1019 & 0,1213 & 0,0876 & 0,1276 & 0,0686 & 0,4891 & 0,1334 & 0,1408 & 0,4187 \\
\hline$I_{c}^{q^{+}}$ & 0,2084 & 0,1111 & 0,0839 & 0,1125 & 0,099 & 0,064 & 0,1469 & 0,1129 & 0,495 & 0,2232 & 0,1034 & 0,353 \\
\hline$I_{d}^{q^{\perp}}$ & 0,7913 & 0,1352 & 0,2192 & 0,1777 & 0,157 & 0,2222 & 1,194 & 0,9877 & 0,7884 & 0,4045 & 0,4727 & 0,1431 \\
\hline$I_{a}^{d}$ & 0,17 & 1,154 & 1,3588 & 1,5044 & 0,7879 & 0,7933 & 3,4915 & 0,959 & 3,9379 & 4,3864 & 0,3367 & 5,5216 \\
\hline$I_{b}^{d}$ & 0,1632 & 1,1056 & 1,3209 & 1,398 & 0,8401 & 0,6045 & 3,1694 & 1,0143 & 3,9321 & 3,9388 & 0,5373 & 5,423 \\
\hline$I_{c}^{d}$ & 0,2191 & 1,0853 & 1,4907 & 1,6128 & 0,8944 & 0,7028 & 3,0637 & 2,4349 & 4,9134 & 4,9264 & 1,4444 & 6,8741 \\
\hline$I_{d}^{d}$ & 0,968 & 1,4987 & 1,7604 & 1,7091 & 1,3976 & 2,7282 & 12,2 & 8,6581 & 7,2821 & 7,8339 & 9,3041 & 0,5894 \\
\hline$I_{\bar{a}}^{p}$ & 0,6151 & 0,8764 & 0,2322 & 0,7283 & 1,0516 & 0,1558 & 1,4731 & 0,858 & 0,3439 & 1,0375 & 1,7713 & 0,4096 \\
\hline$I_{\bar{b}}^{p}$ & 0,213 & 0,7051 & 0,2538 & 0,2494 & 0,4908 & 0,4435 & 1,0994 & 0,7703 & 0,4079 & 0,3913 & 0,3377 & 0,7337 \\
\hline$I_{\bar{c}}^{p}$ & 0,618 & 0,6901 & 0,4093 & 0,39 & 0,5279 & 0,6727 & 2,0323 & 0,9979 & 1,4588 & 0,7227 & 0,3729 & 0,2935 \\
\hline$I_{h}^{p}$ & 0,1048 & 1,0889 & 0,7511 & 1,0343 & 1,1717 & 1,0456 & 0,6071 & 0,5864 & 1,2497 & 1,5729 & 0,7306 & 0,4083 \\
\hline$I_{\frac{a}{a}}^{q^{l \mid}}$ & 0,81 & 0,5383 & 0,4938 & 0,4223 & 0,415 & 0,4118 & 0,9706 & 1,375 & 0,6537 & 1,4173 & 0,9119 & 0,3461 \\
\hline$I_{\frac{q^{q}}{\mathrm{q}}}$ & 0,7076 & 0,4754 & 0,5096 & 0,9775 & 0,4852 & 0,1623 & 1,0643 & 2,1127 & 0,5809 & 1,889 & 1,422 & 0,2643 \\
\hline$I_{\bar{c}}^{q^{\|}}$ & 0,411 & 0,3654 & 0,4619 & 0,5436 & 0,5499 & 0,291 & 0,379 & 0,5382 & 0,3732 & 0,507 & 0,3317 & 1,1163 \\
\hline$I_{h}^{q u}$ & 0,2203 & 0,3878 & 0,2519 & 0,4173 & 0,1264 & 0,4048 & 0,3158 & 0,4893 & 0,4924 & 0,5267 & 0,7767 & 0,8359 \\
\hline$I_{\bar{a}}^{q^{\perp}}$ & 0,1261 & 0,2016 & 1,7296 & 0,5391 & 0,453 & 0,2003 & 1,387 & 0,2565 & 0,2656 & 0,4841 & 0,6567 & 0,364 \\
\hline$I_{\bar{b}}^{q^{\perp}}$ & 0,6281 & 0,3157 & 0,2689 & 0,9762 & 1,0312 & 0,4256 & 1,8546 & 0,3697 & 0,6263 & 1,9675 & 2,1792 & 1,0634 \\
\hline$I_{\bar{c}}^{q^{\perp}}$ & 0,3212 & 0,2952 & 1,5501 & 2,2866 & 1,7577 & 0,7374 & 0,7652 & 0,1625 & 1,65 & 3,2719 & 2,1337 & 0,2606 \\
\hline$I_{h}^{q^{\perp}}$ & 0,2815 & 0,2288 & 0,4175 & 1,0155 & 0,5182 & 1,1416 & 0,3601 & 0,4023 & 0,9585 & 0,8759 & 0,6084 & 1,567 \\
\hline$I_{\bar{a}}^{d}$ & 0,0171 & 14,4837 & 14,9881 & 16,7236 & 17,8488 & 5,5117 & 14,3639 & 15,2134 & 12,2354 & 12,047 & 14,8332 & 12,2483 \\
\hline$I_{\bar{b}}^{d}$ & 0,104 & 13,7065 & 14,1767 & 15,8202 & 16,9947 & 5,3808 & 15,4739 & 11,8205 & 12,0257 & 11,9095 & 13,9761 & 10,5214 \\
\hline$I_{\bar{c}}^{d}$ & 0,0036 & 13,7172 & 13,5952 & 15,978 & 16,9148 & 5,3609 & 14,9028 & 10,5234 & 10,187 & 10,8402 & 12,4969 & 8,3125 \\
\hline$I_{h}^{d}$ & 0,5582 & 2,6032 & 2,3193 & 2,5444 & 2,4454 & 2,5524 & 2,8622 & 2,8899 & 2,1205 & 2,9697 & 2,8123 & 2,3224 \\
\hline
\end{tabular}


Tabela 4.2: Valores RMS dos sinais de tensão e corrente e das componentes ortogonais de tensão das oscilografias mapeadas do Alimentador A

\begin{tabular}{|c|c|c|c|c|c|c|c|c|c|c|c|c|}
\hline Componente & Correlação com $I_{n}$ & HR-12915 & HR-12917 & HR-12919 & HR-12921 & HR-12925 & HR-12938 & HR-13062 & HR-13064 & HR-13066 & HR-13068 & HR-13074* \\
\hline$V_{a}$ & - & 8,2375 & 8,2352 & 8,236 & 8,2442 & 8,2144 & 8,2794 & 8,256 & 8,2403 & 8,2268 & 8,2698 & 8,2448 \\
\hline$V_{b}$ & - & 8,241 & 8,2415 & 8,2391 & 8,2464 & 8,2168 & 8,2694 & 8,2481 & 8,2294 & 8,2206 & 8,2619 & 8,2465 \\
\hline$V_{c}$ & - & 8,2333 & 8,2313 & 8,23 & 8,2373 & 8,2099 & 8,2739 & 8,229 & 8,2124 & 8,2011 & 8,243 & 8,2316 \\
\hline$I_{a}$ & - & 93,5525 & 90,0583 & 81,8114 & 65,2396 & 19,9483 & 168,0952 & 71,5276 & 73,8452 & 75,5238 & 38,1006 & 151,0446 \\
\hline$I_{b}$ & - & 107,8882 & 107,2358 & 97,6828 & 80,5039 & 27,4239 & 105,9241 & 147,4859 & 153,8158 & 154,4291 & 127,1755 & 176,3053 \\
\hline$I_{c}$ & - & 93,1574 & 93,3266 & 85,1261 & 65,9749 & 17,239 & 101,9718 & 88,058 & 94,0062 & 96,6697 & 56,0763 & 169,6436 \\
\hline$I_{n}$ & - & 12,8864 & 13,1436 & 13,0789 & 12,4226 & 13,9903 & 74,037 & 54,0471 & 61,0578 & 68,6601 & 71,7507 & 2,7462 \\
\hline$V_{a}^{p}$ & 0,1345 & 7,9654 & 7,7315 & 7,4776 & 8,0181 & 3,4499 & 7,665 & 8,2031 & 7,0548 & 6,4093 & 8,2787 & 7,7388 \\
\hline$V_{b}^{p}$ & 0,0356 & 7,9916 & 7,852 & 7,6986 & 8,0369 & 7,0354 & 6,8364 & 8,2255 & 7,8351 & 7,82 & 8,2578 & 7,8473 \\
\hline$V_{c}^{p}$ & 0,0182 & 7,9101 & 7,6175 & 7,3822 & 7,8852 & 3,2504 & 6,5816 & 7,8161 & 6,572 & 6,4026 & 7,9324 & 7,375 \\
\hline$V_{d}^{p}$ & 0,5726 & 0,009 & 0,0078 & 0,0089 & 0,0096 & 0,0088 & 0,0059 & 0,003 & 0,0028 & 0,0038 & 0,0041 & 0,0024 \\
\hline$V_{a}^{q \|}$ & 0,1508 & 1,9662 & 2,8307 & 3,4538 & 2,019 & 7,4332 & 3,1501 & 0,9203 & 3,8931 & 5,1448 & 0,3492 & 2,8447 \\
\hline$V_{b}^{q \|}$ & 0,155 & 1,9195 & 2,4935 & 2,9293 & 1,8785 & 4,275 & 4,6754 & 0,6014 & 2,2494 & 2,5745 & 0,1951 & 2,5505 \\
\hline$V_{c}^{q \|}$ & 0,0963 & 2,1934 & 3,1057 & 3,6536 & 2,4763 & 7,5429 & 5,0429 & 2,5248 & 4,6921 & 5,136 & 2,278 & 3,6489 \\
\hline$V_{d}^{q \|}$ & 0,825 & 0,0069 & 0,0077 & 0,0071 & 0,0065 & 0,0075 & 0,0089 & 0,0203 & 0,0235 & 0,0247 & 0,0259 & 0,0032 \\
\hline$V_{a}^{q^{\perp}}$ & 0,2386 & 0,0057 & 0,0041 & 0,0071 & 0,0885 & 0,0143 & 0,0054 & 0,0089 & 0,0133 & 0,2182 & 0,0128 & 0,0279 \\
\hline$V_{b}^{q^{\perp}}$ & 0,4664 & 0,0048 & 0,0051 & 0,0071 & 0,01 & 0,0213 & 0,007 & 0,0035 & 0,0072 & 0,0061 & 0,0078 & 0,0391 \\
\hline$V_{c}^{q^{\perp}}$ & 0,3458 & 0,0073 & 0,006 & 0,0058 & 0,006 & 0,0369 & 0,059 & 0,0071 & 0,2228 & 0,0077 & 0,0092 & 0,0176 \\
\hline$V_{d}^{q^{\perp}}$ & 0,2976 & 0,0002 & 0,0002 & 0,0002 & 0,0002 & 0,0004 & 0,0003 & 0,0003 & 0,0003 & 0,0002 & 0,0003 & 0,0008 \\
\hline$\frac{d}{V_{a}^{d}}$ & 0,1585 & 0,1025 & 0,1277 & 0,1582 & 0,1309 & 0,3389 & 0,1683 & 0,1131 & 0,4074 & 0,421 & 0,0844 & 0,2922 \\
\hline$V_{b}^{d}$ & 0,0601 & 0,0888 & 0,1083 & 0,129 & 0,0933 & 0,2051 & 0,2597 & 0,0578 & 0,2139 & 0,2247 & 0,0321 & 0,2655 \\
\hline$V_{c}^{d}$ & 0,3234 & 0,0957 & 0,13 & 0,1563 & 0,1171 & 0,4224 & 0,261 & 0,2092 & 0,359 & 0,3987 & 0,2147 & 0,3328 \\
\hline$V_{d}^{c}$ & 0,2282 & 0,0011 & 0,0011 & 0,0014 & 0,001 & 0,0023 & 0,001 & 0,0025 & 0,0023 & 0,0023 & 0,0027 & 0,0094 \\
\hline$V_{\bar{a}}^{p}$ & 0,6034 & 0,0011 & 0,0003 & 0,0008 & 0,001 & 0,0005 & 0,0016 & 0,0009 & 0,0004 & 0,0013 & 0,002 & 0,0005 \\
\hline$V_{\bar{b}}^{p}$ & 0,099 & 0,0009 & 0,0003 & 0,0003 & 0,0005 & 0,0014 & 0,0011 & 0,0009 & 0,0005 & 0,0005 & 0,0004 & 0,001 \\
\hline$V_{\bar{c}}^{p}$ & 0,3948 & 0,0009 & 0,0005 & 0,0004 & 0,0006 & 0,0022 & 0,002 & 0,0014 & 0,0021 & 0,001 & 0,0005 & 0,0005 \\
\hline$V_{h}^{p}$ & 0,2512 & 0,0209 & 0,0177 & 0,0195 & 0,0223 & 0,0228 & 0,009 & 0,0094 & 0,0234 & 0,0192 & 0,0142 & 0,0081 \\
\hline$V_{\bar{a}}^{q^{\| I}}$ & 0,2761 & 0,0004 & 0,0003 & 0,0003 & 0,0003 & 0,0005 & 0,0004 & 0,0006 & 0,0002 & 0,0014 & 0,0007 & 0,0009 \\
\hline$V_{\bar{b}}^{q \|}$ & 0,4288 & 0,0006 & 0,0003 & 0,0004 & 0,0003 & 0,0004 & 0,0005 & 0,0006 & 0,0006 & 0,002 & 0,0008 & 0,0009 \\
\hline$V_{\bar{c}}^{q \|}$ & 0,0421 & 0,0004 & 0,0003 & 0,0004 & 0,0003 & 0,0012 & 0,0003 & 0,0002 & 0,001 & 0,0008 & 0,0002 & 0,0006 \\
\hline$V_{h}^{q \|}$ & 0,6952 & 0,0177 & 0,0109 & 0,014 & 0,019 & 0,0214 & 0,0042 & 0,0054 & 0,0112 & 0,0073 & 0,0045 & 0,0075 \\
\hline$V_{\bar{a}}^{q^{\perp}}$ & 0,515 & 0,0048 & 0,0046 & 0,0047 & 0,0047 & 0,0042 & 0,0046 & 0,0047 & 0,0052 & 0,0048 & 0,005 & 0,0046 \\
\hline$V_{\bar{b}}^{q^{\perp}}$ & 0,0659 & 0,0049 & 0,0044 & 0,0044 & 0,0045 & 0,0047 & 0,0041 & 0,0046 & 0,0053 & 0,0048 & 0,0047 & 0,0047 \\
\hline$V_{\bar{c}}^{q^{\perp}}$ & 0,0236 & 0,0049 & 0,0044 & 0,0044 & 0,0045 & 0,0049 & 0,0043 & 0,0047 & 0,005 & 0,0045 & 0,0048 & 0,0047 \\
\hline$V_{h}^{q^{\perp}}$ & 0,255 & 0,0098 & 0,0113 & 0,0073 & 0,0062 & 0,0235 & 0,0127 & 0,0144 & 0,0039 & 0,0054 & 0,015 & 0,0204 \\
\hline$V_{\bar{a}}^{d}$ & 0,5193 & 0,0178 & 0,0173 & 0,0173 & 0,0167 & 0,0167 & 0,015 & 0,0144 & 0,0143 & 0,0141 & 0,0158 & 0,0135 \\
\hline$V_{\bar{b}}^{d}$ & 0,5966 & 0,0172 & 0,0171 & 0,0171 & 0,0169 & 0,0168 & 0,0145 & 0,0144 & 0,0142 & 0,0144 & 0,0148 & 0,0134 \\
\hline$V_{\bar{c}}^{d}$ & 0,5881 & 0,0173 & 0,0171 & 0,0171 & 0,0168 & 0,0165 & 0,0146 & 0,0143 & 0,0142 & 0,0142 & 0,0149 & 0,0134 \\
\hline $\begin{array}{c}c \\
V_{h}^{d} \\
\end{array}$ & 0,3542 & 0,0489 & 0,048 & 0,0478 & 0,0439 & 0,0406 & 0,0443 & 0,0424 & 0,0398 & 0,04 & 0,0433 & 0,0399 \\
\hline
\end{tabular}


Tabela 4.3: Valores RMS dos sinais de tensão e corrente e das componentes ortogonais de corrente das oscilografias mapeadas do Alimentador B

\begin{tabular}{|c|c|c|c|c|c|c|c|c|c|c|c|}
\hline Correlação & Correlação com $I_{n}$ & HR-11831 & HR-11832 & HR-11851 & HR-11852 & HR-11854 & HR-11858 & HR-11860 & HR-11861 & HR-11906* & HR-11910* \\
\hline$V_{a}$ & - & 8,3799 & 8,3625 & 8,3644 & 8,2363 & 8,2787 & 8,3728 & 8,2782 & 8,1082 & 8,2973 & 8,2335 \\
\hline$V_{b}$ & - & 8,3811 & 8,3674 & 8,3686 & 8,2382 & 8,2762 & 8,3674 & 8,2701 & 8,0989 & 8,2948 & 8,2147 \\
\hline$V_{c}$ & - & 8,3908 & 8,3688 & 8,3817 & 8,2548 & 8,2999 & 8,4065 & 8,3045 & 7,9925 & 8,3177 & 8,2506 \\
\hline$I_{a}$ & - & 92,4541 & 120,8256 & 127,0717 & 91,0153 & 55,4023 & 44,3276 & 46,929 & 353,0658 & 104,2189 & 102,0224 \\
\hline$I_{b}$ & - & 55,5393 & 59,7078 & 78,1044 & 42,1662 & 65,3873 & 53,7992 & 54,54 & 392,1598 & 103,9438 & 100,4917 \\
\hline$I_{c}$ & - & 84,9228 & 106,5155 & 76,3915 & 41,2635 & 50,8435 & 38,4815 & 42,3477 & 540,4987 & 104,1871 & 100,1171 \\
\hline$I_{n}$ & - & 31,3755 & 52,1158 & 56,7954 & 56,311 & 15,9797 & 18,5691 & 14,3407 & 4,0432 & 5,5686 & 5,5873 \\
\hline$I_{a}^{p}$ & 0,6525 & 84,9583 & 111,5034 & 117,0617 & 86,1358 & 45,9644 & 30,4845 & 33,4799 & 44,0074 & 86,8347 & 83,9832 \\
\hline$I_{b}^{p}$ & 0,4961 & 43,0002 & 46,1788 & 61,6647 & 31,7903 & 56,1532 & 41,6056 & 42,0262 & 226,9043 & 86,2761 & 81,5756 \\
\hline$I_{c}^{p}$ & 0,2406 & 79,7416 & 100,6342 & 59,7721 & 30,058 & 42,2447 & 27,5904 & 30,1676 & 136,5054 & 86,8459 & 83,0316 \\
\hline$I_{d}^{p}$ & 0,166 & 10,504 & 11,0065 & 3,8635 & 0,287 & 10,5326 & 7,8434 & 8,3639 & 2,0241 & 0,2537 & 0,4401 \\
\hline$I_{a}^{q^{\|}}$ & 0,3851 & 37,7239 & 44,069 & 46,4498 & 27,9077 & 30,1623 & 30,4652 & 32,1695 & 341,3841 & 57,1601 & 57,5072 \\
\hline$I_{b}^{q \|}$ & 0,4101 & 33,608 & 36,6465 & 45,8363 & 26,852 & 32,6606 & 32,2448 & 34,0588 & 295,205 & 57,4886 & 58,0714 \\
\hline$I_{c}^{q \|}$ & 0,3801 & 27,9831 & 32,5263 & 45,9009 & 27,6966 & 27,7775 & 25,3947 & 28,8391 & 539,0113 & 57,117 & 55,9662 \\
\hline$I_{d}^{q \|}$ & 0,998 & 28,9705 & 49,6014 & 55,5158 & 55,2061 & 9,3462 & 15,2133 & 9,9565 & 2,4441 & 0,2378 & 0,416 \\
\hline$I_{a}^{q^{\perp}}$ & 0,3631 & 0,1967 & 0,2095 & 0,2261 & 0,1122 & 0,0844 & 0,0916 & 0,1111 & 32,2332 & 0,1445 & 0,7269 \\
\hline$I_{b}^{q^{\perp}}$ & 0,3569 & 0,0848 & 0,438 & 0,1772 & 0,076 & 0,1103 & 0,1339 & 0,1444 & 29,9055 & 0,1726 & 0,2374 \\
\hline$I_{c}^{q^{\perp}}$ & 0,3627 & 2,599 & 0,1502 & 0,2798 & 0,1883 & 0,4076 & 0,1616 & 0,5778 & 54,2406 & 0,6566 & 0,352 \\
\hline$I_{d}^{q^{\perp}}$ & 0,1494 & 0,2682 & 0,2405 & 0,2434 & 0,1816 & 0,1981 & 1,9476 & 0,2466 & 0,573 & 0,0949 & 0,131 \\
\hline$I_{a}^{d}$ & 0,3656 & 4,0158 & 4,3619 & 6,2089 & 2,7474 & 2,3914 & 3,192 & 2,842 & 104,2584 & 6,5204 & 6,9539 \\
\hline$I_{b}^{d}$ & 0,3689 & 3,5185 & 3,608 & 6,1255 & 2,533 & 2,4769 & 3,2636 & 2,9879 & 100,9861 & 6,3137 & 6,5866 \\
\hline$I_{c}^{d}$ & 0,3647 & 0,6682 & 3,0101 & 5,7135 & 2,4882 & 2,0316 & 2,3108 & 2,1283 & 163,8867 & 6,1642 & 6,257 \\
\hline$I_{d}^{d}$ & 0,9783 & 3,4176 & 5,2422 & 7,3955 & 5,8522 & 1,6181 & 2,3201 & 1,9779 & 1,1032 & 0,44 & 0,5411 \\
\hline$I_{\bar{a}}^{p}$ & 0,293 & 2,246 & 3,3758 & 3,1185 & 3,9426 & 0,6023 & 0,7549 & 0,9968 & 62,3916 & 0,1079 & 0,4316 \\
\hline$I_{\bar{b}}^{p}$ & 0,4247 & 2,8061 & 2,3455 & 1,5698 & 0,3618 & 5,6011 & 6,7806 & 5,9836 & 42,9563 & 1,3049 & 1,8303 \\
\hline$I_{\bar{c}}^{p}$ & 0,3666 & 0,3556 & 1,5432 & 1,3545 & 0,1499 & 0,8769 & 3,1317 & 2,4072 & 99,351 & 0,7399 & 1,4899 \\
\hline$I_{h}^{p}$ & 0,6512 & 5,2705 & 7,3345 & 3,4764 & 4,7629 & 4,9213 & 4,6201 & 4,5771 & 0,4488 & 0,5744 & 0,7421 \\
\hline$I_{\bar{a}}^{q^{\|}}$ & 0,3572 & 0,345 & 0,5178 & 0,756 & 1,6821 & 1,3897 & 1,2862 & 1,3232 & 61,4921 & 0,7444 & 0,4213 \\
\hline$I_{\bar{b}}^{q \|}$ & 0,3749 & 0,7801 & 0,7297 & 0,6028 & 0,5015 & 0,9635 & 3,574 & 2,4615 & 61,2208 & 0,647 & 0,6239 \\
\hline$I_{\bar{c}}^{q^{\|}}$ & 0,361 & 0,6012 & 0,3828 & 0,7136 & 0,868 & 1,2879 & 1,0228 & 1,2496 & 62,9329 & 0,206 & 0,6477 \\
\hline$I_{h}^{q^{\|}}$ & 0,317 & 0,3234 & 0,5549 & 0,9264 & 0,7403 & 0,4995 & 1,0509 & 0,5044 & 0,7259 & 0,4344 & 0,433 \\
\hline$I_{\bar{a}}^{q^{ \pm}}$ & 0,3528 & 0,3907 & 1,2268 & 1,9485 & 1,7229 & 1,0354 & 0,6052 & 0,6678 & 159,5803 & 1,153 & 0,8421 \\
\hline$I_{\bar{b}}^{q^{\perp}}$ & 0,3537 & 3,6103 & 4,8834 & 3,1653 & 2,6972 & 2,1833 & 2,4627 & 2,4623 & 191,6573 & 3,2429 & 3,0563 \\
\hline$I_{\bar{c}}^{q^{\perp}}$ & 0,3617 & 0,9196 & 0,4482 & 0,2291 & 0,6521 & 1,3728 & 1,5113 & 1,456 & 375,6763 & 0,9336 & 1,2844 \\
\hline$I_{h}^{q^{\perp}}$ & 0,0475 & 4,5223 & 4,3779 & 3,0134 & 4,9869 & 4,6533 & 4,884 & 5,0743 & 0,8067 & 5,7715 & 5,654 \\
\hline$I_{\bar{a}}^{d}$ & 0,3475 & 8,6548 & 8,9447 & 8,3465 & 5,768 & 6,5975 & 8,7633 & 6,9697 & 232,139 & 5,0281 & 4,0183 \\
\hline$I_{\bar{b}}^{d}$ & 0,3516 & 8,1027 & 7,4775 & 7,8181 & 5,047 & 6,7831 & 8,2455 & 6,4721 & 218,5806 & 4,9372 & 4,1752 \\
\hline$I_{\bar{c}}^{d}$ & 0,3495 & 8,3688 & 7,8985 & 7,8811 & 4,7882 & 5,7778 & 7,367 & 5,7525 & 221,2174 & 5,362 & 4,0778 \\
\hline$I_{h}^{d}$ & 0,6664 & 3,6303 & 4,6209 & 4,3558 & 3,5678 & 3,6778 & 4,1062 & 3,7149 & 3,4292 & 2,1175 & 2,2337 \\
\hline
\end{tabular}


Tabela 4.4: Valores RMS dos sinais de tensão e corrente e das componentes ortogonais de tensão das oscilografias mapeadas do Alimentador B

\begin{tabular}{|c|c|c|c|c|c|c|c|c|c|c|c|}
\hline Correlação & Correlação com $I_{n}$ & HR-11831 & HR-11832 & HR-11851 & HR-11852 & HR-11854 & HR-11858 & HR-11860 & HR-11861 & HR-11906* & HR-11910* \\
\hline$V_{a}$ & - & 8,3799 & 8,3625 & 8,3644 & 8,2363 & 8,2787 & 8,3728 & 8,2782 & 8,1082 & 8,2973 & 8,2335 \\
\hline$V_{b}$ & - & 8,3811 & 8,3674 & 8,3686 & 8,2382 & 8,2762 & 8,3674 & 8,2701 & 8,0989 & 8,2948 & 8,2147 \\
\hline$V_{c}$ & - & 8,3908 & 8,3688 & 8,3817 & 8,2548 & 8,2999 & 8,4065 & 8,3045 & 7,9925 & 8,3177 & 8,2506 \\
\hline$I_{a}$ & - & 92,4541 & 120,8256 & 127,0717 & 91,0153 & 55,4023 & 44,3276 & 46,929 & 353,0658 & 104,2189 & 102,0224 \\
\hline$I_{b}$ & - & 55,5393 & 59,7078 & 78,1044 & 42,1662 & 65,3873 & 53,7992 & 54,54 & 392,1598 & 103,9438 & 100,4917 \\
\hline$I_{c}$ & - & 84,9228 & 106,5155 & 76,3915 & 41,2635 & 50,8435 & 38,4815 & 42,3477 & 540,4987 & 104,1871 & 100,1171 \\
\hline$I_{n}$ & - & 31,3755 & 52,1158 & 56,7954 & 56,311 & 15,9797 & 18,5691 & 14,3407 & 4,0432 & 5,5686 & 5,5873 \\
\hline$V_{a}^{p}$ & 0,5817 & 7,609 & 7,795 & 7,7857 & 7,8283 & 6,9177 & 5,9174 & 5,9542 & 0,8188 & 6,9139 & 6,7751 \\
\hline$V_{b}^{p}$ & 0,2093 & 6,5966 & 6,5418 & 6,7237 & 6,279 & 7,1451 & 6,5975 & 6,3842 & 4,4147 & 6,8845 & 6,6768 \\
\hline$V_{c}^{p}$ & 0,3843 & 7,9148 & 7,9745 & 6,6499 & 6,0581 & 6,9312 & 6,1889 & 5,9968 & 1,6794 & 6,9332 & 6,8182 \\
\hline$V_{d}^{p}$ & 0,523 & 0,0128 & 0,0122 & 0,0033 & 0,0003 & 0,0141 & 0,0092 & 0,0105 & 0,0065 & 0,0115 & 0,0116 \\
\hline$\frac{a}{V_{a}^{q}}$ & 0,8336 & 3,3838 & 3,0764 & 3,0894 & 2,5414 & 4,5322 & 5,9142 & 5,7196 & 6,4708 & 4,5536 & 4,6431 \\
\hline$V_{b}^{q \|}$ & 0,4876 & 5,1539 & 5,1865 & 4,9899 & 5,3054 & 4,153 & 5,1028 & 5,1868 & 5,0202 & 4,5872 & 4,7498 \\
\hline$V_{c}^{q \|}$ & 0,2974 & 2,7759 & 2,5706 & 5,0989 & 5,5828 & 4,5603 & 5,6905 & 5,7327 & 6,0506 & 4,5605 & 4,5961 \\
\hline$V_{d}^{q \|}$ & 0,9755 & 0,0354 & 0,0549 & 0,047 & 0,0475 & 0,0125 & 0,0179 & 0,0128 & 0,0092 & 0,0079 & 0,0087 \\
\hline$V_{a}^{q^{\perp}}$ & 0,3909 & 0,0176 & 0,0067 & 0,0287 & 0,011 & 0,0196 & 0,0207 & 0,042 & 1,0472 & 0,0176 & 0,0847 \\
\hline$V_{b}^{q^{\perp}}$ & 0,3599 & 0,0107 & 0,0171 & 0,0167 & 0,0117 & 0,0079 & 0,0138 & 0,0134 & 2,0907 & 0,0118 & 0,0292 \\
\hline$V_{c}^{q^{\perp}}$ & 0,363 & 0,0146 & 0,017 & 0,0156 & 0,0117 & 0,0107 & 0,0284 & 0,0101 & 1,4273 & 0,0257 & 0,0184 \\
\hline$V_{d}^{q^{\perp}}$ & 0,5871 & 0,0003 & 0,0005 & 0,0004 & 0,0004 & 0,0002 & 0,0003 & 0,0003 & 0,0025 & 0,003 & 0,0017 \\
\hline$V_{a}^{d}$ & 0,4771 & 0,3479 & 0,2936 & 0,3972 & 0,2444 & 0,3494 & 0,5482 & 0,4519 & 2,2648 & 0,5087 & 0,5382 \\
\hline$V_{b}^{d}$ & 0,3059 & 0,5535 & 0,5236 & 0,6779 & 0,5265 & 0,3297 & 0,5572 & 0,4856 & 2,5472 & 0,52 & 0,5683 \\
\hline$V_{c}^{d}$ & 0,3527 & 0,2769 & 0,2424 & 0,6562 & 0,5121 & 0,3405 & 0,5558 & 0,4708 & 2,5248 & 0,4907 & 0,5075 \\
\hline$\stackrel{c}{V_{d}^{d}}$ & 0,2928 & 0,0041 & 0,0058 & 0,0063 & 0,0049 & 0,0019 & 0,0025 & 0,0027 & 0,005 & 0,0164 & 0,0131 \\
\hline$V_{\bar{a}}^{p}$ & 0,8084 & 0,0031 & 0,0045 & 0,0047 & 0,0054 & 0,001 & 0,0011 & 0,0016 & 0,0036 & 0,0004 & 0,002 \\
\hline$V_{\bar{b}}^{p}$ & 0,7 & 0,0041 & 0,0032 & 0,0025 & 0,0006 & 0,0078 & 0,0081 & 0,0072 & 0,0047 & 0,004 & 0,0061 \\
\hline$V_{\bar{c}}^{p}$ & 0,5036 & 0,0005 & 0,0024 & 0,0023 & 0,0003 & 0,0017 & 0,0052 & 0,0043 & 0,0022 & 0,0026 & 0,006 \\
\hline$V_{h}^{p}$ & 0,5747 & 0,0267 & 0,0296 & 0,0212 & 0,0158 & 0,0226 & 0,0242 & 0,0216 & 0,004 & 0,0054 & 0,0073 \\
\hline$V_{\bar{a}}^{q \|}$ & 0,5836 & 0,0014 & 0,0019 & 0,0006 & 0,0028 & 0,0024 & 0,0023 & 0,0017 & 0,008 & 0,0037 & 0,0038 \\
\hline$V_{\bar{b}}^{q \|}$ & 0,6852 & 0,0007 & 0,0007 & 0,0017 & 0,0003 & 0,0042 & 0,0054 & 0,0042 & 0,0101 & 0,0043 & 0,0019 \\
\hline$V_{\bar{c}}^{q}{ }^{q}$ & 0,2817 & 0,0016 & 0,0027 & 0,0013 & 0,0009 & 0,0019 & 0,0005 & 0,0007 & 0,0018 & 0,0007 & 0,0012 \\
\hline$V_{h}^{q \|}$ & 0,1089 & 0,0061 & 0,009 & 0,0057 & 0,0014 & 0,0065 & 0,0137 & 0,0078 & 0,0042 & 0,0051 & 0,0047 \\
\hline$V_{\bar{a}}^{q^{\perp}}$ & 0,4377 & 0,0026 & 0,003 & 0,0012 & 0,0027 & 0,0035 & 0,002 & 0,0032 & 0,0148 & 0,0032 & 0,003 \\
\hline$V_{\bar{b}}^{q^{\perp}}$ & 0,2149 & 0,001 & 0,003 & 0,0008 & 0,0022 & 0,001 & 0,0006 & 0,0011 & 0,0106 & 0,0008 & 0,0011 \\
\hline$V_{\bar{c}}^{q^{\perp}}$ & 0,6678 & 0,0025 & 0,0027 & 0,0022 & 0,0022 & 0,0031 & 0,0032 & 0,0036 & 0,0025 & 0,0031 & 0,0041 \\
\hline$V_{h}^{q^{\perp}}$ & 0,1893 & 0,0123 & 0,0117 & 0,0178 & 0,0072 & 0,0118 & 0,0152 & 0,0119 & 0,0068 & 0,0116 & 0,0126 \\
\hline$V_{\bar{a}}^{d}$ & 0,6312 & 0,0116 & 0,0115 & 0,0131 & 0,0085 & 0,0106 & 0,0123 & 0,0112 & 0,0225 & 0,0174 & 0,0174 \\
\hline$V_{\bar{b}}^{d}$ & 0,4174 & 0,0126 & 0,0129 & 0,0137 & 0,0089 & 0,0092 & 0,0094 & 0,0078 & 0,0256 & 0,0179 & 0,0173 \\
\hline$V_{\bar{c}}^{d}$ & 0,3724 & 0,0124 & 0,0121 & 0,0136 & 0,0087 & 0,011 & 0,0116 & 0,01 & 0,011 & 0,0181 & 0,0168 \\
\hline$V_{h}^{d}$ & 0,5306 & 0,0228 & 0,0189 & 0,0328 & 0,0173 & 0,0204 & 0,023 & 0,0225 & 0,0319 & 0,0565 & 0,055 \\
\hline
\end{tabular}

\subsection{Análise de Sensibilidade das Componentes Ortogo-}

\section{nais}

Com base na série de amostras de componentes ortogonais obtidas desses casos reais, foi realizada uma análise de sensibilidade de cada uma das componentes com relação à sua correlação com a corrente de neutro para cada alimentador. Apesar dos níveis de corrente de neutro em faltas de alta impedância serem bastante inferiores aos níveis observados em 
demais faltas, é possível observar nos dados obtidos que seus valores são sempre superiores aos valores obtidos em condições normais de operação. Por essa razão, foi escolhida a corrente de neutro para essa análise de correlação com a ocorrência da falta.

Na tabela 4.5, são apresentadas as componentes identificadas com maior correlação com a intensidade da corrente de neutro para o alimentador A, enquanto na tabela 4.6 são apresentados os resultados para o alimentador B. Nota-se que as componentes $I_{d}^{q^{\|}}, I_{d}^{d}$ e $V_{d}^{q^{\|}}$aparecem nos dois cenários como as componentes mais correlacionadas com a falta, sendo estas diretamente derivadas da corrente de neutro. As demais componentes de maior correlação são todas distintas entre os dois cenários, sendo no caso do alimentador A predominantemente componentes resultantes da decomposição dos sinais de corrente no espaço das tensões e o oposto no caso do alimentador B, nos dois casos sendo as componentes perpendiculares ao plano das tensões de linha.

Tabela 4.5: Componentes de maior correlação com $I_{n}$ para o Alimentador A.

\begin{tabular}{|c|c|}
\hline Componente Ortogonal & Correlação com $I_{n}$ \\
\hline \hline$I_{d}^{q \|}$ & 0,9924 \\
\hline$I_{d}^{d}$ & 0,968 \\
\hline$V_{d}^{q \|}$ & 0,825 \\
\hline$I_{\bar{a}}^{q \|}$ & 0,81 \\
\hline$I_{d}^{q^{\perp}}$ & 0,7913 \\
\hline$I_{\bar{b}}^{q \|}$ & 0,7076 \\
\hline$V_{h}^{q \|}$ & 0,6952 \\
\hline$I_{\bar{a}}^{q^{\perp}}$ & 0,6281 \\
\hline$I_{\bar{c}}^{\underline{p}}$ & 0,618 \\
\hline$I_{\bar{a}}^{\frac{p}{a}}$ & 0,6151 \\
\hline
\end{tabular}

Essa análise nos mostra dois aspectos de interesse do estudo da decomposição em componentes ortogonais. O primeiro aspecto é que de fato há uma forte correlação entre determinadas componentes e a ocorrência de faltas de alta impedância, de forma que é possível utilizar a técnica na elaboração de sistemas com a finalidade de identificação de falta. O segundo aspecto é que as componentes que são relevantes para a identificação da falta variam de acordo com a rede em estudo, de forma que o sistema baseado nessa técnica deve 
Tabela 4.6: Componentes de maior correlação com $I_{n}$ para o Alimentador B.

\begin{tabular}{|c|c|}
\hline Componente Ortogonal & Correlação com $I_{n}$ \\
\hline \hline$I_{d}^{q \|}$ & 0,998 \\
\hline$I_{d}^{d}$ & 0,9783 \\
\hline$V_{d}^{q \|}$ & 0,9755 \\
\hline$V_{a}^{q \|}$ & 0,8336 \\
\hline$V_{\bar{a}}^{p}$ & 0,8084 \\
\hline$V_{\bar{b}}^{p}$ & 0,7 \\
\hline$V_{\bar{b}}^{q}$ & 0,6852 \\
\hline$V_{\bar{c}}^{q^{\perp}}$ & 0,6678 \\
\hline$I_{h}^{d}$ & 0,6664 \\
\hline$I_{a}^{p}$ & 0,6525 \\
\hline
\end{tabular}

ser ajustado em cada uma de suas aplicações. Esse último aspecto leva a se pensar que a utilização de sistemas inteligentes é de bastante valor, uma vez que essa família de sistemas é capaz de aprender com base nas observações quais são os parâmetros mais relevantes para cada caso de uso. 


\section{Capítulo 5}

\section{CONCLUSÃO}

Os resultados obtidos demonstram o potencial de aplicabilidade da técnica de decomposição em componentes ortogonais para a identificação de faltas. Essa técnica, já estudada por meio de simulações em estudos anteriores, foi aplicada a exemplos reais de oscilografias de faltas de alta impedância, sendo observado que existe forte correlação entre determinadas componentes e a ocorrência da falta. Esse fato é de bastante interesse na elaboração de sistemas de identificação de falta, normalmente baseados na intensidade da corrente de neutro, uma vez que o seu mecanismo de detecção pode ser baseado na análise de uma quantidade muito maior de sinais.

Outra observação a se realizar sobre os resultados obtidos é que as componentes ortogonais mais relacionadas à ocorrência das faltas são específicas de cada rede. Dessa forma, essa técnica pode ser amplamente utilizada em sistemas de identificação de falta inteligentes, construídos de forma a aprender para cada rede estudada quais são as componentes e os valores limites a serem considerados em seus cálculos. A realização desse treinamento, porém, depende de uma grande quantidade de amostras de faltas de alta impedância a serem apresentadas ao sistema, o que seria difícil de obter por meio de casos reais, já que a quantidade de faltas de alta impedância identificadas atualmente nas redes de distribuição é baixa, conforme evidenciado nos resultados deste estudo, em que foram necessários mais de 12 meses para consolidar 11 oscilografias para cada rede de estudo. A modelagem da rede elétrica e 
das faltas de alta impedância continua, portanto, sendo necessária para a construção de um sistema inteligente baseado na técnica da decomposição em componentes ortogonais, ao menos para a geração de amostras para o treinamento do sistema, complementadas com faltas reais coletadas no campo.

Para trabalhos futuros, a elaboração de sistema computacional capaz de calcular as componentes ortogonais em tempos suficientemente baixos para a utilização dos resultados em sistemas de identificação de falta é uma frente de bastante interesse. O estudo sobre estratégias para treinamento de sistemas inteligentes baseados na técnica de decomposição em componentes ortogonais também é uma necessidade para evoluir na elaboração de sistemas com capacidade de aplicação prática. Por último, além da identificação de faltas, a localização de faltas também pode ser explorada com o uso dessa técnica, sendo mais uma frente de estudo futuro a ser explorada. 


\section{Bibliografia}

AKOREDE, M.; KATENDE, J. Wavelet transform based algorithm for high-impedance faults detection in distribution feeders. European Journal of Scientific Research, v. 41, n. 2, p. $237-247,2010$.

ALAMUTI, M. M. et al. Intermittent fault location in distribution feeders. IEEE Trans. Power Deliv., v. 27, p. 96-103, 2012.

ANEEL. Falta de energia gera $R \$ 346$ milhões de compensações aos consumidores em 2013. 2016. 〈http://www2.aneel.gov.br/aplicacoes/noticias/Output_Noticias.cfm?Identidade= 7903〉. Acesso em: 27/03/2016.

BATISTA, O. E. Sistema inteligente baseado em decomposição por componentes ortogonais e inferência Fuzzy para localização de faltas de alta impedância em sistemas de distribuição de energia elétrica com geração distribuída. Tese (Doutorado) - Escola de Engenharia de São Carlos, Universidade de São Paulo, 2016.

BI, Y.; ZHAO, J.; ZHANG, D. Single-phase-to-ground fault feeder detection based on transient current and wavelet packet. 2004 International Conference on Power System Technology, v. 1, p. 936-940, 2004.

BRETAS, A. et al. A novel high impedance fault location for distribution systems considering distributed generation. 2006 IEEE/PES Transmission 8 Distribution Conference and Exposition: Latin America, p. 1-6, 2006.

CASSIE, A. M. Arc rupture and circuit severity: A new theory. Electrical Research Association, 1939.

CHOI, M.-S. et al. A new fault location algorithm using direct circuit analysis for distribution systems. IEEE Trans. Power Deliv., v. 19, n. 1, p. 33-41, 2004.

DARWISH, H. A.; ELKALASHY, N. I. Universal arc representation using emtp. IEEE Trans. Power Deliv., v. 20, n. 2, p. 772-779, 2005.

DAS, R.; SACHDEV, M. S.; SIDHU, T. S. A fault locator for radial subtransmission and distribution lines. 2000 Power Engineering Society Summer Meeting, v. 1, p. 443-448, 2000. 
ELKALASHY, N. et al. Modeling and experimental verification of high impedance arcing fault in medium voltage networks. IEEE Trans. Dielectr. Electr. Insul., v. 14, n. 2, p. 375-383, 2007.

ELKALASHY, N. I. et al. Dwt-based detection and transient power direction-based location of high-impedance faults due to leaning trees in unearthed mv networks. IEEE Transactions on Power Delivery, v. 23, n. 1, p. 94-101, 2008.

ELMORE, W. A. Protective Relaying: Theory and Applications. 2. ed. [S.l.]: CRC Press, 2004.

EMANUEL, A.; CYGANSKI, D. High impedance fault arcing on sandy soil in $15 \mathrm{kv}$ distribution feeders: contributions to the evaluation of the low frequency spectrum. IEEE Transactions on Power Delivery, v. 5, n. 2, p. 676-686, 1990.

ETEMADI, A. H.; SANAYE-PASAND, M. High-impedance fault detection using multi-resolution signal decomposition and adaptive neural fuzzy inference system. IET Gener. Transm. Distrib., v. 2, n. 1, p. 110, 2008.

FAIG, J. et al. Analysis of faults in power distribution systems with distributed generation. International Conference on Renewable Energies and Power Quality, p. 6, 2010.

FERREIRA, V. et al. Technical and financial assessments for comparison of measurement technologies in the smart city buzios project. CIRED - Open Access Proceedings Journal, v. 2017, n. 1, p. 2914-2917, 2017.

FLAUZINO, R. A. Identificação e localização de faltas de alta impedância em sistemas de distribuição baseadas em decomposição por componentes ortogonais e inferência Fuzzy. Tese (Doutorado) - Escola de Engenharia de São Carlos, Universidade de São Paulo, 2007.

FUNABASHI, T. et al. Influence of fault arc characteristics on the accuracy of digital fault locators. IEEE Trans. Power Deliv., v. 16, p. 195-199, 2001.

GAUTAM, S.; BRAHMA, S. M. Detection of high impedance fault in power distribution systems using mathematical morphology. IEEE Transactions on Power Systems, v. 28, p. 1226-1234, 2013.

IEEE. Power arc-over on overhead distribution lines and newly developed equipment for protection against conductor burn-down from that cause. Electrical Engineering, v. 60, p. 684-690, 1941.

IEEE. Ieee guide for determining fault location on ac transmission and distribution lines. IEEE Std C3\%.114-2014, p. 1-44, 2005.

IEEE. Approved ieee draft guide for fault locating techniques on shielded power cable systems. IEEE Approved Draft Std P1234 / D12, Feb 2007, 2007.

JAMALI, S.; TALAVAT, V. Dynamic fault location method for distribution networks with distributed generation. Electrical Engineering, v. 92, n. 3, p. 119-127, 2010. 
JAVADIAN, S.; MASSAELI, M. A fault location method in distribution networks including dg. Indian J. Sci. Technol, v. 4, n. 11, p. 1446-1451, 2011.

JEERINGS, D. I.; LINDERS, J. R. Ground resistance-revisited. IEEE Trans. Power Deliv., v. 4, n. 2, p. 949-956, 1989.

JEERINGS, D. I.; LINDERS, J. R. Unique aspects of distribution system harmonics due to high impedance ground faults. IEEE Trans. Power Deliv., v. 5, n. 2, p. 1086-1094, 1990.

KAGAN, N. et al. Redes Elétricas Inteligentes no Brasil - Análise de Custos e Benefícios de um Plano Nacional. 1. ed. [S.l.]: Synergia, 2013.

KELLER, J.; KROPOSKI, B. Understanding fault characteristics of inverter-based distributed energy resources. Technical Report NREL/TP-550-46698, 2010.

LAZKANO, A. et al. Study of high impedance fault detection in levante area in spain. Ninth International Conference on Harmonics and Quality of Power. Proceedings (Cat. No.00EX441), v. 3, p. 1011-1016, 2000.

LEE, S.-J. et al. An intelligent and efficient fault location and diagnosis scheme for radial distribution systems. IEEE Trans. Power Deliv., v. 19, n. 2, p. 524-532, 2004.

LIN, S. et al. Travelling wave time-frequency characteristic-based fault location method for transmission lines. IET Gener. Transm. Distrib., v. 6, n. 8, p. 764, 2012.

MAYR, O. Beitraege zur theorie des statischen und des dynamischen lichtbogens. Arch. fuer Elektrotechnik, v. 37, n. 12, p. 588-608, 1943.

MILIOUDIS, A. N.; ANDREOU, G. T.; LABRIDIS, D. P. Enhanced protection scheme for smart grids using power line communications techniques-part ii: Location of high impedance fault position. IEEE Trans. Smart Grid, v. 3, p. 1631-1640, 2012.

MORA-FLOREZ, J.; MELENDEZ, J.; CARRILLO-CAICEDOC, G. Comparison of impedance based fault location methods for power distribution systems. Electric Power Systems Research, v. 78, p. 657-666, 2008.

NAM, S. R. et al. A modeling method of a high impedance fault in a distribution system using two series time-varying resistances in emtp. 2001 Power Engineering Society Summer Meeting. Conference Proceedings (Cat. No.01CH37262), v. 2, p. 1175-1180, 2001.

NARASIMHARAO, G. High impedance fault detection and classification of a distribution system. International Journal of Engineering Research $\&$ Technology, v. 1, 2012.

NOVOSEL, D. et al. System for locating faults and estimating fault resistance in distribution networks with tapped loads. 1998. US Pat. 5.839.093.

NUNES, J.; BRETAS, A. An impedance-based fault location technique for unbalanced distributed generation systems. PowerTech, 2011 IEEE Trondheim, p. 1-7, 2011. 
PICCHI, D. et al. Learnings from pilot implementation of smart city by a brazilian energy utility. In: SILVA, I. N. (Ed.). Smart Cities Technologies. London: IntechOpen, 2016. cap. 5, p. 79-99.

REPORT, A. C. Bibliography and summary of fault location methods [includes discussion]. Trans. Am. Inst. Electr. Eng. Part III Power Appar. Syst., v. 74, n. 3, 1955.

SAHA, M.; IZYKOWSKI, J.; ROSOLOWSKI, E. Fault location on power networks. [S.l.]: Springer London, 2010.

SALIM, R. H. et al. Extended fault-location formulation for power distribution systems. IEEE Transactions on Power Delivery, v. 24, p. 508-516, 2009.

SEDIGHI, A.-R. et al. High impedance fault detection based on wavelet transform and statistical pattern recognition. IEEE Trans. Power Deliv., v. 20, n. 4, p. 2414-2421, 2005.

SHARAF, A. M. High impedance fault detection using feature-pattern based relaying. 2003 IEEE PES Transmission and Distribution Conference and Exposition (IEEE Cat. No.03CH37495), v. 1, p. 222-226, 2003.

SHIELDS, F. J. The problem of arcing faults in low-voltage power distribution systems. IEEE Trans. Ind. Gen. Appl., IGA-3, p. 15-25, 1967.

SILVA, I. N. et al. Redes Inteligentes de Distribuição de Energia Elétrica. 1. ed. [S.l.]: Artliber, 2018.

SRINIVASAN, K.; ST-JACQUES, A. A new fault location algorithm for radial transmission lines with loads. IEEE Power Engineering Review, v. 9, n. 7, p. 52, 2009.

STRINGFIELD, T. W.; MARIHART, D. J.; STEVENS, R. F. Fault location methods for overhead lines. Trans. Am. Inst. Electr. Eng. Part III Power Appar. Syst., v. 76, n. 3, p. 518-529, 1957.

TAKAGI, T. et al. A new alogorithm of an accurate fault location for ehv/uhv transmission lines: Part i - fourier transformation method. IEEE Transactions on Power Apparatus and Systems, PAS-100, p. 1316-1323, 1981.

TAKAGI, T. et al. Development of a new type fault ldcator using the one-terminal voltage and current data. IEEE Transactions on Power Apparatus and Systems, PAS-101, p. 2892-2898, 1982.

TENGDIN, J. T. et al. Application of high impedance fault detectors: a summary of the panel session held at the 1995 ieee pes summer meeting. Proceedings of 1996 Transmission and Distribution Conference and Exposition, p. 116-122, 1996.

TERZIJA, V. et al. Detection of arcing faults: Modelling, simulation, testing and algorithms aspects. Power Tech, 2007 IEEE Lausanne, p. 1147-1152, 2007.

TLEIS, N. Power Systems Modelling and Fault Analysis. 1. ed. [S.l.]: Newnes, 2007. 
WAGNER, C. F.; FOUNTAIN, L. L. Low-voltage arcing-fault currents. Electrical Engineering, v. 67, p. 769-771, 1948.

WU, H. et al. Arc fault model for low-voltage ac systems. IEEE Transactions on Power Delivery, v. 20, n. 2, p. 1204-1205, 2005.

XINZHOU, D. X. D. et al. Optimizing solution of fault location. IEEE Power Engineering Society Summer Meeting, v. 3, p. 1113-1117, 2002.

XU, L.; CHOW, M.-Y. A classification approach for power distribution systems fault cause identification. IEEE Trans. Power Syst., v. 21, n. 1, p. 53-60, 2006.

YIN, J. et al. Large-scale data challenges in future power grids. 2013 IEEE Seventh International Symposium on Service-Oriented System Engineering, p. 324-328, 2013.

ZHOU, J. et al. High-performance arcing-fault location in distribution networks. IEEE Trans. Ind. Appl., v. 48, p. 1107-1114, 2012.

ZHU, J.; LUBKEMAN, D. L.; GIRGIS, A. A. Automated fault location and diagnosis on electric power distribution feeders. IEEE Trans. Power Deliv., v. 12, n. 2, p. 801-809, 1997.

ZIOLKOWSKI, V. Estratégias experimentais para ensaios de faltas fase-terra com alta impedância em sistemas de distribuição de energia elétrica. Dissertação (Mestrado) Escola de Engenharia de São Carlos, Universidade de São Paulo, 2007. 